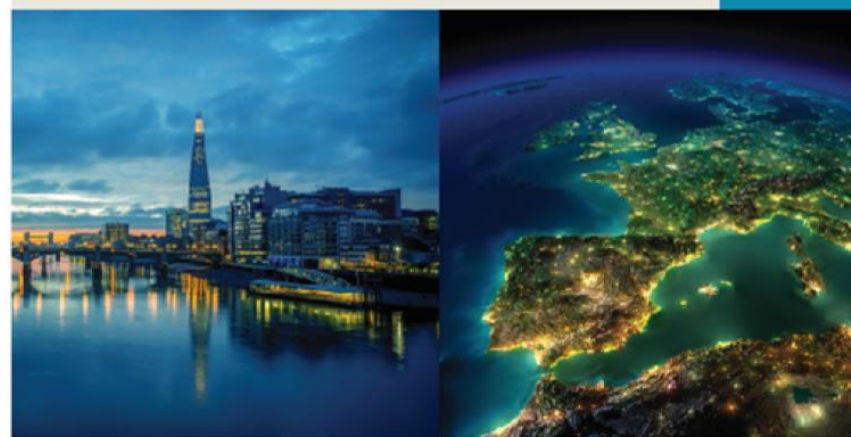

\title{
Smart energy solutions in the EU: State of play and measuring progress
}

\author{
Authoring Team: Abhishek Shivakumar, João Anjo (KTH); Michael Miller (University of Stuttgart); \\ Steve Pye (UCL); Pierre Boutinard Rouelle, Martin Densing, Tom Kober (PSI) \\ Reviewer: \\ Carine Sebi (Enerdata)
}

Legal notice: Responsibility for the information and views set out in this report lies entirely with the authors.

This report is also available on our website: www.insightenergy.org 


\section{ABOUt INSIGHT_E}

INSIGHT_E is a multidisciplinary energy think tank which provides the European Commission and other energy stakeholders with advice on policy options and assesses their potential impact.

The INSIGHT_E consortium is formed by twelve complementary partners representing various sectors: academia, research centres, consultancies, one think tank, one stakeholder organization and one of the Knowledge and Innovation Community of the European Institute of Technology. Our partners are based in ten European countries. This sectoral and geographical diversity is also reflected in the thematic scope of INSIGHT_E, ranging from energy infrastructure, new energy technologies to economic analysis, geopolitics and trade, environmental and climate impact, and social and behavioral change.

To receive regular updates about INSIGHT_E programme of work and to learn more about participation opportunities, please visit the following links:

Website: www.insightenergy.org

Contact us: info@insightenergy.org

Follow us on: Facebook \& LinkedIn: Insight Energy and on Twitter: INSIGHT_E@EuropeEnergy
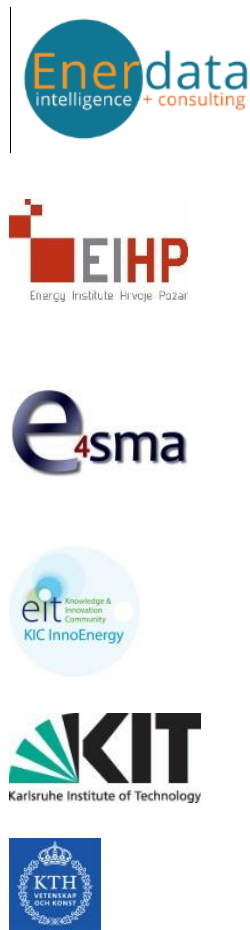

Enerdata

Energy Institute
"Hrvoje Pozar"

Energy Engineering

Economic Environment

Systems Modeling And

Analysis SRL

KIC InnoEnergy

Karlsruhe Institute for Technology

KTH Royal Institute of Technology
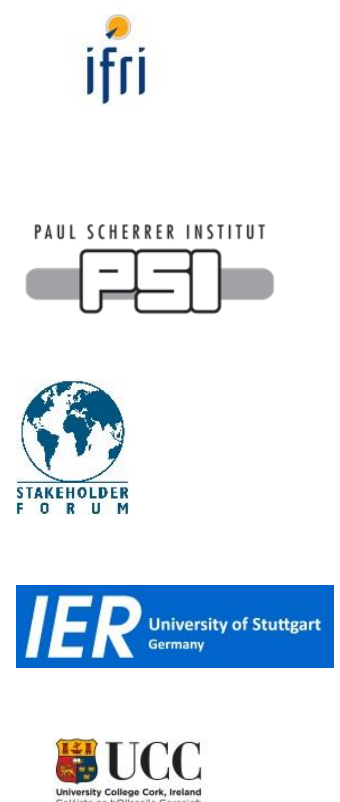

AICL UGEL ENERGY
University of Stuttgart

Institut Français des Relations internationales

Paul Scherrer Institute

Stakeholder Forum for a Sustainable Future

University College Cork

University London

College 


\section{Contents}

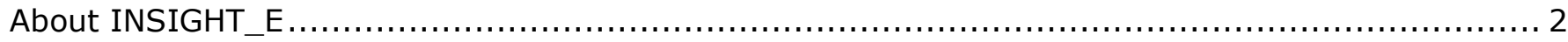

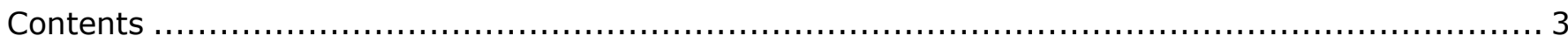

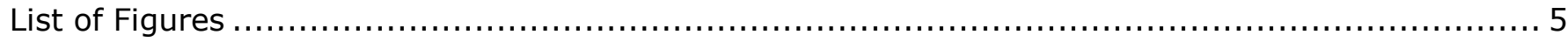

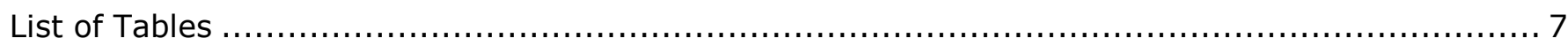

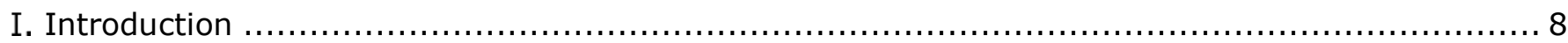

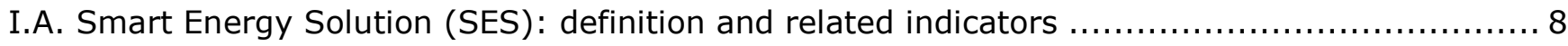

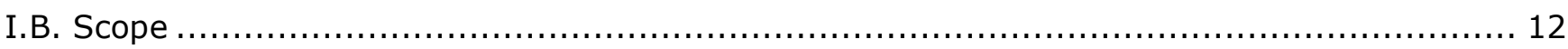

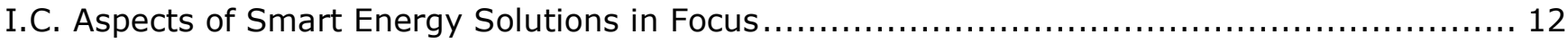

I.D. Indicators to describe uptake of Smart Energy Solutions ................................. 14

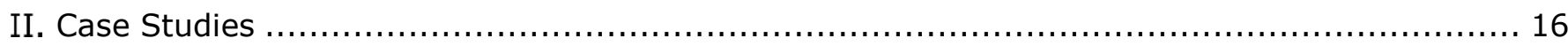

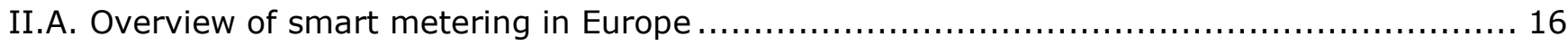

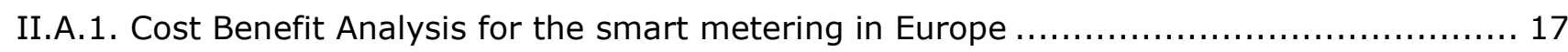

II.A.2. Feedbacks on electricity consumption using smart meters .......................... 19

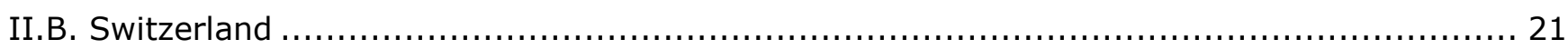

II.B.1. Smart meter roll-out and technical specifications......................................... 21

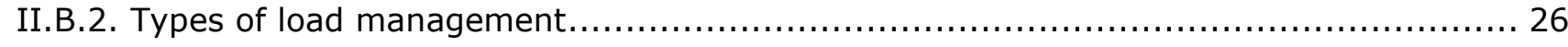

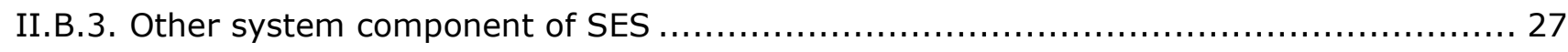

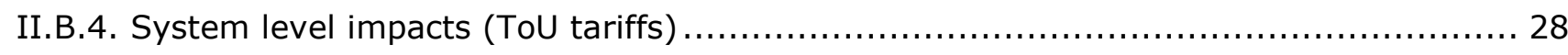

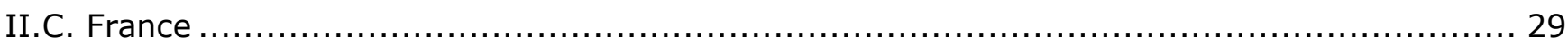

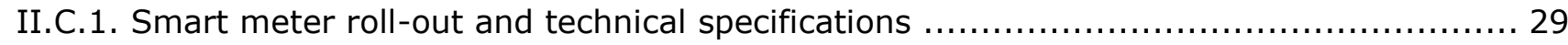

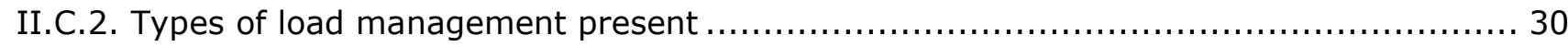

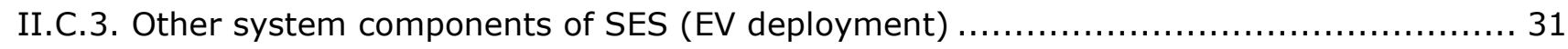

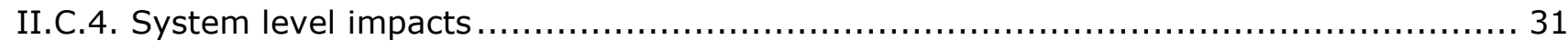

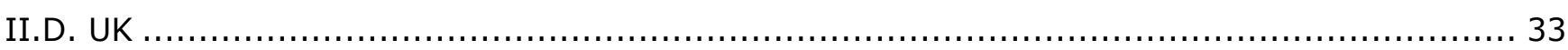

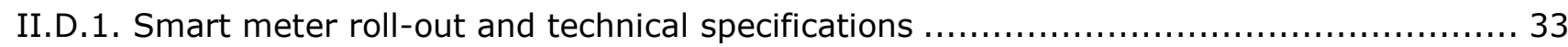

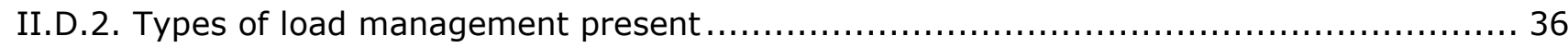

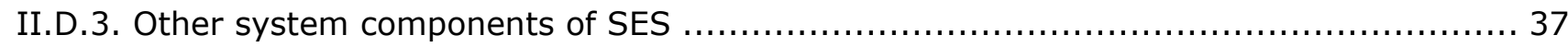

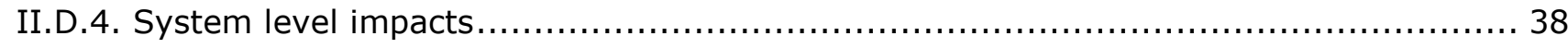

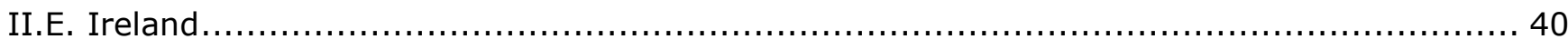


II.E.1. Smart meter roll-out and technical specifications.... 40

II.E.2. Types of load management present 40

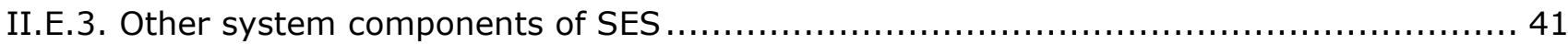

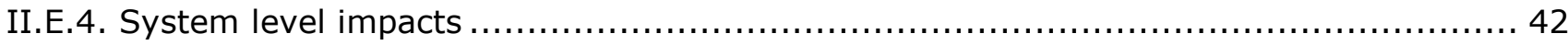

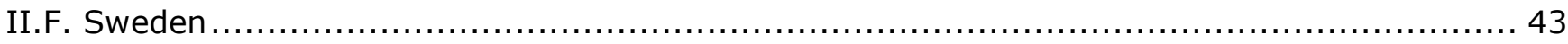

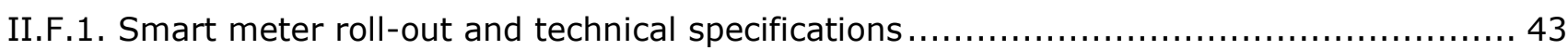

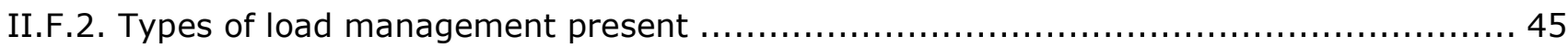

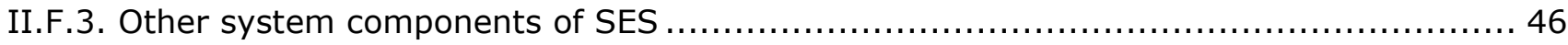

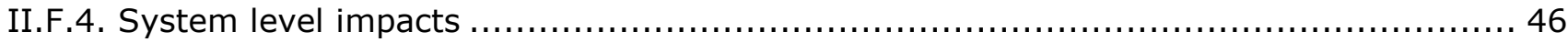

II.F.5. Improving the implementation of a complete smart-meter system .................... 47

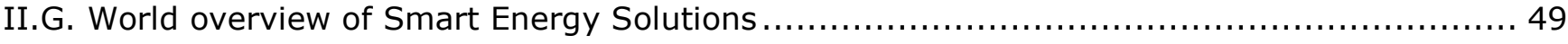

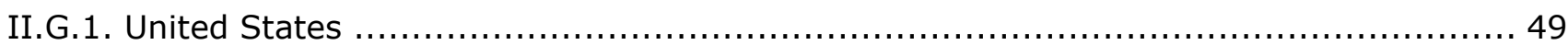

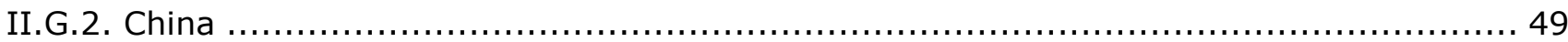

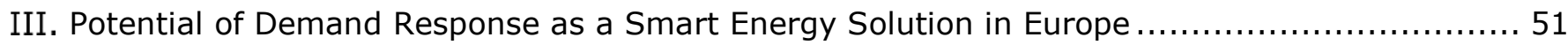

III.A. Methodology and indicators to determine Demand Response potential of the EU $\ldots \ldots \ldots \ldots \ldots 1$

III.B. Assessment of the theoretical demand response potential in Europe........................ 54

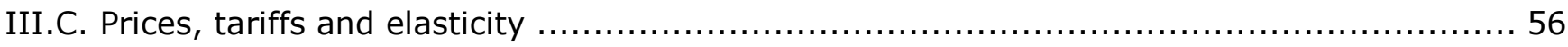

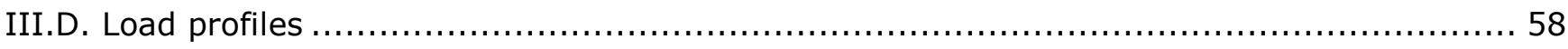

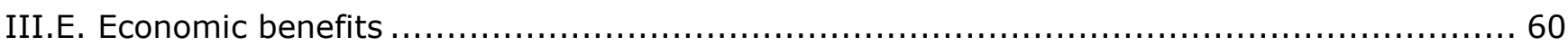

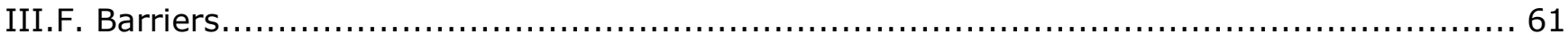

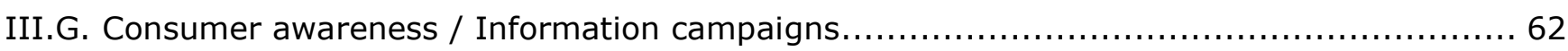

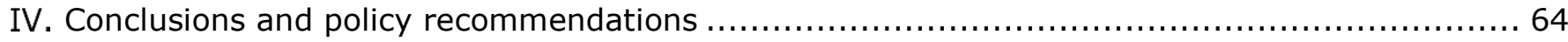

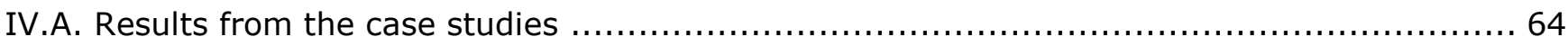

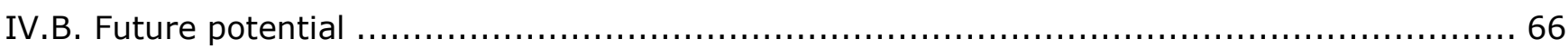

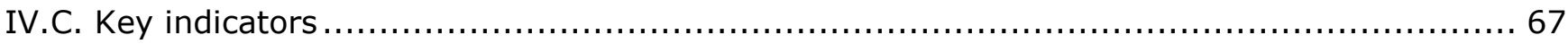

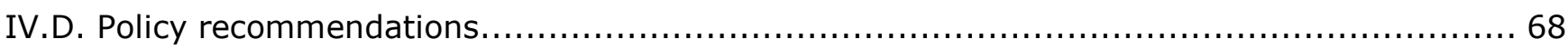

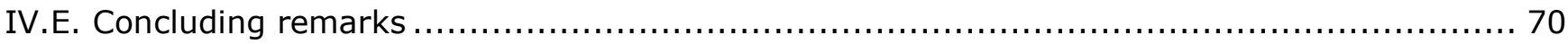

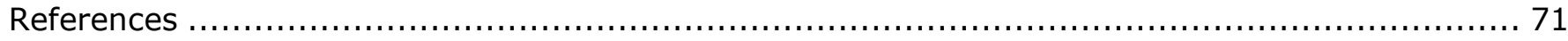




\section{LIST OF FIGURES}

Figure I-I - Conceptual visualization of elements of a Smart Electricity Solution ....................... 10 Figure I-II - Different signals and incentives for smart energy solutions for the example of Demand

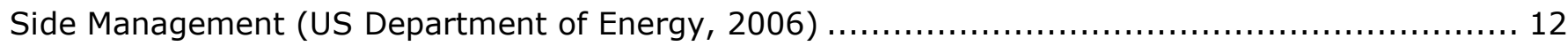
Figure I-III - Indicators that describe or measure uptake of and penetration with smart energy solutions

Figure II-I - Regulatory status versus implementation for smart metering (Hierzinger et al., 2012) 17 Figure II-II - European Electric Smart Metering roll-out, with CBA results (Source: (European

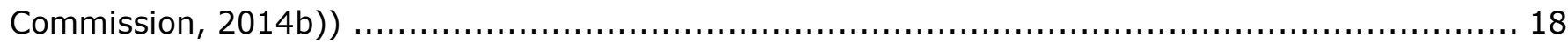
Figure II-III: Interconnections between smart meter and smartphone (eMeter, ETHZ, 2013) 20

Figure II-IV - Smart and conventional meters operated by VSGS members in 2014; adapted from (VSGS, 2015) 24

Figure II-V - Drive-by concept

Figure II-VI - Stepwise increasing implementation of smart meter and the setting-up point; adapted

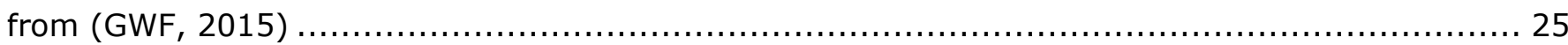

Figure II-VII - Interconnections between Smart meter, hub and operator ....................... 26

Figure II-VIII - Theoretical flexibility potential of load management; adapted from (VSE, 2016a) .. 27

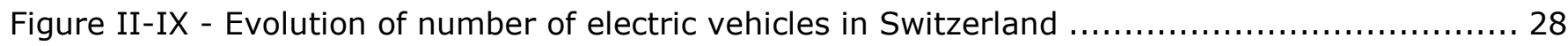

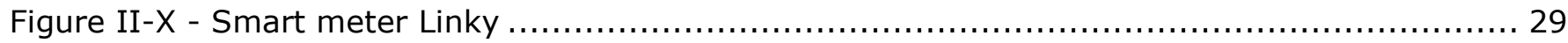

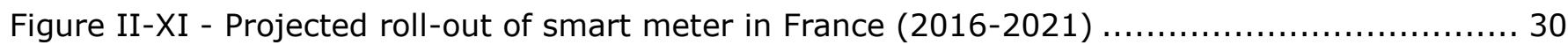
Figure II-XII - Projected roll-out of smart meter in France (2014-2020) (European Commission,

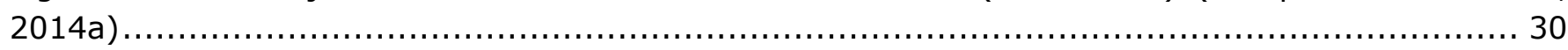

Figure II-XIII - Price components of Enercoop (Enercoop, 2016) ................................... 30

Figure II-XIV - a. Newly licensed EVs in France; b. Monthly EV licensing for 2015 and 2016 (Auto,

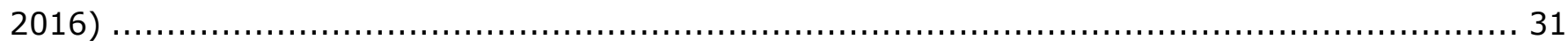

Figure II-XV - Information loop using the Linky smart meter (Source: (Fournisseur, 2016b))....... 32 Figure II-XVI - Information flow and list of possible electricity suppliers; adapted from (Foucaud and

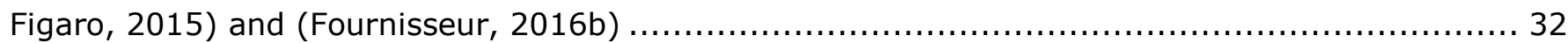
Figure II-XVII - Quarterly domestic installation activity for large energy suppliers (Source: (BEIS,

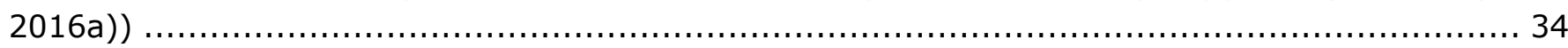
Figure II-XVIII - Number of smart and advanced meters installed by large energy suppliers in smaller non-domestic sites, by fuel type and quarter (Source: (BEIS, 2016a)) ...................... 35 Figure II-XIX - Stages in the development of the UK smart grid (Source: (DECC/Ofgem, 2014)) ... 36

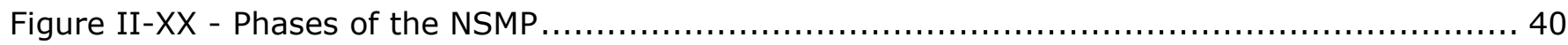
Figure II-XXI - Schematic structure of Swedish Electricity Retail Market (Nord Pool Spot, 2012) ... 43 Figure II-XXII - Types of smart meters (AMR) (Söderbom and Vattenfall AB, 2012) ......................... 44 Figure II-XXIII - Geographical coverage of DSOs in Sweden (Söderbom and Vattenfall AB, 2013) . 45 Figure III-I - Evolution of Smart-Meter roll-out in Member States (Source: European Commission) 55

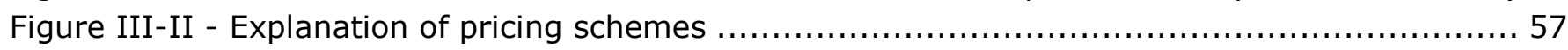
Figure III-III - Economic potential and complexity of dynamic tariffs Source: Katz et al. (Katz et al.,

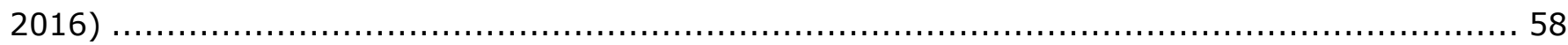

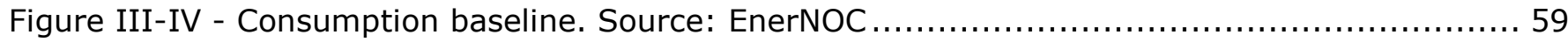


Figure III-V - Economic benefits and costs of different available technologies (Source: DNV GL (DNV GL et al., 2014))

Figure III-VI - Societal appropriation of DSM (Source: INSIGHT_E (Jullien and Serkine, 2016)) ....6 63 


\section{LIST OF TABLES}

Table II-I - CBA of smart metering system in European countries (BFE, 2014a) 18

Table II-II - Example of detail of minimal technical requirements of smart meters (BFE, 2014a) ... 22

Table II-III - Scenarios of smart meter rollout (BFE, 2012).....

Table II-IV - Requirements and impacts of price-based load management 26

Table II-V - Number of private cars in Switzerland.

Table IV-I - Summary of case studies 


\section{INTRODUCTION}

The EU's broad energy policy objectives 2030 Climate and Energy strategy are security of supply, environment, and competitiveness. In the electricity sector, this will require decarbonisation of the electricity generation and reducing primary energy consumption by increasing energy efficiency.

To achieve those strategic goals, many measures need to be taken. The increased use of smart energy solutions is one such measure that can contributes to achieving those goals. "The widespread use of smart [energy] solutions should not be a goal itself, but rather be seen as a tool amongst many" (Jullien and Serkine, 2016) to achieve the overall objectives.

Such smart solutions are expected to support the ongoing shift on the supply side towards more renewable generation, both on the central grid system and also in distributed systems. Smart energy solutions could also provide consumers with ways to reduce costs, both by shifting demand and by having improved information and automation to optimize energy use, and also through a move towards being prosumers.

Therefore, from the policy maker's perspective there needs to be a distinction between the technical feasibility (technical components installed, smart energy solutions technically possible) and the actual contribution of smart energy solutions to the wider electricity supply system (cost of installing and running smart energy solutions vs. savings achieved). This broader perspective then needs to be further broken down to the level of individual agents in the electricity system (e. g. end-users, companies), because the increased use of smart energy solutions can only be achieved by regulatory enforcement or the right economic incentives.

This will need to be accomplished by empowering consumer through the establishment of a regulatory framework that allows demand-response and energy efficiency services, where the availability of information for consumers is guaranteed and a secure but non-discriminatory handling of data is in place. It will also require an improved understanding of how consumers understand and view smart solutions. Finally, it will require significant efforts in the field of research and innovation.

In this section, indicators relevant to smart energy solutions are identified and explained. In order to do so, smart energy solutions are first defined. The scope of the smart energy solutions identified is then elaborated, with specific aspects described in more detail. The conceptual differentiation used to define smart energy solutions by describing different layers is taken as starting point to elaborate on indicators that describe the uptake of smart energy solutions.

\section{I.A. Smart Energy Solution (SES): definition and related indicators}

Information and communication technologies (ICT) are increasingly applied in almost all technological areas. This trend towards 'smartness' (Koomey et al., 2013) is usually driven by the goal to gain more control over technical processes, decisions and communication (Hilty, 2013). The fact, that (new) smart components interact with the (existing) physical world by sending and receiving data is referred to by the term cyber-physical-system (International Energy Agency, 2014). 
In accordance with (Höjer and Wangel, 2015), this policy report does not employ the term smart normatively as a desirable state, but it is rather understood as a description of a technical system that uses more ICT (Hilty et al., 2014). The focus in this policy report lies on smart solutions with relevance for the energy system from the end-user perspective. ("Skip" Laitner, 2010) describes smart energy solutions as follows: "Any energy solution that is described as "smart" [...] has semiconductor sensors to measure temperature or other variables; communications chip to receive and transmit data; memory chips to store the information; and microcontrollers, microprocessors, and power management chips to adjust energy loads". By energy loads, in this policy report we focus on electricity loads that are either stored (by the storage), fed-in (by the storage or electricity generation component) or consumed. The definition of a smart energy solution of ("Skip" Laitner, 2010) focuses on the use of ICT and the influence of an energy load. Smart energy solutions are generally applicable to all energy carriers. However due to the importance of the electricity supply system for the transformation of the European energy system, we focus on the electricity markets. The coupling of different energy carriers, e. g. through the use of hybrid systems provides additional potential for cost saving and flexibility. Couplings of different sectors (e.g. mobility, household and companies) for electricity are considered within the smart energy solutions analysed.

For a better understanding of what an energy load can be in the electricity sector that can be influenced by a smart energy solution, we conceptually divide the technical components of such smart energy solutions. From an end-user perspective there are storing, generating and consuming components in use (Figure I-I).

The main characteristic of a smart energy solution is therefore the data driven influence of those storage, generation or consumption processes. Key component of such a smart energy solution is ICT, that allows to gather, compute and communicate data and influence the system towards the desired goal. Both the way of influence and the goals need to be further distinguished.

The technical components, regardless whether it is an electricity consuming, storing or generating device, can either be influenced completely automatically or by a user interaction (active or passive end-users). In the case of an automated influence of the system the end user only defines the degrees of freedom, that can be used by the technical automation. This would e.g. allow to start a dish washer or a laundry machine within a defined time period or would allow the air conditioning to operate within a range of temperature around a target temperature or for the storage a minimum load is defined. In case of an influence of the system solely based on user interaction, the only way to influence the technical system is by executing manual control by the end user. By providing targeted information (e. g. about the consumption, the current electricity price, the current electricity generation) the behavioural pattern of the end user can be changed in the short- and the long-term. As shown in Figure I-I the informational connection of the smart energy solution is the basis for both kinds of controls. In case of the automated control of the system, the decision of how to influence loads is decided by the algorithms (and the aspired goal) based on the current states in the technical system. Those states of the system are prepared for the end-user interface and therefore are the basis of the end-user interaction as well. Again the goal(s) of the end-user determine(s) the outcome of the influence. 


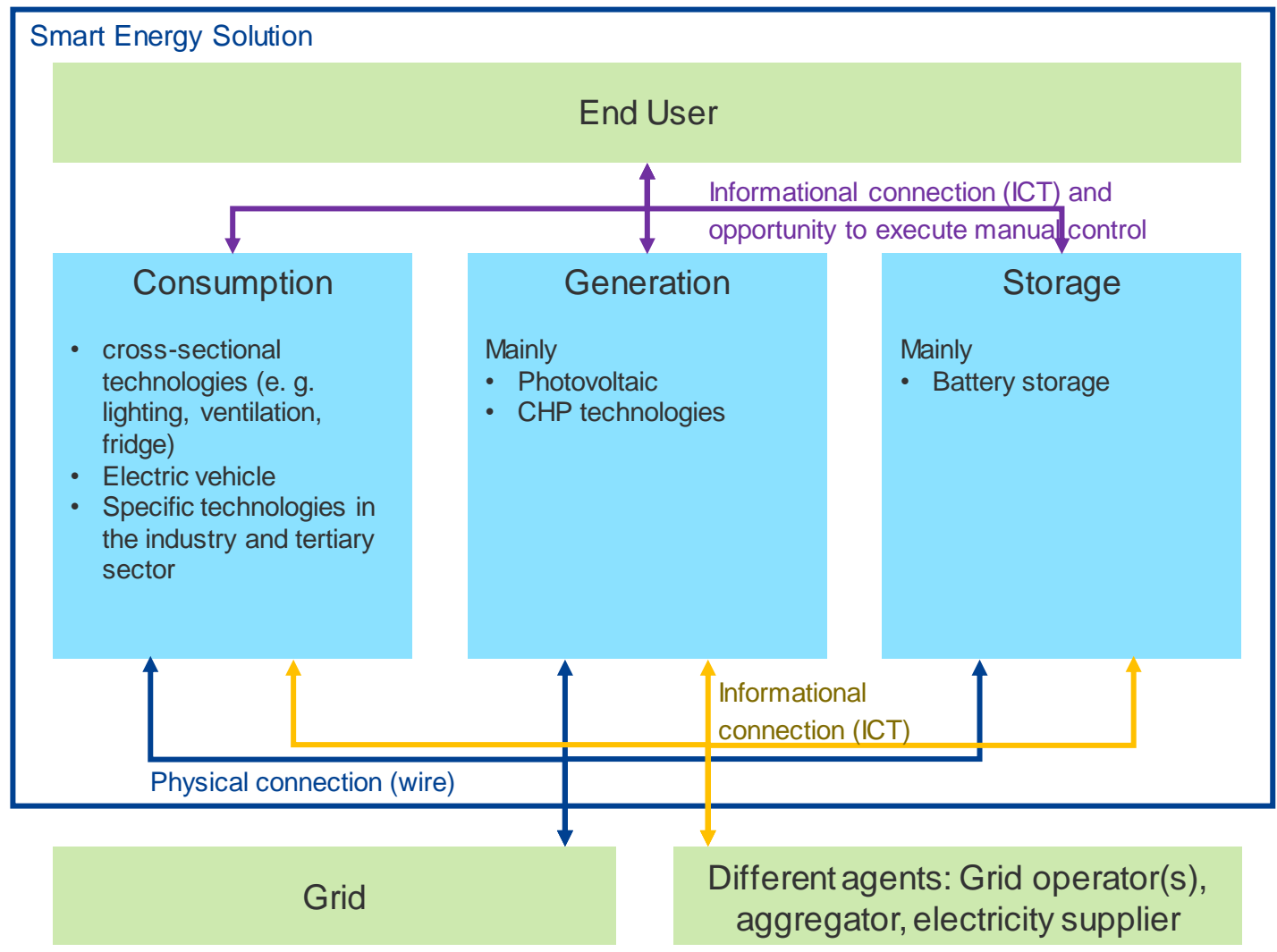

Figure I-I - Conceptual visualization of elements of a Smart Electricity Solution

The influence of the system is always motivated by the desired goal. As there are many agents involved (e. g. end-user, grid operator, aggregator) and one agent can have different goals there are several mutually supportive and competing goals. The goals can be broadly divided in four categories:

- Economic goals (e. g. minimal cost): The goal of such a smart energy solution is to minimize the cost for electricity. All different components can be considered, regardless, whether they consume, generate or store electricity. An electrical car could be declared as storage, depending on the charging strategy used. Depending on the type of the electricity tariff (variable or flat), the feed-in (generation), the storage and the consumption are influenced in such a way that the cost (electricity consumed of the grid by the storing or consuming device) and the earnings (electricity fed-in by the storage or the generation) are maximized. The influence of the electricity consumption is called demand side management (DSM). The storage can be used as a device that does both feeding in and consuming electricity. This smart energy solution can either be completely automated or manually controlled by the consumer.

- Energetic goals (e. g. maximal electricity produced, produced electricity used within the smart energy solution, reduced energy consumption). The first example for a smart energy solution with an energetic goal is maximizing energy savings. The main goal of such a smart energy solution is to reduce the amount of electricity consumed. Therefore, the monetary value of the electricity consumed is not the decisive factor. There are two approaches to achieve energy savings with a smart energy solution. Either the savings are achieved through the automated technical system that relies on sensor data and algorithms or the end-user 
performs manual control based on the provided information about the energy system. The second example of a smart energy solution with an energetic goal is the maximizing of autarky. The goal of a smart energy solution that pursues autarky is to have as less electricity exchanged with the grid as possible. Therefore, the loads of the consumer are shifted to times of high self-produced electricity generation. In addition to the shift of consuming loads (DSM), the storage can be used to keep self-produced electricity within the household or company premises and used at a later time. Such a smart energy solution is usually performed with an automated technical system. The end-user might be able to set the framework conditions; to what degree the autarky is preferred over an economic disadvantage (e. g. in case electricity of the grid would be more reasonable).

- Technical goals (e. g. maximum capacity of the grid, required feed-in of storages due to low feed in of volatile renewables and high demand). As an example we take a smart energy solution that provides flexibility. Such a smart energy solution incorporates storing, generating and consuming components. The control of storage, consumption and generation is used to provide flexibility to a third party (e. g. aggregator, grid operator). Flexibility describes an increase or a decrease of electrical load for a defined time period. The smart energy solution has different options to provide such a flexibility. The increase of load can either performed through an increased use of the storage that stores electricity, a decrease of the generation (in case that is technically possible) or an increase of the consumption with demand side management. For a decrease of load all those options could be used the opposite way. This smart energy solution can either be completely automated or manually controlled by the consumer.

- Comfort goals of the end-user (e. g. quickest time possible to have clean laundry or dishes, most precise set temperature)

From a political perspective another set of goals can be added. Those Political goals describe towards which direction the energy system should be heading. In the long-term this could be a certain degree of energy efficiency, a certain share of renewable electricity generation and a certain degree of autarky. In the short-term a certain degree of security of supply could set a framework condition, which needs to be achieved by the grid operators. For this policy report with respect to the named goals it is important to distinguish between the 'given' goals of the agents (regarding the economic, technical or utility outcome) and the set goals of policy makers. The set goals of the policy makers always need to take all other 'given' goals into account.

A key characteristic of a smart energy solution is therefore the ability to pursue a target by using gathered data. From an external perspective a smart energy solution in the electricity sector can be seen as a flexibility provider. From an internal perspective, a smart energy solution allows for coordination of different components (consumers, storage, generation) to pursue (different) targets.

The smart energy solutions require some kind of a signal to interact with the environment. This signal can range from a strict 'switch of' or 'switch on'-signal, which does not leave any degrees of freedom to the smart energy solution, to a tentative indication, what influence of the loads summarised in a smart energy solution should be carried out. Signals can be send from different agents (e. g. grid operator(s), aggregators, electricity supplier etc.) (SEDC, 2015) and be a price signal for electrical load fed-in or consumed, a qualitative signal such as signal lights or a strict binary signal that is the control signal itself and does not leave any degrees of freedom to the smart energy solution. Policy makers and regulatory authorities need to design the system in such a way that all involved agents have an incentive to use a smart energy solution, given a positive 
contribution to the overall electricity supply system. Figure I-II shows different signals and incentives for smart energy solutions for the example of Demand Side Management.

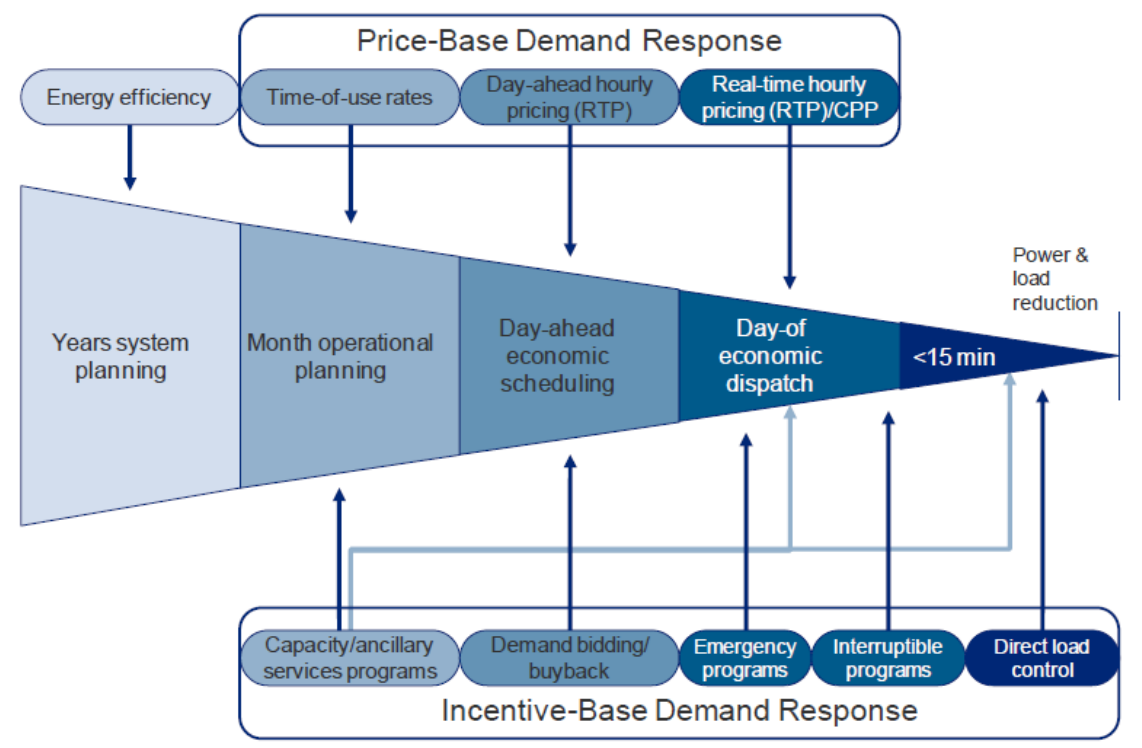

Figure I-II - Different signals and incentives for smart energy solutions for the example of Demand Side Management (US Department of Energy, 2006)

\section{I.B. Scope}

The focus of this Policy Report lies on the influence of demand processes, as this is relevant for all end-consumers, whereas the influence of generating and storing processes is only relevant to those companies or households that are equipped with such components. As flexibility of the demand processes is one of the most important contributions of smart energy solutions to the wider energy system, we focus on this technical capability. Due to similar technical and behavioural characteristics we focus on households and small/medium enterprises. The work is intended to generate results for all EU28 member states. However, for certain analysis (e. g. the actual values for a set of indicators), we focus on case studies and therefore do not cover the EU28 comprehensively. Due to their abstract content, sections 0 and IV can be used for all EU28 member states. A focus of the analysis is put on the aspects elaborated in the following section.

\section{I.C. Aspects of Smart Energy Solutions in Focus}

A smart energy solution can be described by different layers (see (CEN-CENELEC-ETSI, 2012) for the Smart Grid Reference Architecture that defines layers for the smart grid context). Firstly the technological layer, which can be unequivocally defined by the components included within a smart energy solution (see Figure I-I). Secondly a process layer, which describes how the different technical components interact with each other (e.g. which signals are used) and thirdly an economical layer, which describes what cash flows occur and how different agents are enumerated (see incentives in Figure I-II). Ideally each affected agent accrues some benefit from the smart energy solution. Otherwise, in case an agent is not benefiting i.e. in the absence of incentives, regulation would need to force agents to behave in a certain way. 


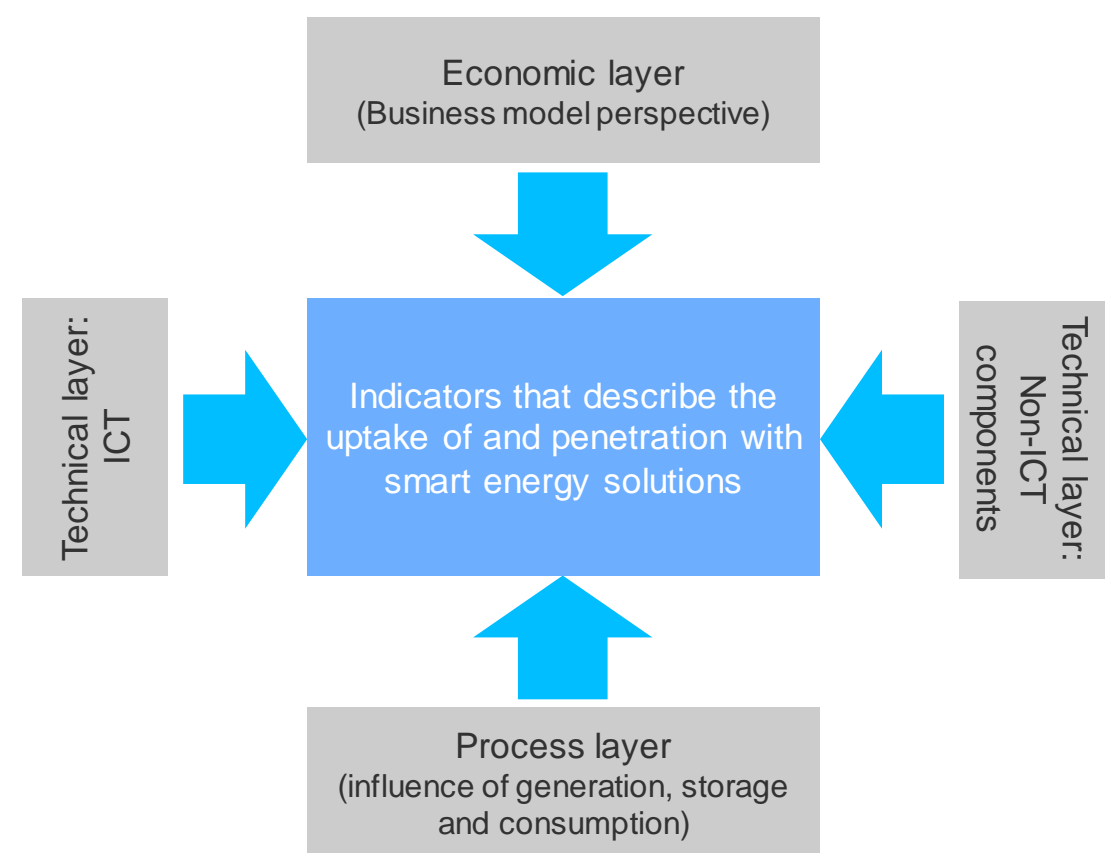

Figure I-III - Indicators that describe or measure uptake of and penetration with smart energy solutions

There is no comprehensive list of smart energy solutions, as the different layers and the multiplicity of options within one layers makes it impossible to capture all possible smart energy solution. We therefore elaborate on selected aspects in more detail, which are essential for a smart energy solution on the one hand and the interaction with the broader energy system on the other hand.

The process layer can be conceptually divided in data and electricity flows. With respect to the electricity flows there are two particularities for smart energy solutions. Firstly, in line with the electricity system with more volatile decentral electricity generation there are bidirectional electricity flows (mainly in the distribution grid). Accordingly, smart energy solutions are in many cases both a sink and a source of electricity. Secondly, smart energy solutions influence consumption, storing and generation processes, which was not possible for end-users in the traditional electricity supply system. A completely new aspect is an increased collection, handling and communication of data. Almost all new processes that involve smart energy solutions are based on data exchange, as a key characteristic of smart energy solutions is the increased use of ICT. Data flows between different ICT components contain information about prices (e. g. real time pricing), electricity currently consumed, stored, generated and the potential of changed load in the near-future (within 1 day).

Within the economic layer, new markets and new players generate different cash flows. As there are new players (e.g. aggregators of flexibility, smart meter operators, data platform operator) there are also more possible interactions for end users. An example of a new market is a market for flexibility.

The technical layer describes the technical components installed. There are many different technical components of relevance for smart energy solutions (as shown in Figure I-I) as the technical layer compromises both ICT and non-ICT components. The most important ICT components are the telecommunication technologies. These connect different components as part of a smart system with the ability to pursue a common, pre-defined goal. Secondly, smart meters are crucial and a 
prerequisite to smart energy solutions. They allow the measurement and recording of electricity fedin and consumed at any given point of time. On the non-ICT components, new technologies are controllable loads, storages (e. g. battery storage, electrical cars) and decentralised renewable generation at small scale.

\section{I.D. Indicators to describe uptake of Smart Energy Solutions}

Indicators to describe or measure uptake of and utilisation of smart energy solutions, such as the ones described in I.B, can be classified based on the method, or layer, through which 'indicative' information is collected. Figure I-III shows the identified layers, from which an indication of the use and the feasibility of smart energy solution can be drawn.

Installed ICT is an indicator for the technical layer that takes a key characteristic of smart energy solution as an indication on the degree of potential usage of smart energy solutions. Indicators with a focus on that could be:

- Percentage of households/companies with smart meters;

- Number of households with an internal network that connects different devices.

However, those indicators do not measure the actual use of smart energy solutions. Therefore, additional indicators need to be taken into account.

The technical layer (apart from ICT) has the focus on the components that are possibly connected and controlled with ICT. Particularly controllable loads, storages and electricity generation are the basis of smart energy solutions. Therefore, the following indicators reflect the characteristics of that layer:

- Percentage of households/companies with storage installed

- Percentage of households/companies with a controllable load

- Percentage of households/companies with own electricity generation

- Number of consuming loads, storages and generation, that are controllable via communication technology

- Load shifting potential (controllable loads that are accessed via communication technologies) for an average household/company and in total for an EU28 member state or all the EU28

Taking the economic layer as a starting point reflects the perspective of business model. There are different indicators that can indicate whether smart energy solutions are viable from an economic point of view. Possible indicators are:

- Percentage or number of customers with variable tariffs (e. g. real time pricing)

- Existence of a market for flexibility

- Number of markets with end-user (demand, feed-in, short-term flexibility, long-term flexibility)

The process layer describes the key characteristic of a smart energy solution that is the targeted influence of electricity generation, consumption and storage processes. The following indicators quantify the control of those processes: 
- Amount of electricity demand shifted [kWh]

- Amount of electricity stored and fed-back to the system [kWh]

- Amount of electricity generation shed [kWh]

- Amount of self-generated electricity consumed [kWh, \%]

- Control signal for increase or decrease of electrical load in place (e. g. ripple control)

- Amount of energy saved [kW]

- Number of ramp ups of conventional power plants

The indicators provided are either to be calculated or the data needs to be acquired through technical measurements or empirical data. There are several parties involved that could take on responsibility for the collection and provision of the data in each member state: statistical bodies, regulatory bodies, grid operators, meter operators, aggregators, and data platform operators. Another data source could also be found in tax or subsidy relevant information provided to official financial institutions (e.g. CHP levy in Germany). Furthermore, sales numbers might be a source of how many devices are approximately installed.

For many technological applications (e.g. DSM, load shedding, economic potential of storages in households) potentials have been assessed in scientific studies. Those potentials can be matched to the indicators. With the help of an identified economic DSM potential the indicators "amount of electricity demand shifted [kWh]" and "Load shifting potential (controllable loads that are accessed via communication technologies) in total" can be classified. In case such a reference value for an indicator is available, it is possible to use the indicator as a target at the political level. However, it always needs to be kept in mind that only a few indicators actually provide information on whether the potentials are actually realized. Most indicators provide the information on whether the potential could be realized technically. It is therefore necessary to use multiple indicators to describe the uptake of a smart energy solution; firstly, indicators describing the technical feasibility (mainly technical layer), and secondly, indicators describing the actual contribution of a smart energy solution (mainly process and economic layer). 


\section{Case Studies}

In this section, a set of country cases studies provide insights into the present levels of SES deployment, and what the implications for consumers. The information presented comprises that on smart metering and its installation, the effect of smart meters in national electricity markets, and its impact in the wide electrical system. In addition, other types of smart energy solutions are also described that are in the early stage of development. It is important, however, to point out that for the case study of Sweden, the second part of the case study is handled in a different way due to the fact that Sweden has been a pioneer country in the deployment of smart meters, and, therefore, provides the opportunity to analyse a country further evolved in SES.

Prior to the Member State case studies, a European overview is presented to provide a more holistic overview of SES, and their potential role in the future.

\section{II.A. Overview of smart metering in Europe}

Within the Intelligent Energy Europe programme, the Austrian Energy Agency (AEA) published a report on the European smart metering landscape (Hierzinger et al., 2012). Figure II-I provides an overview of the regulatory situation (horizontal axis) versus the progress in implementation (vertical axis) of smart metering. Several dimensions are considered for the classification of the countries. For the regulatory axis, four dimensions are considered:

1. cost benefit analysis and rollout plan,

2. timeline of rollout,

3. barriers from new regulations (privacy and data protection, measurement and calibrating meters),

4. legal minimum functional requirements.

For the progress of implementation axis, three dimensions are considered:

1. enabling infrastructure,

2. rollout status,

3. services already available for consumers.

By weighting the dimensions, the Member States ${ }^{1}$ were clustered into five groups: Dynamic movers, Ambiguous movers, Market drivers, Waverers and Laggards.

${ }^{1}$ EU27 and Norway 


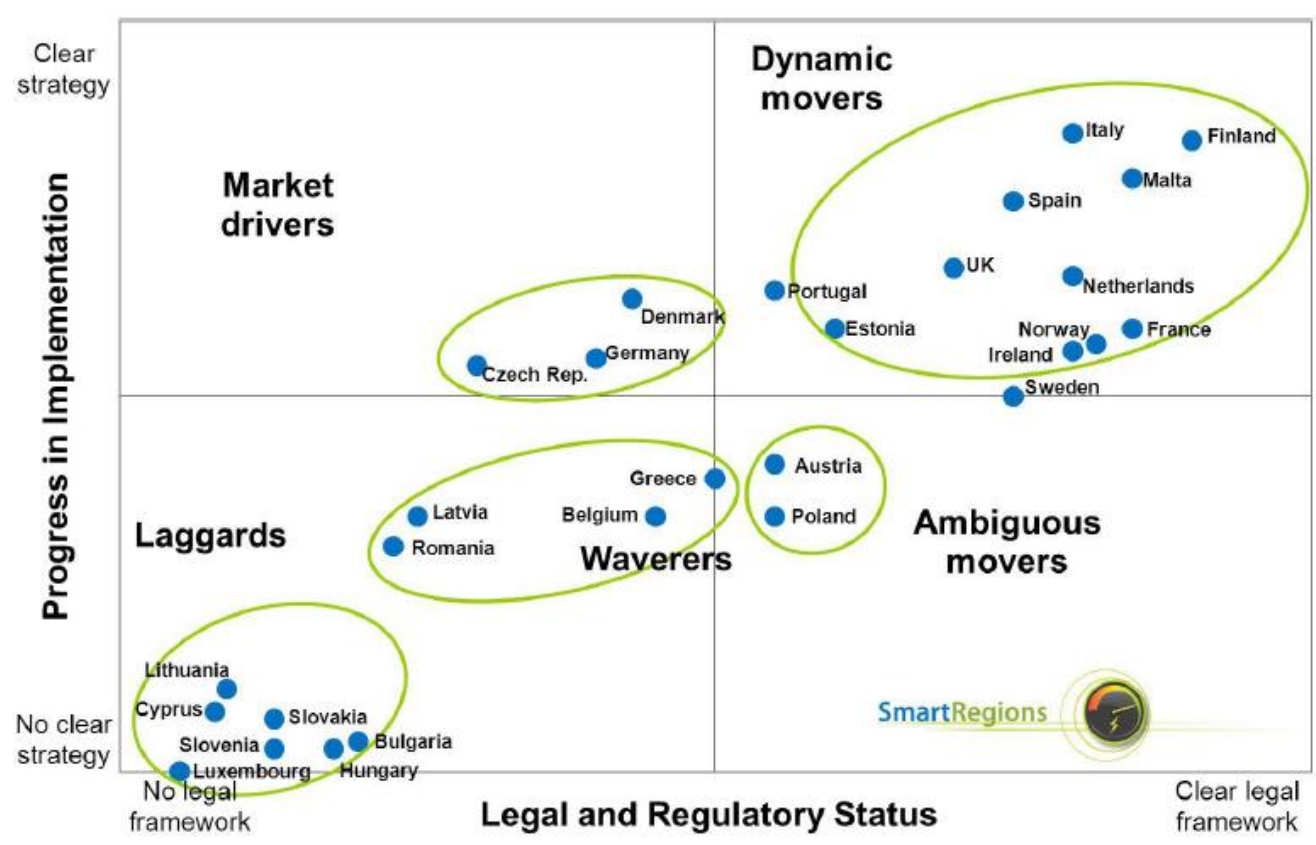

Figure II-I - Regulatory status versus implementation for smart metering (Hierzinger et al., 2012)

"The dynamic movers" are characterised by a clear path towards a full rollout of smart metering. Either the mandatory rollout is already decided, or there are major pilot projects that are paving the way for a subsequent decision. The market drivers are countries where there are no legal requirements for a rollout. Some DSOs or legally responsible metering companies nevertheless go ahead with installing electronic meters either because of internal synergetic effects or because of customer demands. Ambiguous movers represent a situation where a legal and/or regulatory framework has been established to some extent and the issue is high on the agenda of the relevant stakeholders. However, due to lack of clarity with-in the framework, at this point only some DSOs have decided to install smart meters. The waverers show some interest in smart metering from regulators, the utilities or the ministries. However, corresponding initiatives have either just started, are still in progress or have not yet resulted in a regulatory push towards smart metering implementation. Finally, laggards are countries where smart metering is not yet an issue. However, since transposition of Directive $2009 / 72 \mathrm{EC}^{2}$ is on-going, it is possible that the laggards will suddenly gain momentum" (Hierzinger et al., 2012). All considered countries are roughly on the diagonal line from no clear strategy, no legal framework to the opposite. Hence, implementation progress is linked with a clear legal framework.

\section{II.A.1. Cost Benefit Analysis for the smart metering in Europe}

Following the 2012 Energy Efficiency Directive of the European Union, Member States are required to perform a long-term Cost Benefit Analysis (CBA) of electricity smart metering (European Commission, 2014a). In case of positive results, they have committed to an implementation rate of $80 \%$ by 2020 .

\footnotetext{
2 Directive concerning common rules for the internal market in electricity: http://eurlex.europa.eu/LexUriServ/LexUriServ.do?uri=OJ:L:2009:211:0055:0093:EN:PDF
} 


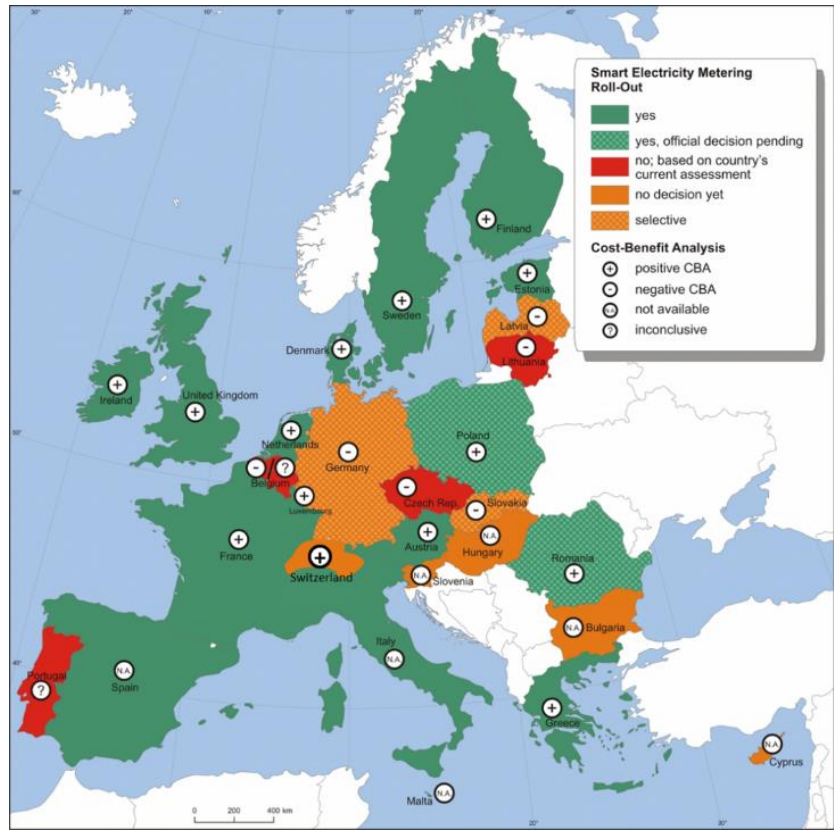

Figure II-II - European Electric Smart Metering roll-out, with CBA results (Source: (European Commission, 2014b))

In Figure II-II, we see a graphical summary of the CBA and the commitment status of the European countries and Switzerland. Table II-I summarizes the achievable savings through smart meters: Most countries showed positive results.

Table II-I - CBA of smart metering system in European countries (BFE, 2014a)

\begin{tabular}{|l|l|l|l|l|}
\hline Country & CBA & Result & $\begin{array}{l}\text { Energy } \\
\text { saving } \\
\text { potential }\end{array}$ & $\begin{array}{l}\text { Life } \\
\text { expectancy }\end{array}$ \\
\hline Austria & yes & positive & $3.5 \%$ & 15 \\
\hline Belgium & yes & unclear & n.a. & n.a. \\
\hline Bulgaria & n.a. & n.a. & n.a. & n.a. \\
\hline Cyprus & on going & n.a. & n.a. & n.a. \\
\hline Czech Republic & yes & negative & $0 \%$ & 12 \\
\hline Denmark & yes & positive & $2 \%$ & 10 \\
\hline Estonia & yes & positive & n.a. & 15 \\
\hline Finland* & yes & positive & $1 \%-2 \%$ & $15-25$ \\
\hline France ${ }^{\dagger}$ & yes & positive & n.a. & 20 \\
\hline Germany & yes & negative & $1.2 \%$ & 13 \\
\hline Greece & yes & positive & $5 \%$ & 15 \\
\hline Hungary & on going & n.a. & n.a. & n.a. \\
\hline Ireland** ${ }^{+}$ & yes & positive & $2.9 \%$ & 17 \\
\hline Italy* & n.a. & n.a. & n.a. & $15-20$ \\
\hline Latvia & yes & negative & $2 \%-5 \%$ & 12 \\
\hline & & & & \\
\hline
\end{tabular}




\begin{tabular}{|l|l|l|l|l|} 
Lithuania & yes & negative & $2.3 \%$ & 15 \\
\hline Luxembourg & yes & positive & $3.6 \%$ & 20 \\
\hline Malta & no & n.a. & $5.0 \%$ & 11 \\
\hline Netherlands** & yes & positive & $3.2 \%$ & 15 \\
\hline Poland & yes & positive & $1.0 \%$ & 8 \\
\hline Portugal & yes & unclear & $3.0 \%$ & 15 \\
\hline Romania & yes & positive & $3.8 \%$ & 20 \\
\hline Slovak Republic & yes & negative & $1.0 \%$ & 15 \\
\hline Slovenia & on going & n.a. & n.a. & n.a. \\
\hline Spain & no & n.a. & n.a. & 15 \\
\hline Sweden $*^{+}$ & yes & positive & $1 \%-3 \%$ & 10 \\
\hline UK***+ & yes & positive & $2.2 \%$ & 15 \\
\hline
\end{tabular}

\section{Legend}

* roll-out finished

n.a. no information available

tincluded in case studies

\section{II.A.2. Feedbacks on electricity consumption using smart meters}

Feedback on power consumption is crucial for Smart Energy Solutions (SES), especially up-to-date feedback within weekly or daily cycles, which typically can be accessed online (via a secured webpage), or can be pushed on a smartphone app, or can be delivered on an In-Home Display (IHD). The end-user can decide to reduce or modify electricity consumption accordingly. It has been shown in behavioural studies that feedbacks on consumption should be regularly provided to the consumer to lower consumption (BFE, 2014b). The key component is ICT with the smart meter. Figure II-III sketches the interconnections between the smart meter and the consumer. In this case, the front-end application is on a smartphone. Through this "app", the consumer can monitor and manage consumption. Via pop-up messages (i.e., feedbacks), consumption may be reduced. Hence, in terms of indicators, the number of installation of smart meters is still a fundamental figure, but the number of installed smart meters linked with installed feedback monitoring may constitute the crucial indicator for effective SES deployment. 


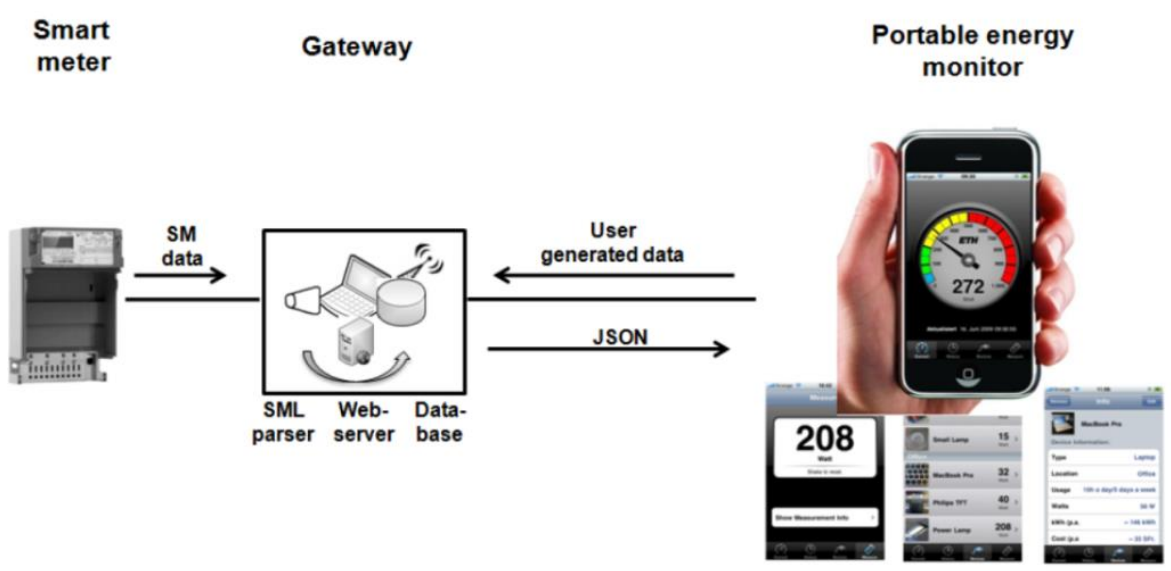

Figure II-III: Interconnections between smart meter and smartphone (eMeter, ETHZ, 2013) 


\section{II.B. Switzerland}

\section{II.B.1. Smart meter roll-out and technical specifications}

After the liberalisation of the electricity market in $2009^{3}$, the number of Distribution System Operators (DSOs) in Switzerland has increased. This is due to, for instance, municipalities creating their own DSO ${ }^{4}$. As of January 2016, there are 653 DSOs. To enhance liberalisation and market rules, the Swiss Federal Office of Energy (SFOE) issued minimal requirements for smart metering (BFE, 2014c), which may be used as indicators. The requirements target the following areas.

- Creation of a technical framework to allow profitable business models;

- Allow the consumer to change easily electricity suppliers. Thus, commercial barriers are avoided;

- Legal and investment security for DSOs;

- Facilitate the deployment of SES and other innovative power solutions.

Table II-II provides an example of the detail of examined minimal technical requirements for Switzerland, comparing them with those of four other countries and with the recommendations of the EU. Five categories were analysed:

1. Input, processing, transmission and back-up of measured values;

2. Requirements of the consumer and of power supplier;

3. Data security and privacy;

4. Requirement of the smart meter operator;

5. Other.

For example, "Subsection 4.1.2 B", which is in the second category, deals with the display of consumption/production (black square in table). All considered countries (except France) require a load display every 15 minutes. Data protection (fourth point) is required in every country. Moreover, time-of-use tariffs for smart meters are not a (minimal requirement) in Switzerland, because the Measuring Instrument Directive ${ }^{5}$ for smart meter consists mostly of technical guidelines (BFE, 2014a).

\footnotetext{
3 The liberalisation of the Swiss electricity market started in 2009, and is currently restricted to large electricity consumers, who can freely choose their power suppliers. Free choice for smaller consumers is expected in 2018.

http://www.frenergie.ch/fre-bulletin/louverture-du-marche-de-lelectricite-en-suisse/

${ }^{4}$ Swissgrid: https://www.swissgrid.ch/swissgrid/fr/home/reliability/griddata/distribution.html

5 Adopted in Switzerland in 2006, the MID (Measurement Instrument Directive) is a European directive on measurement instruments.
} 
Table II-II - Example of detail of minimal technical requirements of smart meters (BFE, 2014a)

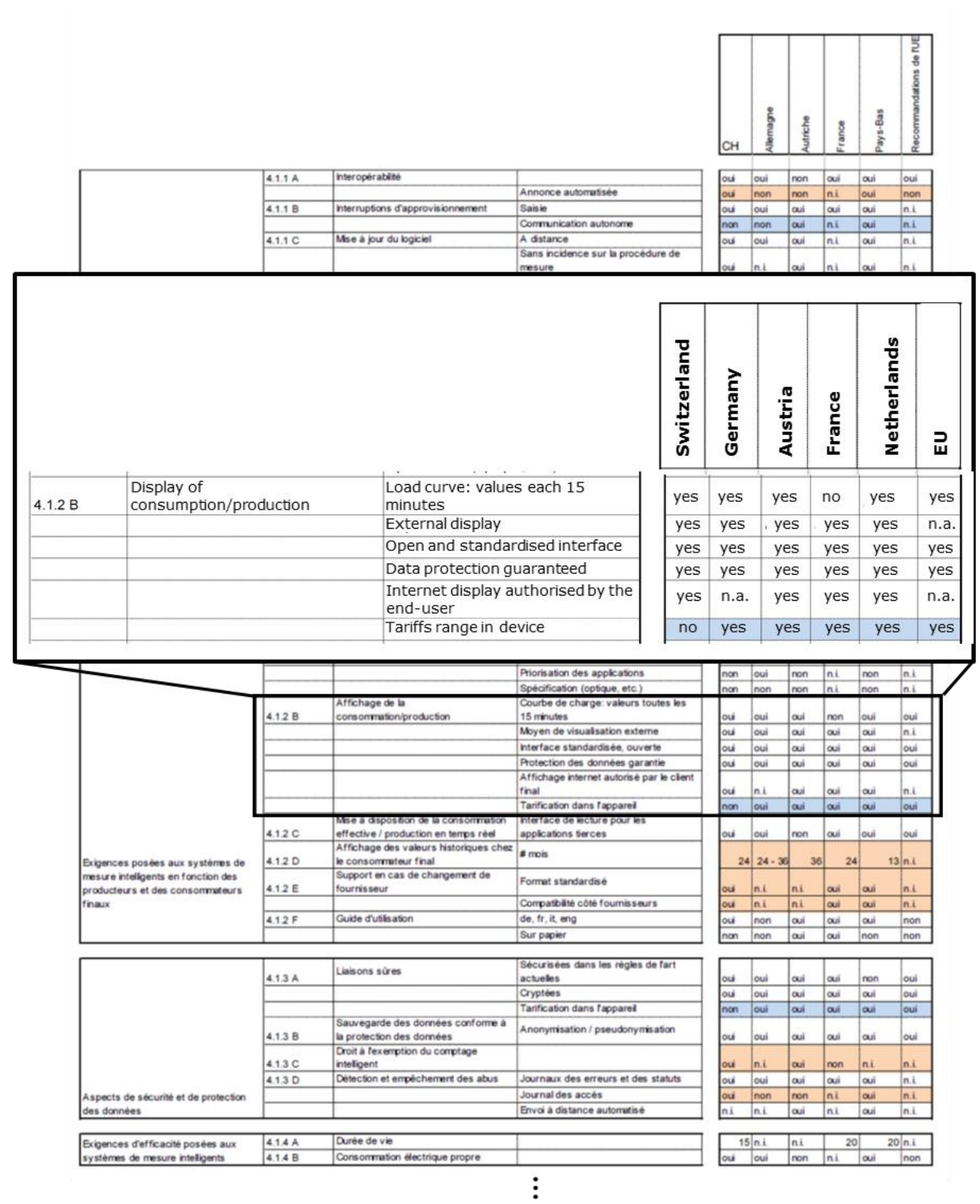


Currently, there is no national Swiss policy roadmap for the implementation of smart metering. On the other hand, electricity suppliers and DSOs within the liberalisation of the Swiss electricity market drive local deployment of smart meters. Several pilot projects and case studies were launched in recent years, which may be used as an indicator.

In 2012, the SFOE published a study comprehensively assessing future likely deployments of smart meters between 2015 and 2035 in five scenarios (Table II-III). In the Full rollout scenario, smart metering equipment and installation are expected to cost one billion CHF (compared to the Status quo scenario). However, the end user is expected to have net benefits resulting from energy savings worth between 1.5 and 2.5 billion CHF. The saving for households is assessed to be between 0.945 and 1.154 billion CHF (BFE, 2012).

Table II-III - Scenarios of smart meter rollout (BFE, 2012)

\begin{tabular}{|c|c|}
\hline Scenario & Characteristics \\
\hline \multirow{3}{*}{ Status quo } & No smart meter rollout \\
\hline & Current infrastructure prevails \\
\hline & Current energy efficiency campaigns prevail \\
\hline \multirow{4}{*}{ Status quo+ } & No smart meter rollout \\
\hline & Current infrastructure prevails \\
\hline & New energy efficiency campaigns are launched but without smart meters \\
\hline & Basic load management already available is optimised \\
\hline \multirow{6}{*}{ Selective rollout } & $20 \%$ of the electricity meters are smart meters \\
\hline & Installation of smart meters driven by the end-user's demand \\
\hline & Roll-out goal: $20 \%$ smart meter around 2030 \\
\hline & Set-up of infrastructure compatible with smart meters, corresponding with end-user demand \\
\hline & ToU tariff (with more than two steps) \\
\hline & Load management for heat (hot water and heat pumps) \\
\hline \multirow{6}{*}{ Full rollout } & $80 \%$ of the electricity meters are smart meters \\
\hline & If feasible, 400,000 smart meters are installed yearly \\
\hline & Rollout goal: 80\% smart meters around 2025 \\
\hline & Set-up of infrastructure compatible with smart meters \\
\hline & Time-of-Use tariff (ToU) tariff (with more than two steps) \\
\hline & $\begin{array}{l}\text { Load management for heat (hot } \\
\text { water and heat pumps) }\end{array}$ \\
\hline \multirow{4}{*}{ Full rollout+ } & All points from Full rollout scenario \\
\hline & Dynamic tariffs offered to the end-user \\
\hline & Data recording and communication every 15 minutes \\
\hline & Load management of electric appliances in household (optional) \\
\hline
\end{tabular}


The Full rollout+ scenario, based on the Full rollout scenario, is the only scenario that allows enduser dynamic tariffs, that is, not only Time-of-Use tariff (ToU) but also Critical Peak Pricing (CCP) and Real Time Pricing (RTP), that is, the pricing is not fixed in previously fixed time intervals. This scenario envisages also communication of the electricity consumption to the consumer and load management for household appliances. The current status of these advanced features is discussed next.

Three major DSOs in Switzerland are currently operating smart meters: Elektrizitätswerke des Kantons Zürich (EKZ), Industrielle Werke Basel (IWB), and Elektrizitätswerk der Stadt Zürich (EWZ).

Figure II-IV shows the percentage of smart meters installed by the Smart Grid Swiss Association members (Verein Smart Grid Schweiz - VSGS). In 2014, already 64,000 smart meters (with remote readout) were installed (VSGS, 2015), which can be clearly used as an indicator. It is important to note that the VSGS statistics do not distinguish between meters in household, SME, or large corporates. Some smaller DSOs have also launched minor smart meters projects (Smart Linth Region, SWG Grenchen, Abron Energie AG), for which official statistics are not available.

\subsection{3 million of electricity meters}

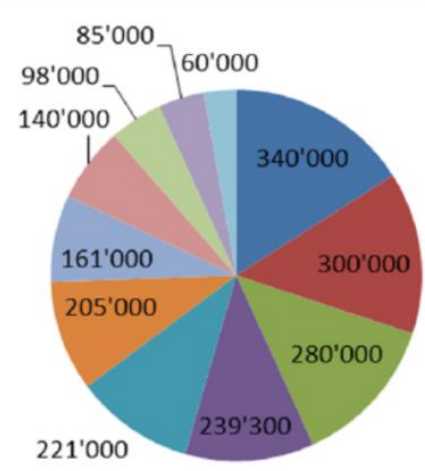

\section{about 64,000 of Smart Meter (remotely)}

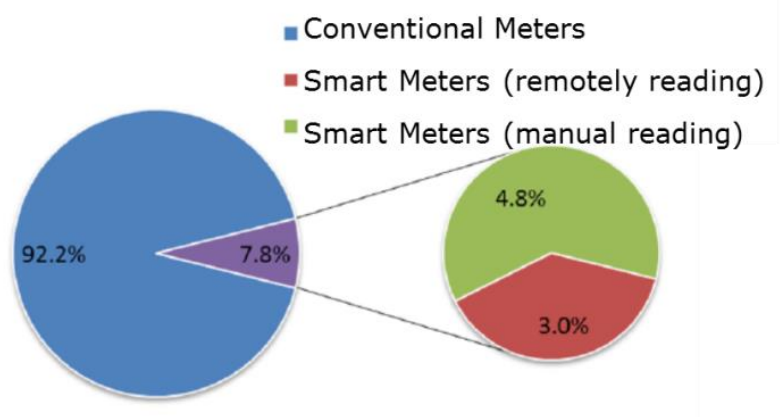

Figure II-IV - Smart and conventional meters operated by VSGS members in 2014; adapted from (VSGS, 2015)

GWF MessSysteme AG (GWF) is the largest manufacturer for smart meters in Switzerland (producing also water, gas and heat meters). They produce an upgraded conventional meter that has additionally a wireless device allowing "drive-by" readout (Figure II-V). However, this enhanced meter cannot be considered as fully smart for use in SES. As a second product, their more advanced meter fulfils the minimal requirements for smart metering systems by the SFOE (as discussed in the previous section, 'Smart meter roll-out and technical specifications'). The communication is by electrical signals following the RS-485 standard and allows up to 30 devices to be connected to a single collector (GWF, 2016). According to GWF, such smart meters are ready for a "Smart Grid" in Switzerland. 


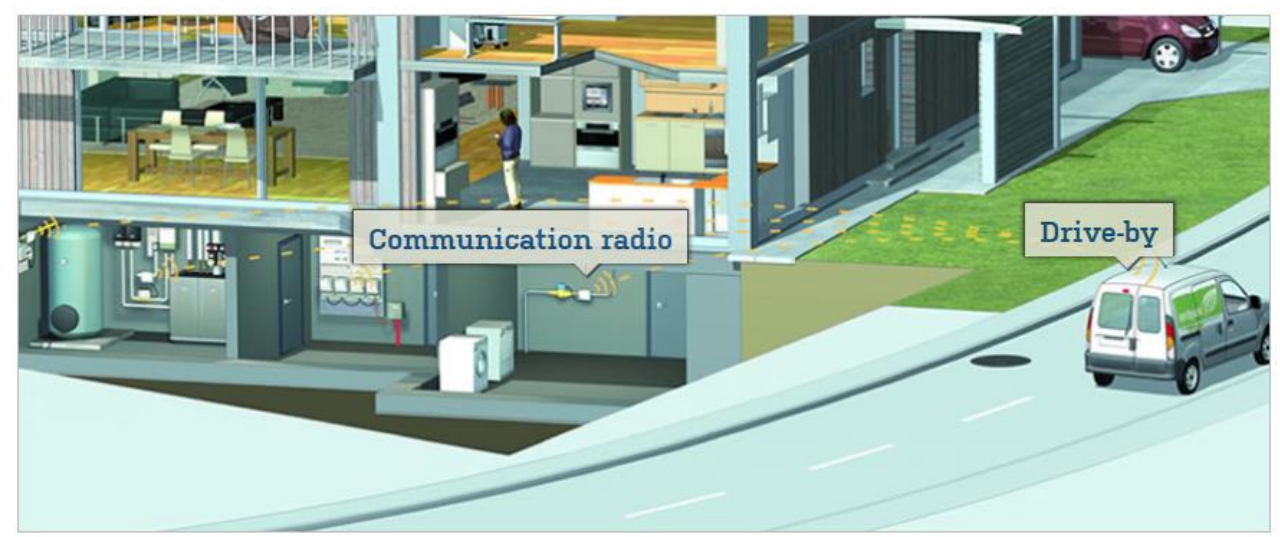

Figure II-V - Drive-by concept ${ }^{6}$

The relation between investment and implementation of smart metering is depicted in Figure II-VI, which shows also the setting-up (threshold) point for the Smart Grid. This setting-up - envisaged by GWF in the year

2025 - is when the share of smart meters reaches 80\% (GWF, 2015), which is in line with the previously detailed Full rollout scenario in Table II-III of the Swiss government. Smart meters are installed in bundles as the information is gathered by the $\mathrm{SM}^{7}$ hub and then transmitted to the operator (

Figure II-VII - Interconnections between Smart meter, hub and operator

), which explains the cyclic investment pattern in Figure II-VI.

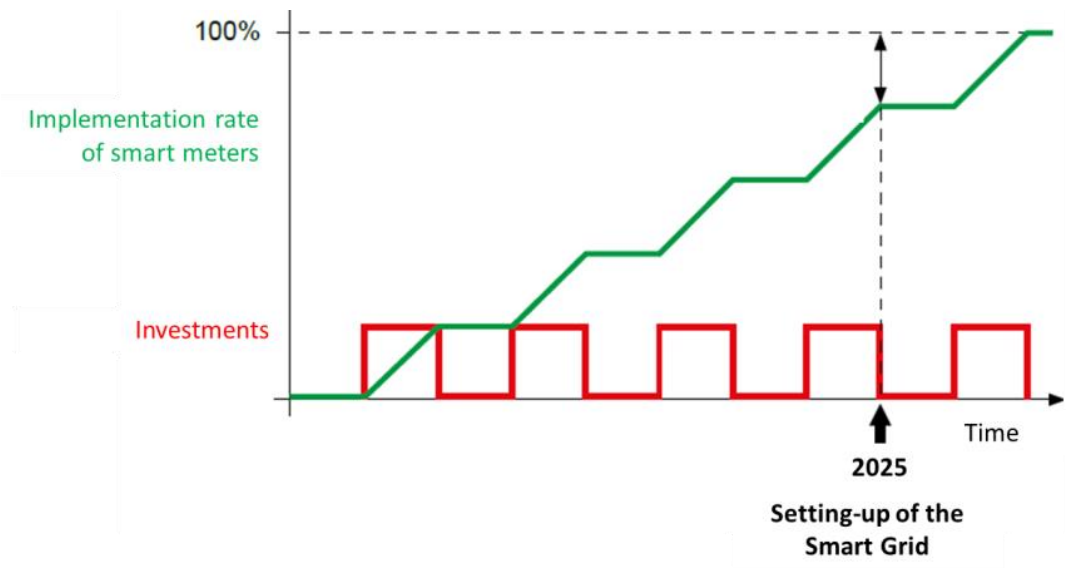

Figure II-VI - Stepwise increasing implementation of smart meter and the setting-up point; adapted from (GWF, 2015)

${ }^{6}$ GWF: http://smartmetering.gwf.ch/fr/home

7 Smart Meter 


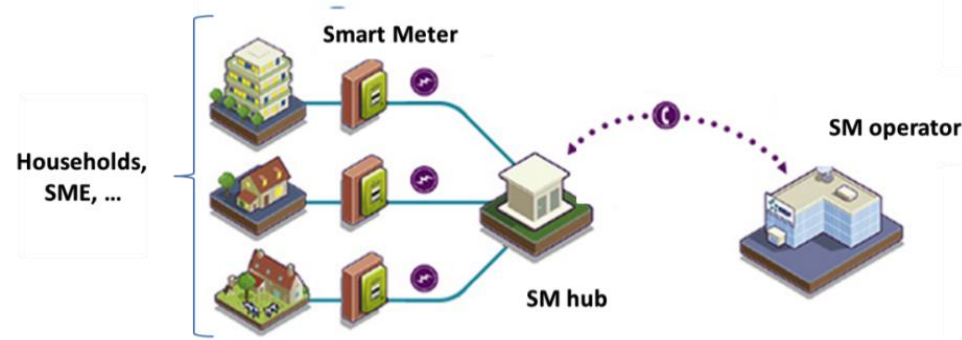

Figure II-VII - Interconnections between Smart meter, hub and operator ${ }^{8}$

\section{II.B.2. Types of load management}

\section{Indirect load management}

ToU tariffs (without explicit feedback) are available in Switzerland since several years (VSE, 2016a). Conventional power meters are already offering the possibility to record the consumption split into two tariff steps. With smart meters, such contracts can be improved with more steps, which could allow to increase the load shifting potential between $2.5 \%$ and $5 \%$ compared with a two-step tariff (BFE, 2012). CPP (critical peak pricing) and RTP (real time pricing) are demand response tools not yet available for small consumers, and could serve with ToU tariffs deployment as an indicator. Table II-IV summarizes the requirement and impact of price-based load management.

Table II-IV - Requirements and impacts of price-based load management

\begin{tabular}{|c|c|c|c|c|c|c|c|c|}
\hline \multirow[b]{2}{*}{ Tariff model } & \multicolumn{3}{|c|}{ Requirements (for utility) } & \multicolumn{5}{|l|}{ Impact on } \\
\hline & $\begin{array}{l}\text { Smart } \\
\text { meter } \\
\text { required? }\end{array}$ & Complexity & Expenses & Load profile & $\begin{array}{l}\text { Forecast } \\
\text { deviations }\end{array}$ & $\begin{array}{l}\text { Network and } \\
\text { power plant } \\
\text { outage }\end{array}$ & $\begin{array}{l}\text { Energy } \\
\text { savings }\end{array}$ & $\begin{array}{l}\text { Market } \\
\text { involvement }\end{array}$ \\
\hline $\begin{array}{l}\text { Time of Use } \\
\text { tariff (ToU } \\
\text { tariff) }\end{array}$ & $\begin{array}{l}\text { no; Swiss } \\
\text { electricity } \\
\text { meters } \\
\text { allow } \\
\text { already } 2 \\
\text { steps ToU } \\
\text { tariff } \\
\end{array}$ & low & low & $\begin{array}{l}\text { only long- } \\
\text { term; } \\
\text { general } \\
\text { shift } \\
\text { towards } \\
\text { low tariff } \\
\text { periods } \\
\end{array}$ & none & none & small & $\begin{array}{l}\text { none, only via } \\
\text { average costs }\end{array}$ \\
\hline $\begin{array}{l}\text { Critical Peak } \\
\text { Pricing (CPP) }\end{array}$ & $\begin{array}{l}\text { also } \\
\text { possible } \\
\text { without } \\
\text { SM but } \\
\text { with SM, } \\
\text { more } \\
\text { flexibility }\end{array}$ & medium & high & $\begin{array}{l}\text { response to } \\
\text { specific } \\
\text { market and } \\
\text { network } \\
\text { events }\end{array}$ & $\begin{array}{l}\text { during } \\
\text { short-term } \\
\text { announced } \\
\text { events }\end{array}$ & $\begin{array}{l}\text { medium } \\
\text { (during short- } \\
\text { term } \\
\text { announced } \\
\text { events) }\end{array}$ & $\begin{array}{l}\text { yes, } \\
\text { unless a } \\
\text { load } \\
\text { shift } \\
\text { occurs }\end{array}$ & $\begin{array}{l}\text { yes but } \\
\text { limited }\end{array}$ \\
\hline
\end{tabular}

\footnotetext{
${ }^{8}$ Adapted from https://electroallergique.files.wordpress.com/2013/04/100915-linkycommuniquant.jpg?w=700
} 


\begin{tabular}{|c|c|c|c|c|c|c|c|c|}
\hline $\begin{array}{l}\text { Real Time } \\
\text { Pricing (RTP) }\end{array}$ & no & very high & very high & high & $\begin{array}{l}\text { high (but } \\
\text { not during } \\
\text { days where } \\
\text { prices are } \\
\text { pre- } \\
\text { decided) }\end{array}$ & $\begin{array}{l}\text { high (but not } \\
\text { during days } \\
\text { where prices } \\
\text { are pre- } \\
\text { decided) }\end{array}$ & $\begin{array}{l}\text { yes, } \\
\text { unless a } \\
\text { load } \\
\text { shift } \\
\text { occurs }\end{array}$ & $\begin{array}{l}\text { yes, } \\
\text { theoretical } \\
\text { adjustment } \\
\text { according to } \\
\text { marginal } \\
\text { generation } \\
\text { costs possible }\end{array}$ \\
\hline
\end{tabular}

\section{Direct load management}

Apart from ToU tariffs, direct load management through controlled electric appliances are already available and deployed in Switzerland (SVE, 2016, 1). However, the remote controls are simple, that is, no information about the live-characteristics of the appliance is transmitted; it is just switched off or on, and currently mainly used only for water heaters (usually combined with water storage and electric heating). In Figure II-VIII, the flexibility potential of categories of electric appliances is shown. The appliance category offering the best flexibility potential is the hot water, offering a potential of $75 \%$ when the flexibility duration goes beyond 4 hours.

\begin{tabular}{|c|c|c|}
\hline Appliances category & $\begin{array}{l}\text { oretical flexibility potential } \\
\text { ording to the flexibility length }\end{array}$ & \multirow{2}{*}{$\begin{array}{l}\text { Flexibility } \mathbf{p} \\
\text { (or share of } t \\
\text { can be shiftec }\end{array}$} \\
\hline until 1 ho & from 1 to 4 hours more than 4 hours & \\
\hline \multicolumn{3}{|l|}{ Central heating system } \\
\hline \multicolumn{2}{|l|}{ Heating system (direct electric, heat pump) } & $50 \%$ \\
\hline \multicolumn{3}{|l|}{ Hot water } \\
\hline \multicolumn{3}{|l|}{ Refrigerators and freezers } \\
\hline $\begin{array}{l}\text { Individual heating system (radiator); } \\
\text { individual cooling system; wash/dry } \\
\text { clothes; wash-up; computer/audio/video } \\
\text { hardware }\end{array}$ & & $0 \%$ \\
\hline
\end{tabular}

Figure II-VIII - Theoretical flexibility potential of load management; adapted from (VSE, 2016a)

\section{II.B.3. Other system component of SES}

Batteries of electric vehicles (EV) -while not being used but connected to loading stations- can be used as a buffer at the household scale or even at the regional scale (BKW, 2016; Soares M.C. Borba et al., 2012). This vehicle to grid (V2G) concept is not yet implemented in Switzerland (VSE, 2016b). Nevertheless, the number of EVs could be an indicator for SES. The number of EVs in Switzerland (Table II-V) rose by almost 70\% between 2014 and 2015. In 2015, 7,531 EVs were on the roads. However, they represent still only $0.2 \%$ of the car fleet.

Table II-V - Number of private cars in Switzerland ${ }^{9}$

\begin{tabular}{|c|c|c|c|c|c|c|c|}
\hline & & 2010 & 2011 & 2012 & 2013 & 2014 & 2015 \\
\hline & Gasoline & 3308634 & 3301501 & 3278675 & 3234560 & 3201710 & 3173806 \\
\hline \multirow{7}{*}{${ }^{9} \underline{\text { https }}$} & Diesel & 739112 & 827094 & 934084 & 1035843 & 1123676 & 1214075 \\
\hline & Gasoline-electric & nin.ch/deffautsto & 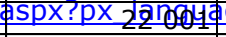 & $g e=f r \quad 27321$ & 33160 & 38839 & 45285 \\
\hline & Diesel-electric & 17 & 31 & 769 & 1674 & 2319 & 3223 \\
\hline & Electric & 665 & 1044 & 1758 & 2683 & 4439 & 7531 \\
\hline & Gas & 6652 & 7349 & 7742 & 8457 & 9174 & 9878 \\
\hline & Others & 3606 & 3983 & 4376 & 4508 & 4333 & 4271 \\
\hline & Total & 4075825 & 4163003 & 4254725 & 4320885 & 4384490 & 4458069 \\
\hline
\end{tabular}


Figure II-IX shows a possible evolution of the EV fleet in Switzerland. These projections were calculated using the Swiss TIMES energy system model (STEM) developed by the PSI. By 2040, plug-in hybrid electric vehicles (PHEVs) together with battery electric vehicles are the majority. The share of the latter increases to $95 \%$ in 2050 to around five million vehicles (Kannan and Hirschberg, 2016)

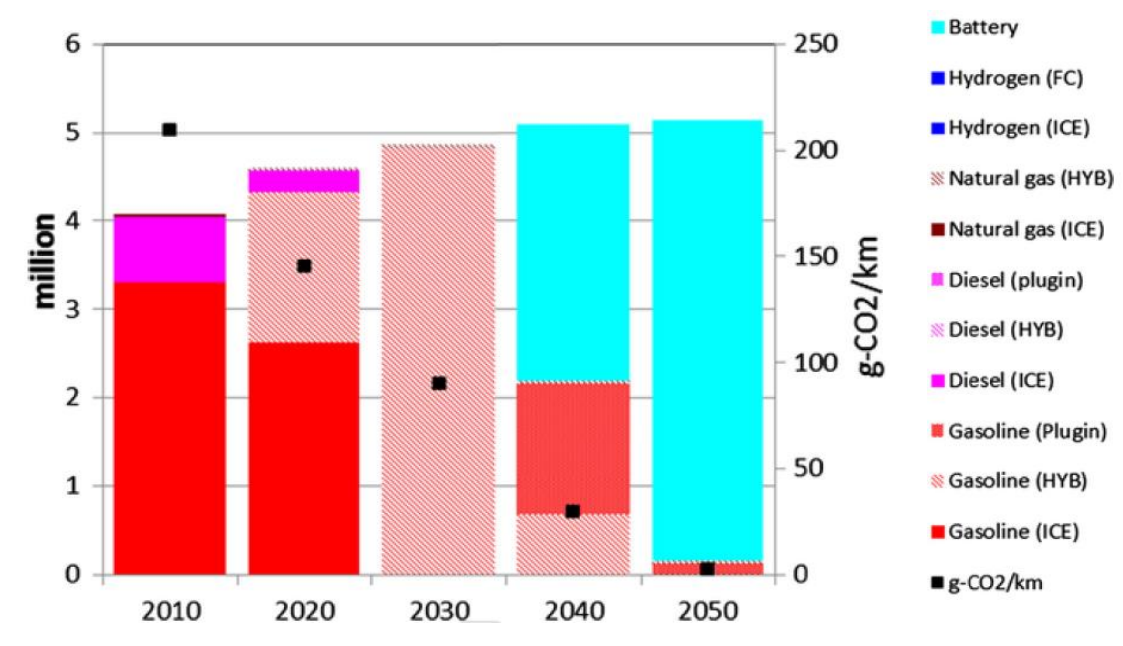

Figure II-IX - Evolution of number of electric vehicles in Switzerland

\section{II.B.4. System level impacts (ToU tariffs)}

The major Swiss electricity suppliers are currently not providing ToU tariffs together with feedback to end-users, likely because the number of smart meters is still negligible. However, small pilot projects linked with feedbacks programs have already been implemented in the smaller cities (e.g. in Arbon and Dietikon), which could be used as indicators. As of today, no exhaustive data statistics or impact reports are available of these still marginal efforts for ToU tariffs. 


\section{II.C. France}

\section{II.C.1. Smart meter roll-out and technical specifications}

In France, most of the smart meters are installed by ENEDIS, which is the largest DSO covering $95 \%$ of power distribution (Fournisseur, 2016a). Figure II-X shows the usual Linky smart meter. The interface is still simple and allows the consumer to monitor the current electricity tariff, the actual load, and the maximal subscribed load. The guidelines for minimal requirements of the Swiss government for smart meters (see chapter II.B.1) are roughly comparable to those of French authorities.

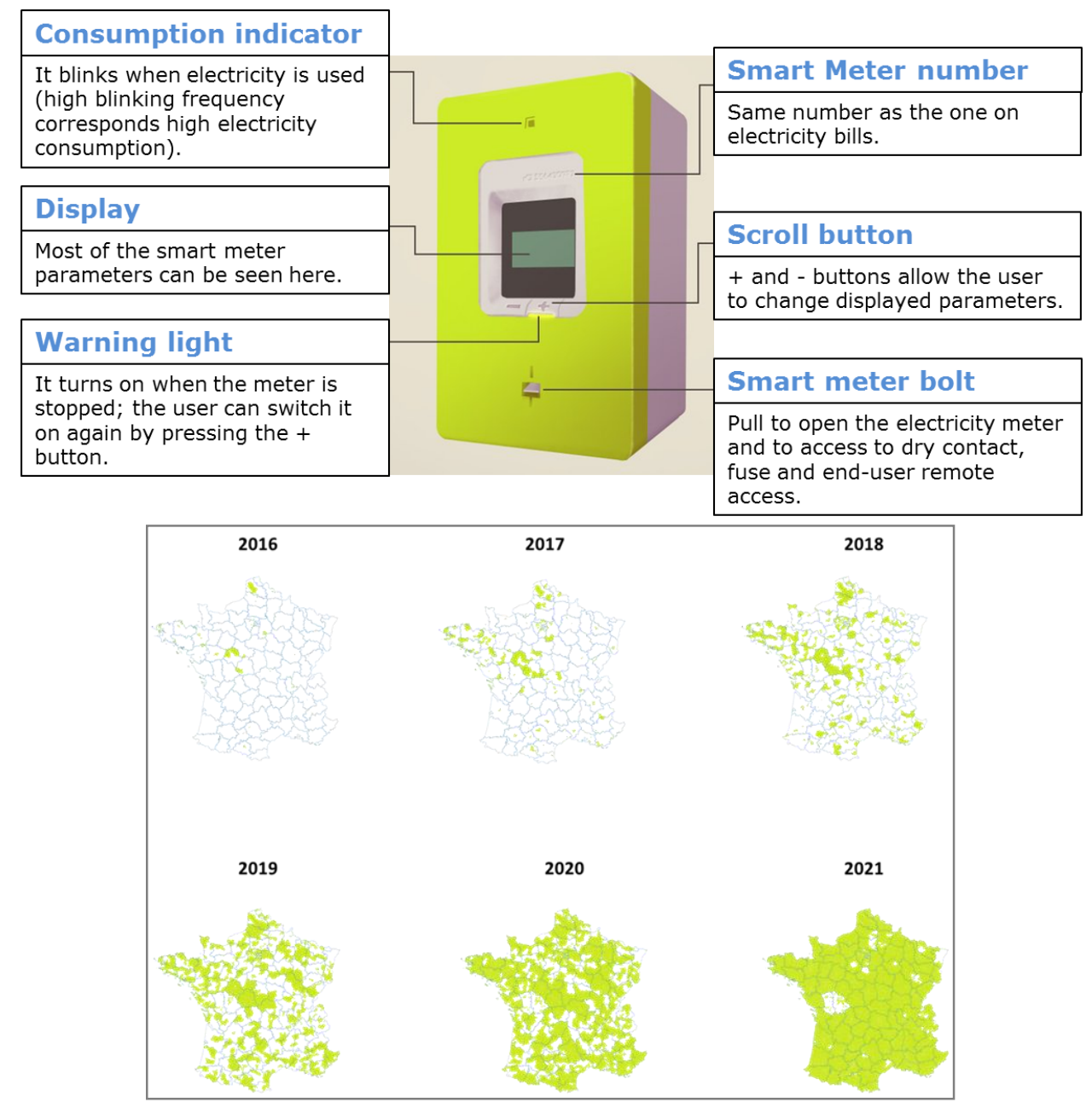

Figure II-X - Smart meter Linky

Smart metering implementation in France started officially in December 2015 (CRE, 2016). By October 2016, 1,751,200 smart meters were installed ${ }^{10}$. Figure II-XI shows how this implementation should continue as envisaged by ENEDIS. The next implementation period is from 2016 to 2021, which should result in a smart meter coverage of $90 \%$. It may be interesting to compare with the more ambitious roll-out plan in 2014 reported the European Commission: Figure II-XII shows that

10 personal communication with ENEDIS 
the French government had committed to have an implementation period finished in 2020, and the objective for 2016 was to have three million smart meters installed, which could be used as an indicator.

Figure II-XI - Projected roll-out of smart meter in France $(2016-2021)^{11}$

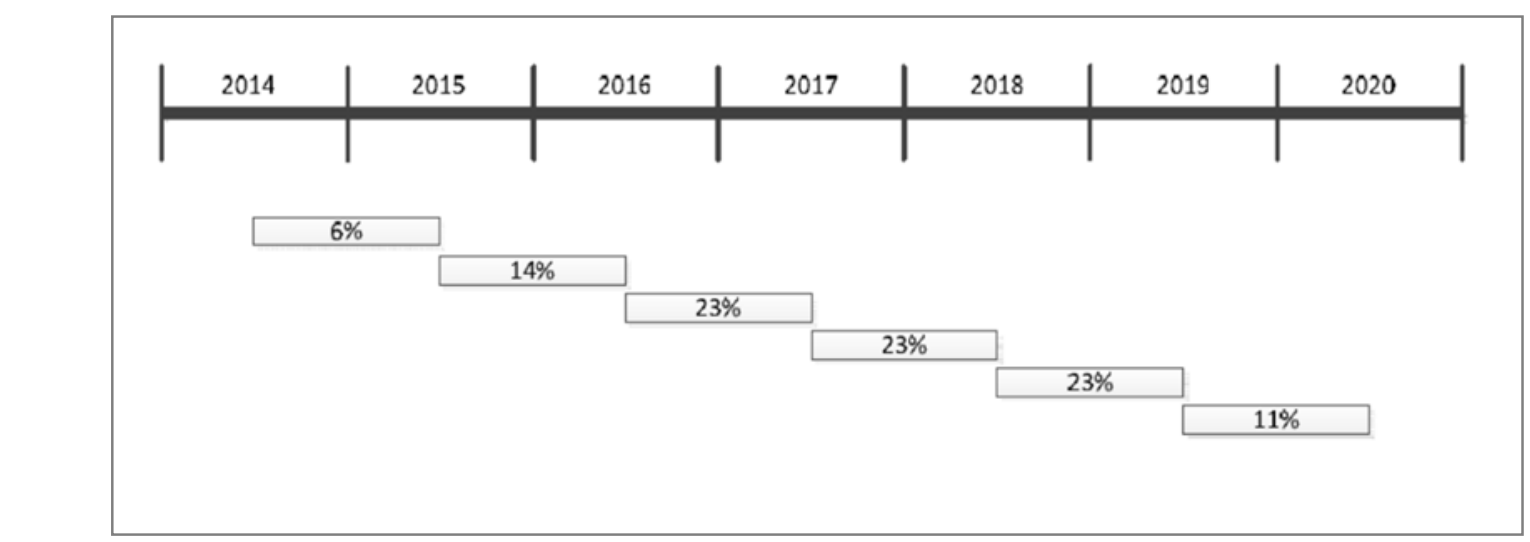

Figure II-XII - Projected roll-out of smart meter in France (2014-2020) (European Commission, 2014a)

\section{II.C.2. Types of load management present}

Already ten of the eleven electricity suppliers in France are offering ToU tariffs to small consumers. The exception is Enercoop offering only a fixed tariff; Enercoop's power is 100\% renewable and they follow the "Negawatt" approach ${ }^{12}$, which results in electricity tariffs that are $15 \%$ more expensive than those of competitors. In Figure II-XIII the price components are shown for Enercoop, which may constitute also useful alternative information for consumers.

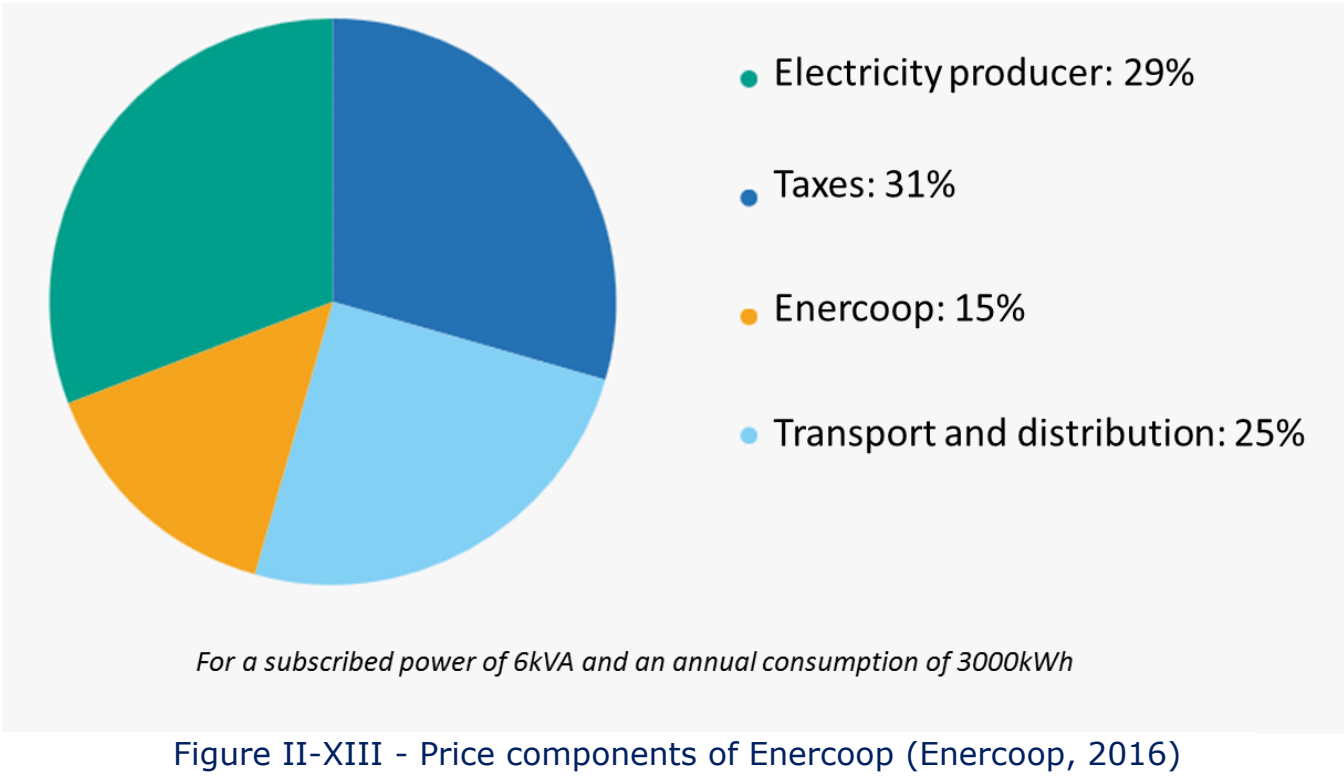

11 Adapted from ENEDIS: https://espace-client.erdf.fr/linky-consulter-deploiement

12 Negawatt means "power that is saved" 


\section{II.C.3. Other system components of SES (EV deployment)}

Figure II-XIV shows the number newly licenced electric vehicles (EV) in France since 2011 and monthly statistics for 2015 and 2016. Over the past years, EV deployment grew constantly. In 2016, 13,516 licences were issued (the monthly statistics indicates that 2016 will continue to exceed previous years). Number of EVs could be used as an indicator, as well as the governmental grants.

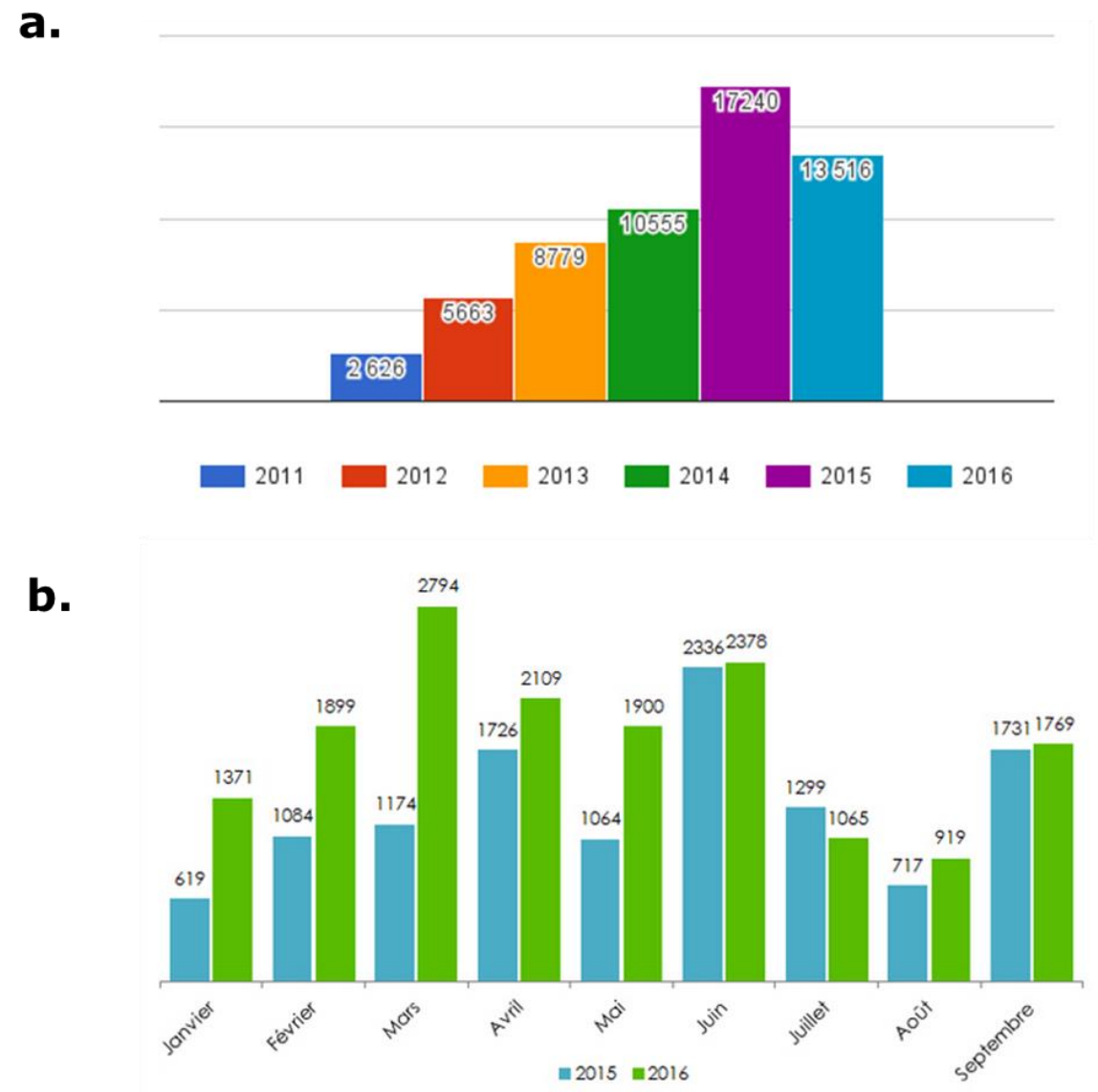

Figure II-XIV - a. Newly licensed EVs in France; b. Monthly EV licensing for 2015 and 2016 (Auto, 2016)

\section{II.C.4. System level impacts}

The feedback loop of information proposed by Electricité de France ${ }^{13}$ (EDF) is shown in Figure II-XV. The central element is the smart meter Linky. In a first step, the electricity consumption is recorded by the smart meter with a period of minimal 10 minutes. The French legislation has recommended this lower boundary of 10 minutes to protect consumer privacy (CNIL, 2012). The consumer has to agree on the recording periodicity with the supplier and can usually choose between 10,30 or 60 minutes. In a second step, the smart meter transmits daily the data to ENEDIS who transfers the data to the electricity supplier. The customer can monitor the electricity consumption of the previous day and get feedback and advices.

13 EDF is the largest power producer in France; in 2014, 92.6\% of the electricity of small consumers was provided by EDF (Fournisseur, 2016a) 
Small consumers can choose between eleven electricity suppliers as of today. However, none of them are providing in their contracts such feedback yet (Figure II-XVI). EDF offers a contract called e.quilibre where the user can monitor the electricity consumption on a monthly basis only. With more nation-wide deployment of smart metering in the future more flexible feedback contracts may emerge (currently it seems that the almost two million smart meters installed are below the threshold for such contracts). Moreover, a consumer having a Linky smart meter can already monitor consumption, but only at the online platform of ENEDIS, which may be still too inconvenient as a major downside.

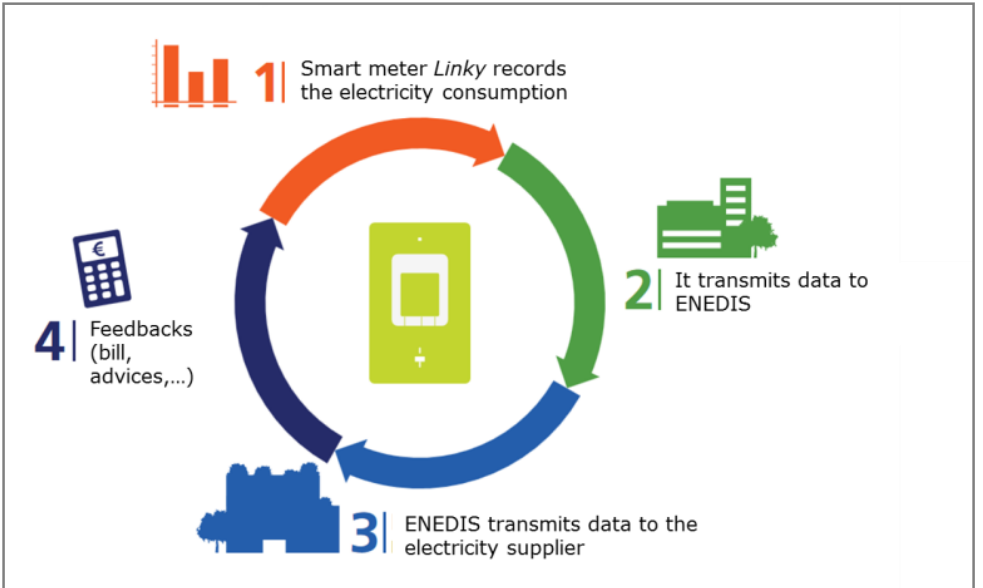

Figure II-XV - Information loop using the Linky smart meter (Source: (Fournisseur, 2016b))

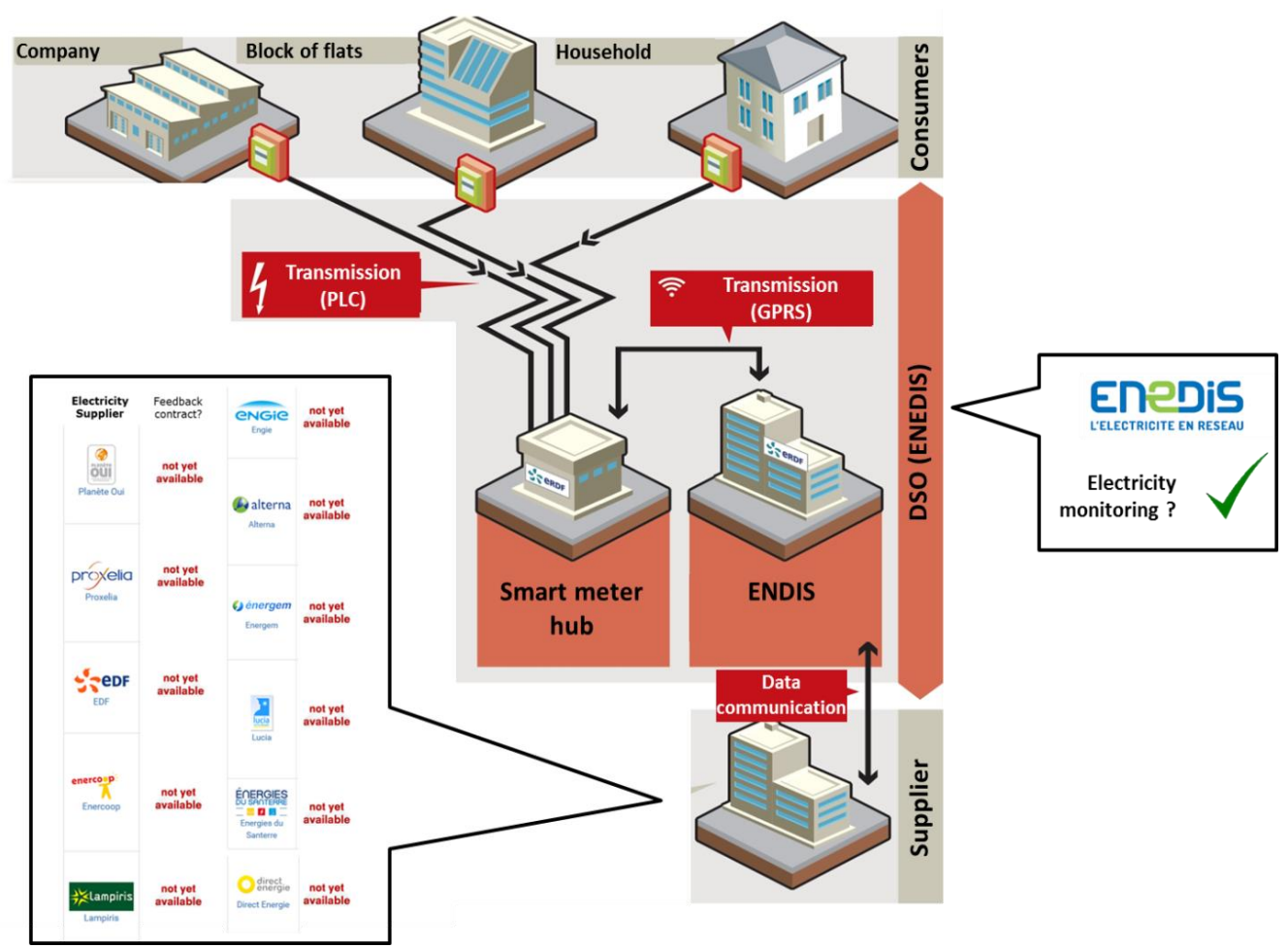

Figure II-XVI - Information flow and list of possible electricity suppliers; adapted from (Foucaud and Figaro, 2015) and (Fournisseur, 2016b) 


\section{II.D. UK}

\section{II.D.1. Smart meter roll-out and technical specifications}

The fundamental requirement for any home smart energy solution (SES) is a smart meter, which provides additional information and/or the ability to control use, to either increase or decrease demand to meet the mutual aims of both the consumer, supplier and network operator. Therefore, indicators for smart meters are critical.

\section{Smart meter roll-out: physical installation}

The UK Government's Smart Metering Implementation Programme aims to roll out 53 million smart meters to all domestic consumers and smaller non-domestic premises ${ }^{14}$ in Great Britain by the end of 2020 (DECC/Ofgem, 2014). Suppliers need to take all possible steps to get full coverage, although smart meters are not compulsory for households i.e. they are not obliged to agree to an installation, and could refuse a supplier's request.

As part of the roll-out, installation will include both a smart electricity meter, a smart gas meter, and a communications hub. Consumers are also offered an In-home Display at no upfront cost. Data will be used by energy suppliers (for billing) and energy network operators (to help manage load and enable improved planning). Use of data by other organisations will be subject to agreement by consumers. A Data and Communications Company (DCC), overseen by the regulator, will put in place communications to allow for information to be sent from smart meters to energy suppliers, energy network operators and energy service companies.

Indicators used to monitor progress on the roll-out are provided in a quarterly statistical publication (BEIS, 2016a) ${ }^{15}$. The following indicators of installation are used -

- No. of smart meters installed by large energy suppliers in domestic properties, by fuel type (quarterly)

- No. of smart meters installed by small energy suppliers in domestic properties, by fuel type (annual)

- No. of domestic gas and electricity meters operated by the large energy suppliers by meter type (quarterly), distinguished by fuel type

- No. of domestic gas and electricity meters operated by small energy suppliers by meter type (annual)

An important distinction is made between installation (first two bullet points) and operation (second two bullet points). Operation means those meters which the energy suppliers are operating in 'smart mode' (BEIS, 2016b). This may differ from 'installations' for the following reasons; i) customers with smart meters who are in the process of switching to a smaller supplier whose data is currently not collected; ii) as per i), but where the new supplier is currently unable to operate the

\footnotetext{
14 These are business or public sector customers whose sites use low to medium amounts of electricity (defined as a smaller non-domestic site falling within Balancing and Settlement Code Profile Classes6 1, 2, 3 or 4) or gas (defined as a smaller nondomestic site using less than 732MWh of gas per annum). The sites therefore range from individual micro- and small businesses to the smaller sites of private and public sector organisations (BEIS, 2016a).

15 BEIS states - Currently these data are considered to be Experimental Statistics; this means they are new statistics and have not undergone the full evaluation process that is required for National Statistics.
} 
installed smart meter in smart mode; iii) technical issues preventing smart mode operation, and therefore is operating in a traditional mode.

It is worth highlighting that in the 'meter type' indicators, traditional and 'smart-type' categories are also included. 'Smart-type' do not have the full functionality of smart meters ${ }^{16}$, and are therefore not included in the roll out numbers. The above indicators are repeated for non-domestic sites; for these indicators, 'smart' and 'advanced'17 meters are distinguished but both count towards the rollout targets.

Some of the indicator information for both households and non-domestic sites is presented below (Figure II-XVII and Figure II-XVIII).

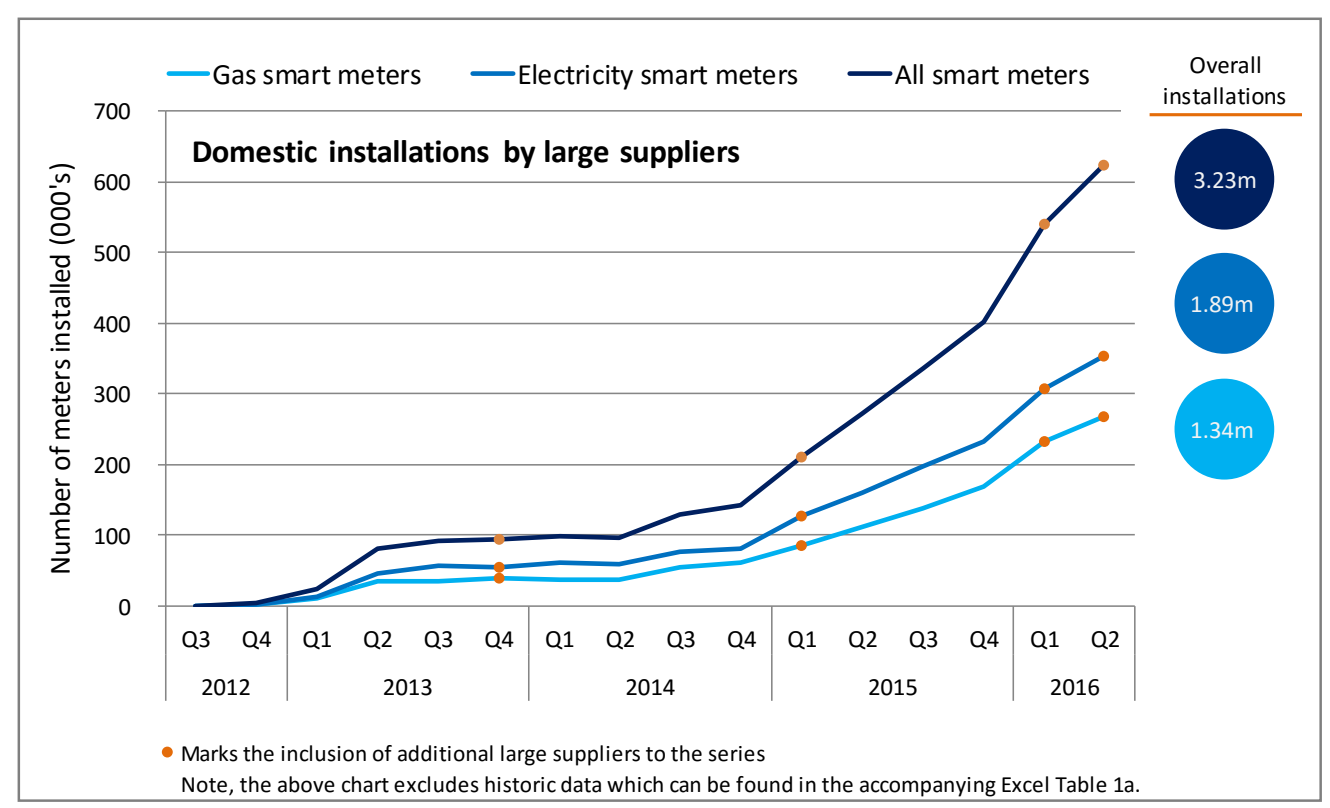

Figure II-XVII - Quarterly domestic installation activity for large energy suppliers (Source: (BEIS, 2016a))

\footnotetext{
16 They do not meet the criteria under the Smart Meter Equipment Technical Specification (SMETS). A full overview of required smart meter specifications can be found in (DECC, 2014).

17 Advanced meters must, at minimum, be able to store half-hourly electricity and hourly gas data, to which the customer can have timely access and the supplier has remote access. In smaller non-domestic sites, advanced meters may be installed as an alternative to SMETS-compliant smart meters until April 2017, in the case of large suppliers, and August 2017 in the case of small suppliers. These meters will not have to be replaced with SMETS meters in non-domestic sites before 2020 and therefore count towards the supplier's roll-out obligation (BEIS, 2016a).
} 


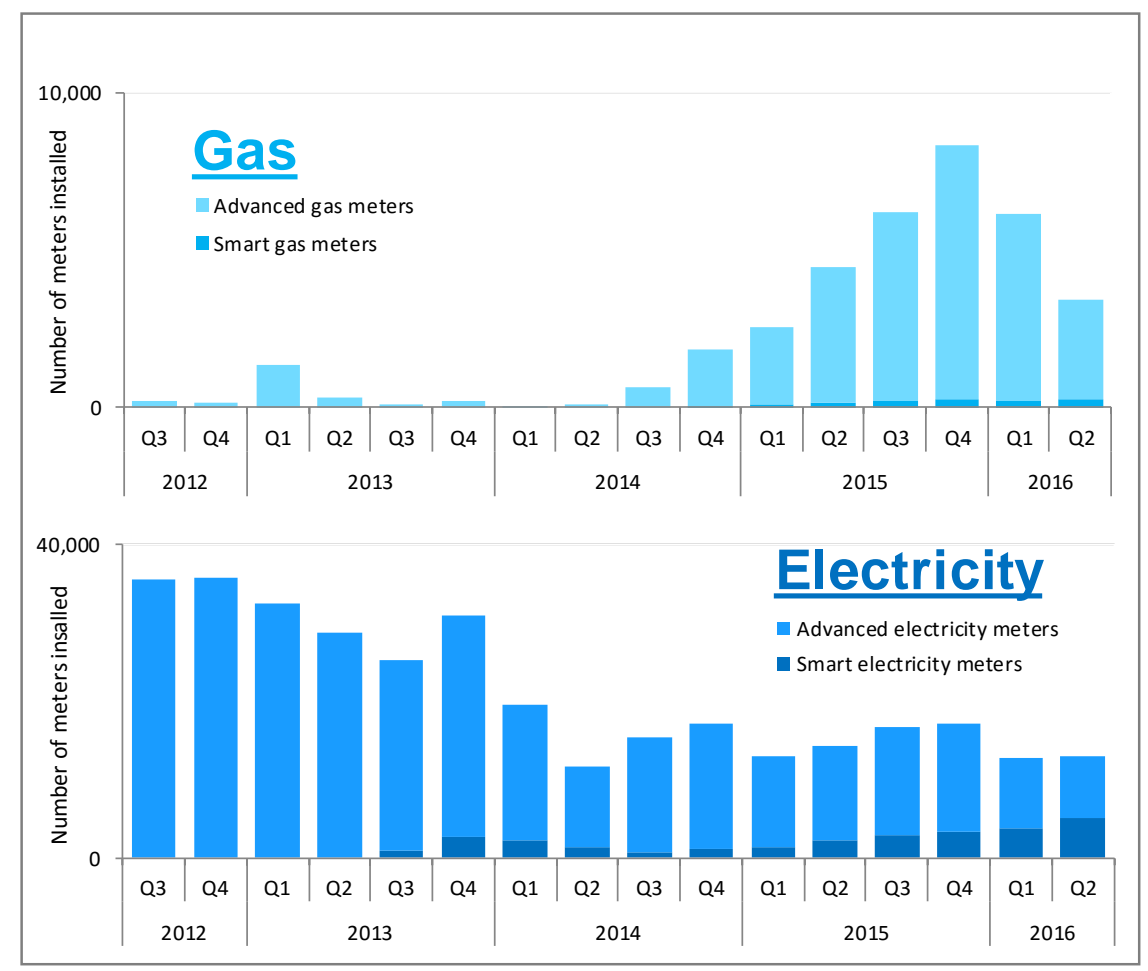

Figure II-XVIII - Number of smart and advanced meters installed by large energy suppliers in smaller nondomestic sites, by fuel type and quarter (Source: (BEIS, 2016a))

As the regulator, Ofgem (Ofgem, 2014) has an obligation to monitor the roll out of smart meters, and has stated a range of indicators. This includes numbers of installations, consumers declining installations, problems with equipment, primarily In-Home Displays, and coverage of PSR consumers $^{18}$.

\section{Smart meter roll out: investment}

There are other ways of measuring the penetration of smart meter roll out, through the investment in the roll out programme. The National Infrastructure Pipeline ${ }^{19}$ shows a total $£ 2.1$ billion (approx.. $€ 2.4$ billion) investment to 2020 , followed by a further $£ 4.3$ billion (approx. $€ 5$ billion) post-2020 for rollout of smart meters to domestic and small non-domestic customers. The investment includes dedicated communications infrastructure, IT systems upgrades across the energy industry and enduser smart meter equipment.

\section{Smart meter roll out: mode of operation}

Smart meters in the UK are primarily being installed and operated so that they feed back the information to energy suppliers and network operators, via the DCC. It is important to recognise that they are not yet being exploited to realise their full functionality (automations, links to smart devices). However, they do have the necessary functionality to (in the future) reflect real-time prices and allow either direct consumer responses or automated services via third parties (Committee on Climate Change, 2015). In fact, the Roadmap (DECC/Ofgem, 2014) does not

\footnotetext{
18 PSR customers i.e. those on the Priority Services Register are a list of vulnerable customers who may have additional needs in relation to energy.

19 National Infrastructure Pipeline 2016, https://www.gov.uk/government/publications/national-infrastructure-pipeline-2016
} 
envisage this 'smarter' role until the late 2020s and into the 2030s (see Figure II-XIX below). In part this is due to the lack of integrated systems in households, absence of time-of-use tariffs to provide incentives, and the fact that a stronger potential will be seen as the technology mix changes e.g. move to heat pumps (hybrid-based or with storage, EVs etc.) (Frontier Economics, 2015). Such technologies are therefore considered to have strong option value (if they have the necessary functionality), with a strong current use now but with greater potential in years to come (Strbac et
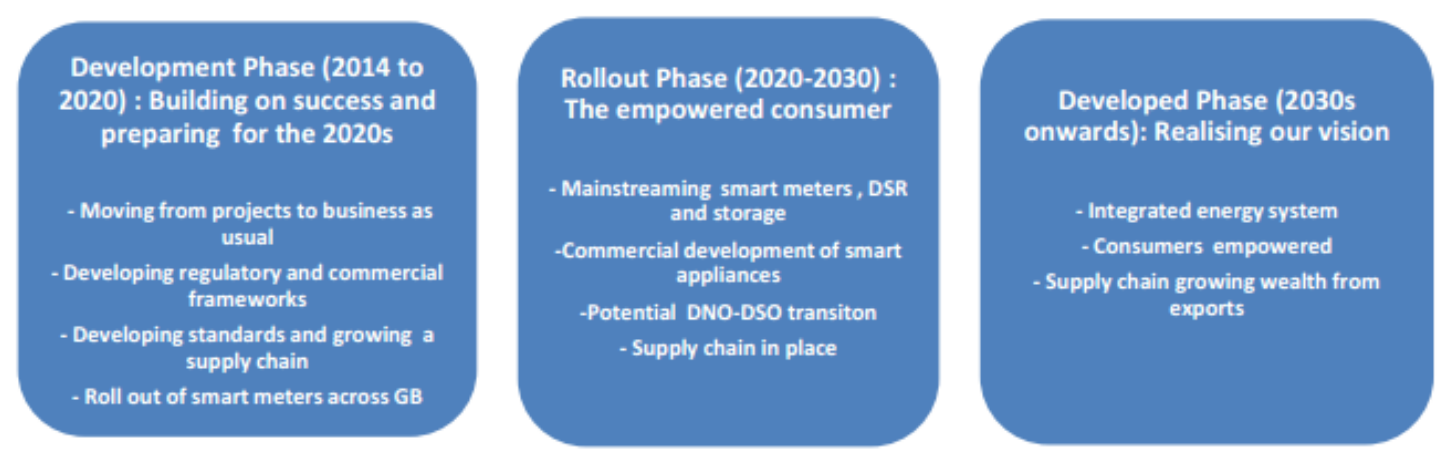

al., 2016).

Figure II-XIX - Stages in the development of the UK smart grid (Source: (DECC/Ofgem, 2014))

Future indicators will need to consider how the smart meter is being used, to better understand the additional potential. A number of indicators could be foreseen that provided information on the level of automation of the household system (uptake of smart appliance systems ${ }^{20}$ ), through types of agreements with suppliers on handing over some control for automation, the uptake of time-of-use tariffs, and other key elements of smart energy solutions that might further the role of the smart meter e.g. home power storage systems, electric vehicle ownership etc.

\section{II.D.2. Types of load management present}

The National Infrastructure Commission made a range of recommendations about the UK's move to increasing power system flexibility (National Infrastructure Commission, 2016). It states that in order for these consumers to directly engage with and benefit from demand flexibility, Ofgem [the regulator] needs to ensure that the regulatory framework incentivises suppliers to offer 'smart tariffs', so that the prices people pay can reflect the cost of providing electricity over time (e.g. on a half-hourly basis).

ToU tariffs incentivise consumers to shift demand away from higher tariff periods to lower tariff periods. These are largely absent from the UK, with the exception of Economy 7, where customers

20 A number of tech giants are developing hub systems that allow for control of smart appliances, such as Samsung (SmartThings), LG, Sony (Life Space UX) and Google (NEST). 
benefit from cheaper electricity at night. Economy 7 tariffs tend to be used by consumers who use electricity rather than gas for heating, and have hot water storage tanks and electric storage heaters, and can therefore utilise electricity at night. This is estimated to encourage two million household customers to shift electricity use to the night, resulting in a shift of $20 \%$ of annual household demand from the day (Parliamentary Office of Science and Technology, 2014) ${ }^{21}$.

In (DECC, 2015), the UK's first residential dynamic time of use tariff has been trialled Under Ofgem's Low Carbon Network Fund, by UK Power Networks, EDF Energy and partners. Over 1,100 households participated to explore response to variable price signals. The result was reduced demand in response to network constraint events by approximately $10 \%$ as well as increasing their demand during supply demand balancing events. This was based on manual response, which could be enhanced with automated smart appliances. A review of previous demand side response trials with a range of different tariffs (e.g. Time of Use, Critical Peak Pricing) found that peak energy demand reductions are $60-200 \%$ greater with automation and / or control by other parties (e.g. suppliers, Distribution Network Operators) than without. There are moves afoot to see how half hourly settlement could work, an important precursor to allowing for ToU pricing 22 .

There are two types of indicator that should be considered in the future. The first relates to the uptake of ToU tariffs, and the second to the impact. On impact, this could include indicators that measure the expenditure and consumption under ToU tariffs by ToU period (available via aggregated smart meter data). This could then be compared to household consumption without ToU tariffs.

It is also worth noting that there might be other tariffs that are available that do not necessarily focus on price as a means of incentivising consumers. In addition to being price-based, contracts with a supplier could also be volume-based or control-based. Volume-based impose some cap or constraint on electrical power consumption while control-based see customers cede some level of control over specified appliances to the DSR operator (Fell, 2016). Therefore, indicators could track the type and level of consumer contracts in the future - and their subsequent effectiveness. This is vital for learning how to maximise potential; (Fell, 2016) notes that the evidence is limited in respect of how consumers will respond to ToU pricing, and therefore learning of effectiveness via indicators will be crucial for decision makers.

\section{II.D.3. Other system components of SES}

There are a number of key elements of further developing smart energy solutions. These include the stronger integration of energy using appliances into building level communication systems (energy management systems \& smart appliances), and opportunities for increased electricity storage, either through electric vehicles or dedicated building level storage solutions e.g. Tesla Powerwall.

On smart appliances, (BIS, 2013) states that potential is large; however, this will take some time to feed through to the domestic appliance stock, with consumers reluctant to switch until a new appliance is required. No formal statistics on smart appliances or energy management systems is available in the UK, although a number of market research companies have made estimates.

21 Of consumers with Economy 7, 38\% were recently found not to have a storage heater or run any of their appliances at night, therefore paying more than they need to, to the advantage of no one but the energy companies (Citizen's Advice Bureau, 2014)

22 (Ofgem, 2016) 
Ultra low emission vehicle (ULEV) statistics now account for $1.1 \%$ of new registrations, showing strong growth from previous periods (UK Department for Transport, 2016). In 2015, the share was $0.8 \%$, and in 2014 , it was $0.2 \%$. However, in the current data, distinction between vehicle types is not provided; ULEVs are those with pure electric engines, plug-in hybrid engines or cars with $\mathrm{CO}_{2}$ emissions below $75 \mathrm{~g} / \mathrm{km}$ at tailpipe.

\section{II.D.4. System level impacts}

This section focuses on ex ante analysis of how broader system response based on smarter control of supply and demand could impact the broader system, and the potential economic benefits. Much of this analysis is based on modelled simulations, to better understand future potential, which is crucial for system planning. Therefore, these are not indicators of existing activity and progress towards such systems, but do provide evidence of future system potential.

\section{System level peak demand shift}

In the UK, there is a recognition that many of the building level SES will contribute to system level demand response. (Strbac et al., 2016) state that the demand side reduction (DSR) potential of industry ${ }^{23}$ and commercial consumers in the UK has been estimated to be between $4 \%$ and $30 \%$ of their corresponding peak demand. The importance of DSR from I\&C consumers is expected to grow greatly in importance and may constitute as much as $15 \%$ of flexible demand resources by 2030 .

(DECC, 2015) cites two studies assessing the overall potential of DSR; firstly, non-domestic buildings (excluding industry) could contribute 1.2 - 4.4 GW (winter week day, Great Britain) to peak energy demands (by (Element Energy and De Montfort University, 2012)). Secondly, another study on domestic and SME sectors concludes peak reduction in 2030 could be up to $2.5 \mathrm{GW}$ in the domestic sector and up to $2 \mathrm{GW}$ for SMEs (by (Redpoint/Baringa, 2012)). Other reports, such as (Frontier Economics, 2015), also consider future potential across different appliance types, and assess DSR in a modelling framework.

\section{Economic benefits}

In addition to the physical system effects, a number of analyses have also estimated the potential economic benefits of $\mathrm{DSR}^{24}$. There is reduction in costs associated with energy systems that integrate flexible technologies, of which DSR is one, in addition to storage, interconnection, and flexible generation. Analysis by (Strbac et al., 2016) for the NIC estimated avoided investment due to flexible technologies to range between $£ 2.9 \mathrm{bn}$ and $£ 8.1 \mathrm{bn}$ per year in 2030. It is quite difficult, however, to pinpoint the savings from building level SESs specifically, due to the consideration of a range of technologies working together in an integrated system.

(National Infrastructure Commission, 2016) also highlights the economic benefits for growth and UK firms, another potential way of monitoring the efforts in relation to SES. (DECC/Ofgem, 2014) highlight an E\&Y analysis (for SmartGrid GB) that estimates that the development of smart grids

\footnotetext{
23 Note that DSR is already being used in industry, through schemes such as Frequency Control by Demand Management (FCDM), demand interruption to safeguard system stability, and Triad, where incentivizes are in place to reduce demand at highest peak times of the year.

24 DSR defined by Ofgem as 'customers responding to a signal to change the amount of energy they consume from the grid at a particular time', and its basic purpose is to inject a degree of flexibility into the electricity system (Citizen's Advice Bureau, 2014).
} 
could lead to approximately $£ 13 \mathrm{bn}$ of Gross Value Added between now and 2050; export earnings of E5bn to 2050 and jobs could be boosted by an average of 8,000 during the 2020s rising to 9,000 during the 2030s if sufficient investment is made. Developing an indicator that measures impact on wider economy is potentially difficult because many of the firms involved in software development and systems operation apply their skills in many different sectors.

In a Consumer Futures paper on DSR and the domestic consumer, it was estimated that with the correct regulatory framework, smart solutions including DSR could save between $£ 2$ billion and $£ 4$ billion throughout the value chain to 2050, compared to conventional grid upgrades (DECC/Ofgem, 2014). (Citizen's Advice Bureau, 2014) state that the overall financial benefit from DSR is hard to estimate. One model commissioned by DECC, suggests savings from DSR between 2025 and 2030 are likely amount to roughly $£ 10$ per household per year if evenly shared. Alternatively, if not shared, participants could benefit in the region of $£ 90$ per year ${ }^{25}$. This analysis focuses on DSR, a specific outcomes of SES, and is based on modelled future outcomes.

Furthermore, R\&D levels are also a possible indicator of future commercial benefits. A JRC report Smart Grid Projects in Europe - Lessons Learned and Current Developments put UK levels investment in smart grid technologies at some of the highest in the EU (DECC/Ofgem, 2014).

25 (Redpoint/Baringa, 2012) 


\section{II.E. Ireland}

\section{II.E.1. Smart meter roll-out and technical specifications}

CER, the Irish energy regulator, in conjunction with the relevant government ministry (DCENR) established the National Smart Metering Programme (NSMP). This programme will aim to upgrade approximately 2.2 million electricity meters. The programme has 5 phases (Figure II-XX), and is currently in Phase 3, having published the High Level Design in October 2014 (CER, 2014). Phase 3 is focused on a range of activities around changes to consumer policy (regulatory changes, switching to time of use tariffs), developing consumer engagement activities and network activities, including procurement by operators for smart meter solutions and required network changes (CER, 2015a). The rollout of electricity smart meters for all residential and small and medium sized businesses is planned to commence in 2018 (Phase 5 Deployment), subject to the successful completion of Phases $3 \& 4$.

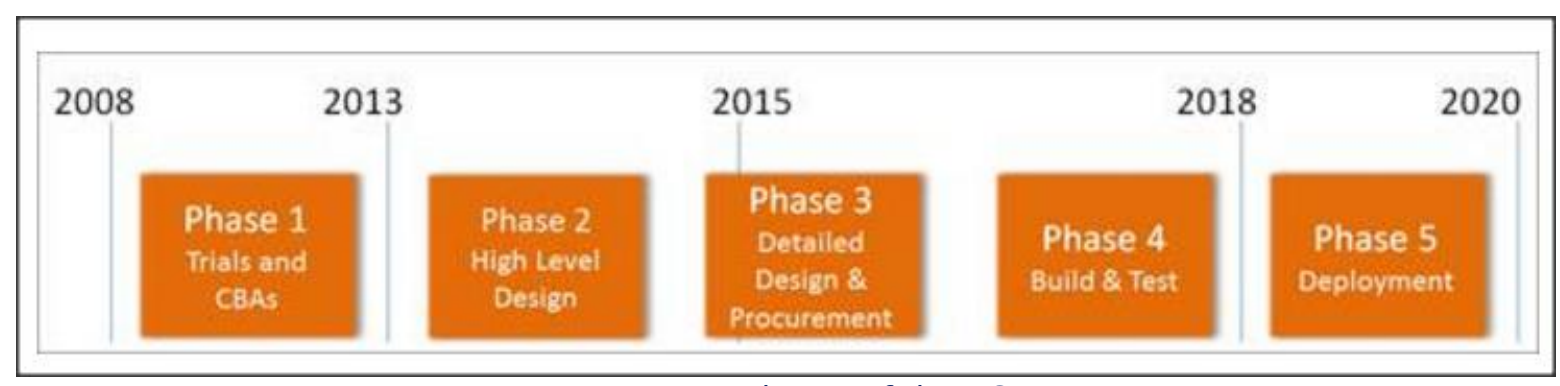

Figure II-XX - Phases of the NSMP

In the High Level Design (CER, 2014), the key features include -

- Limiting functionality of smart meters, with most of the data processing being done centrally (back office), and data on half hourly consumption, ToU tariffs etc. being passed to the consumer via non-AMI (automated meter infrastructure) such as online, apps, and mobiles.

- Introduction of ToU tariffs, to maximise the benefit of roll out

- Minimum information requirements through in-home display, smart bill and downloadable data file.

- Allow for switching between Pay As You Go (PAYG) and credit payment.

\section{II.E.2. Types of load management present}

As stated above, an important feature of the Irish smart metering programme is the introduction of ToU tariffs alongside smart meter roll-out. A decision document by (CER, 2015b) sets out the approach to ToU tariffs. Key features include - Suppliers to take reasonable effort to offer and migrate all (in a timely manner) residential and smaller business customers to a ToU tariff in a timely manner.

- Suppliers may offer a customer such a tariff from a date when relevant readiness criteria to that customer have been met (known as "TOU Go-Active").

- Suppliers must make available such a tariff for any customer for whom more than 12 months has elapsed since their "ToU Go Active" date. For residential customers, one of the tariffs choices must be its simplest ToU Standard Smart Tariff. 
- Suppliers must provide, at least once annually, a prompt to each customer not on a Time-ofUse Tariff for the purpose of encouraging sign-up.

- The CER will, subject to progress on rollout, set out a date by which other (no ToU) tariffs will need to start being removed from the market.

Monitoring of the uptake of ToU tariffs by CER will be critical for providing insights into consumer acceptance, and in estimating the potential effect (in combination with the smart meter data).

Under Phase 1 of the NSMP, a range of trials were undertaken to explore technical and operational issues associated with smart meter roll out, as well as behavioural response. The residential behaviour trial, one of the largest of its kind ( 5000 homes), found that ToU tariffs, in combination with other informational stimuli (web access to information, detailed billing, in-home displays, reduction target incentives) led to average overall electricity usage reductions of $2.5 \%$ and $8.8 \%$ for peak usage $\left(\right.$ CER, 2011) ${ }^{26}$.

Current ToU tariffs for electricity, which have limited customer reach, only extend to a day-night tariff, known as Nightsaver, which differentiate unit charges between the day and night periods. The lower charge period at night is from 11 p.m. to 8 a.m. in wintertime (late October to late March) and from 12 midnight to 9 a.m. in summertime (late March to late October).

\section{II.E.3. Other system components of SES}

Ireland has ambitious plans for electric vehicle roll out. The electric vehicle roadmap (SEAI, 2011a) describes how the passenger car stock is set to increase by $57 \%$ from 2011, with 2.9 million vehicles on the road by 2050. By 2020, the ambition is for the EV contribution to this fleet to be $10 \%$ (as set out in current policy), growing to $60 \%$ by 2050 under a medium scenario. Currently, new EV sales represent much less than $1 \%$ of all new sales, based on statistics produced by the $\mathrm{CSO} .{ }^{27}$

Electric and plug-in electric vehicles are being encouraged through a grants scheme, with a maximum grant of $€ 5,000$ available for qualifying electric vehicles when purchased privately ${ }^{28}$. In addition to the grant, there is also substantial relief on Vehicle Registration Tax (VRT) for these vehicles, as the VRT is tied to the emission level of the vehicle.

There is also progress on the infrastructure to facilitate electric vehicle take-up. Ecars, set up by the Electricity Supply Board, operate the infrastructure network and have over 1,200 public, standard and fast charge points across the country. This includes over 300 public charge points in Northern Ireland. Fast charge points number around $70 .{ }^{29}$

Key indicators to capture these elements of smart energy solutions could include:

- No. of EVs

- Establishment of charging infrastructure (no. of charge points)

\footnotetext{
26 A smart meter trial for gas was also undertaken, with 2000 households (CER, 2011b). This found average overall reductions, based on the use of variable seasonal tariffs, and similar stimuli to those in the electricity trial, to be $2.9 \%$.

27124 electric vehicles in class A/B were sold in January-February 2016, out of a total of 45,000. http://www.cso.ie/en/releasesandpublications/er/vlftm/vehicleslicensedforthefirsttimefebruary2016/

28 Electric Vehicles Grant Scheme, http://www.seai.ie/Grants/Electric Vehicle Grant Scheme/

29 ecars description, https://www.esb.ie/our-businesses/ecars/
} 
- Policies to incentivise take up, such as vehicle grants, differentiated road duty etc.

\section{II.E.4. System level impacts}

The opportunities for developing a smart grid, in which smart energy solutions in building will make an important contribution, are outlined in the Smart Grid Roadmap (SEAI, 2011b). This is very much tied to the requirement to decarbonise, and the need for smarter grids to cope with the increasing renewable generation. A headline finding of the roadmap is that decarbonisation of the electricity system will result in a $13 \mathrm{Mt} \mathrm{CO}_{2}$ saving by $2050.8 \mathrm{MtCO}_{2}$ will be directly from the implementation of smart grid, while the rest will be due to the displacement of fossil fuels due to the electrification in end use sectors. Some other key findings from this road map relevant to smart energy solutions include -

- Strong electrification of the transport system, predominately in the domestic sector, with an expected annual demand close to 8,000 GWh by 2050.

- Increased interconnection, of $1.6 \mathrm{GW}$ by 2040.

- 10,000 Irish jobs created through implementation of smart grid infrastructure and its associated technologies. 


\section{II.F. Sweden}

The energy market in Sweden was deregulated in 1996. Ever since, both producers and retailers have experienced a competitive market that drives the electricity prices based on demand and supply. The wholesale market occurs on an hourly basis in the Nordpool spot market. Elspot is the market for day-ahead and Elbas is the market for intraday, both with hourly operating bids and asks. Swedish electricity supply is based largely on hydropower and nuclear power. Since 2011, Sweden has been divided into four electricity areas as a result of the EC demanding that Sweden change its previous method of managing transmission limitations within the Swedish electricity network. The aim of partitioning into areas is to make it clear where in Sweden there is a need to reinforce and expand the national grid. Following the partitioning, there is no "Swedish price" for electricity. These wholesale prices are traded in the Nord Pool Spot. Nord Pool's actors consist of power producers, electricity suppliers, major end-users, portfolio managers, capital managers and brokers. In 2013, $84 \%$ of the electricity that was used in the Nordic countries was traded in the Nord Pool Spot (Swedish Energy Agency, 2015a).

In order for electricity to reach end-users, the system grid is operated by non-commercial monopolies. In each area a local grid operator ensures the security of the grid and handles the local low-voltage grid. The high voltage grid is also operated by a non-commercial TSO, which in Sweden is called Svenska Kraftnät. In cases of high demand, the TSO makes sure there is enough supply and the grid stays at operable levels. When demand falls and supply levels stay high, the TSO has the right to act accordingly, so that the system balances into equal supply and demand levels.

In terms of the retail market, end-consumers are free to choose from 120 suppliers. The Swedish Energy Markets Inspectorate (Ei) is responsible for independently analyse and advise consumers on the available offers that they can choose from the retail market (Nord Pool Spot, 2015, 2012).

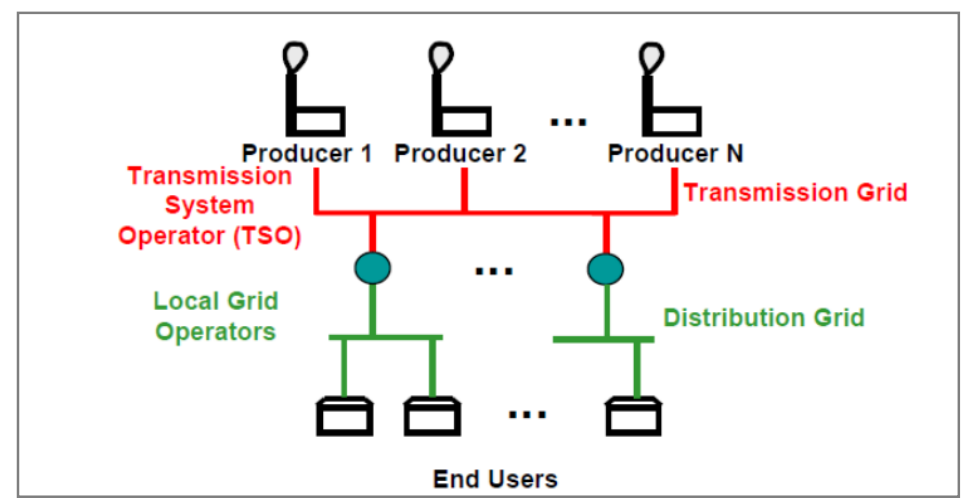

Figure II-XXI - Schematic structure of Swedish Electricity Retail Market (Nord Pool Spot, 2012)

\section{II.F.1. Smart meter roll-out and technical specifications}

Sweden is a country with $100 \%$ smart meter roll out - completed in 2009 . The roll out was one of the first to be completed, alongside Italy. This case study gives us a different perspective from the previous case studies above, one where the state of play on smart meters is much more advanced. The responsibility of the roll out was charged to the distribution system operators, who benefited from distribution tariffs to fund the smart meter installation (Söderbom and Vattenfall $A B, 2012$ ). 
All smart meters installed have hourly reading technology and remote load control of customer equipment. Automated Meter Reading (AMR) 3 has all 10 functionalities required by the European Commission, AMR 2 has 4 full and 1 partial functionality, AMR 1 only 4 . Surprisingly, AMR3 has the least service and investment costs. AMR systems gives improved control of non-technical network losses caused by broken meters, thefts, faults in data quality, faults and missing meter values, etc. (Söderbom and Vattenfall AB, 2012)

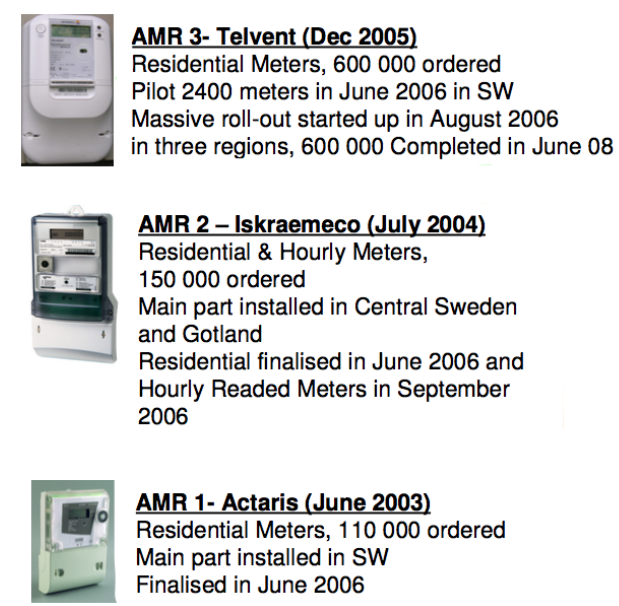

Figure II-XXII - Types of smart meters (AMR) (Söderbom and Vattenfall AB, 2012)

From the 1st of July 2006 hourly metering was introduced to customers with main fuses of 63A (large-customers) and from the 1st July 2009 monthly metering was introduced to customers with main fuses at most 63 ampere (small-customers). Measures are being taken to improve the meter data management systems, which in 2010 only had capacity to process $30 \%$ of the hourly information (NordREG, 2014).

After 2012, hourly metering was widened to all small-consumers in Sweden. This meant that they could have hourly metering upon request, if their contract with the supplier accorded this. Hourly metering for large-consumption customers is mandatory since the installation of the smart meter (NordREG, 2014).

As the metering is the DSO responsibility and there are over 120 DSO in Sweden, the actual number of smart meters installed is not available. 


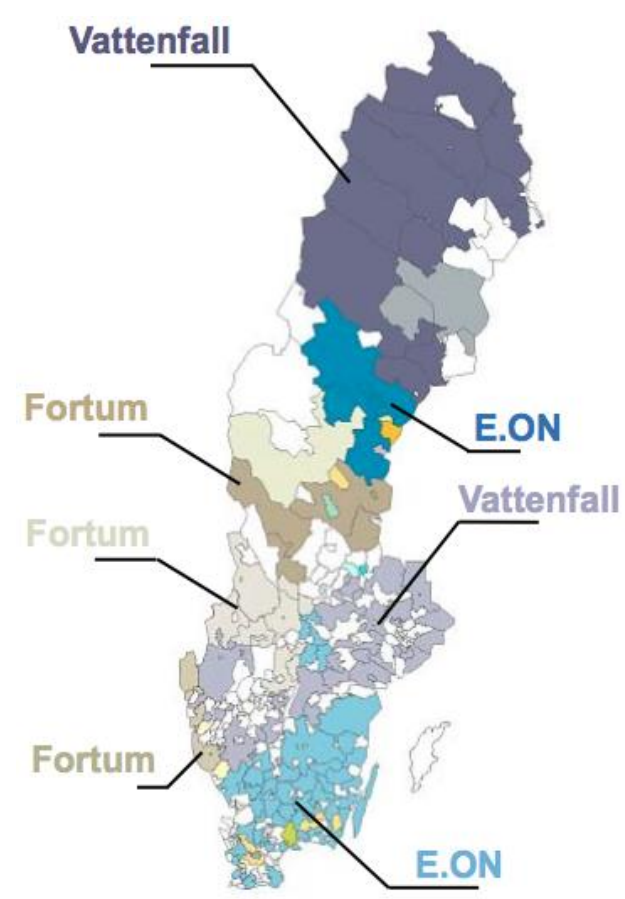

Figure II-XXIII - Geographical coverage of DSOs in Sweden (Söderbom and Vattenfall AB, 2013)

\section{II.F.2. Types of load management present}

There are roughly 5.3 million electricity consumers in Sweden, of which approximately 4.6 million are domestic consumers. At the end of 2014 there were 123 electricity supply companies (according to Elpriskollen). Price regulation in Sweden doesn't exist and the most common form of electricity contract is a variable price contract. The long-term trend is that more people are moving from fixed price to variable price contracts. The website elpriskollen.se is a state-owned price comparison platform for costumers to compare electricity contracts, and choose which option suits them best, based on geography, consumption and preferences. As there are a big number of retailers in Sweden there isn't a standard practice in terms of tariffs or prices, but time-of-use tariffs have been in place for several years now. For all large-consumers (with a fuse above 80A) ToU tariffs are mandatory. There are some suppliers that offer the ToU option to small-consumers, but it is up to the end-user to decide which contract to go for. Other contracts can be arranged in a way that no ToU is considered, like for example, spot price contracts that charge the customers the Elspot price (day-ahead market) plus a fixed mark-up. From a demand response perspective, hourly prices are the pre-condition for the customers to shift consumption. Fixed price and variable (but not related to ToU) contracts offer no incentives for shifting consumption.

From the data gathered by the Swedish Energi Market Inspectorate (Ei), time-of-use tariffs are used both for grid tariffs and power tariffs - being grid tariffs related to the energy consumed and power tariffs related to the power required for each consumer. For power tariffs the proportion of time-ofuse tariffs in the price of power is around $60 \%$ of the total price of electricity paid by the end-user. 


\section{II.F.3. Other system components of SES}

The electric vehicle market share in Sweden was $2.4 \%$ in 2015 . It increased from the share of the previous year, but at a lower rate than the year before. In what concerns taxes and incentives related to EV's, Sweden is trying to push EV's into the market. For EV buyers, there are rebates on the purchase of the car worth $4100 €$ (40000SEK), and there is also an exemption from the road circulation tax. VAT (value added tax) is $25 \%$, which still holds the base price of the EV's quite high for a bigger demand. However, the way that the incentives and policies are designed pushes buyers more towards plug-in hybrid electric vehicles PHEV rather than battery electric vehicles BEV. All in all, the total incentive provided by the government in a BEV is $5600 €$ for a company and $7500 €$ for a private buyer, as for the PHEV is $8400 €$ for a company car and $12200 €$ for a private buyer. This value is gathered combining the rebate and the road tax exemption (Mock and Yang, 2014).

Concerning bigger vehicles, advances are also being made. There is a 30 units electric vehicle bus fleet in Sweden. In the city of Gothenburg they are already operating as normal route city busses (IEA, 2016). Sweden is also pushing forward the technology in trucks. New projects studying the electrification of the roads for truck transportation to be viable are being done, especially in cooperation with Scania and Siemens. The first eHighway was inaugurated in north of Stockholm, where Siemens is testing a $2 \mathrm{~km}$ stretch. With the goal of having totally de-carbonised transport sector by 2030, this is a step ahead in that direction (Siemens AG, 2016).

\section{II.F.4. System level impacts}

Vattenfall's analysis estimates show the impact of smart metering installation in the following results: more than $€ 1$ million a year in reduced costs with AMR related to monthly billing, supplier change, move out/in and customer support; almost $€ 7$ million a year related to avoided technical network losses (broken meters, thefts, faults in data quality, etc.); generated financial benefits from extended business cases of around $€ 2.5$ million a year (Söderbom and Vattenfall $A B, 2012$ ).

The Swedish government decided Ei should propose a general framework for an information management model to suit future use of electricity data in Sweden. The outcome was a service hub based on a holistic approach where information is gathered and available in a simple way for all parties to assess it. This would mean access to historic data for customers and significantly lower costs of data handling for DSO's. This also addressed the problem stated above around the lack of capability of present data systems to process all of the hourly data provided by the smart meters. The study evaluates the average economic benefit to be of $€ 198$ million in a 10 -year span (for different scenarios), when compared to a system without data management hubs (Ei, 2015).

Still, there are still some barriers that delay the development of the market at the initial stages. For aggregators, market entry can have its challenges and obstacles. Information retrieved from the SEDC report (SEDC, 2015) shows that a BRP (Balancing Regulating Party) has to first sign a contract with the consumer's supplier. Then, it has to pay an annual fee of $2500 €$ and have an electronic reporting system installed and connected to EDIEL (Electronic Data Interchange for the electricity industry). Plus, as the suppliers also work as a BRP, the contract between both parties is unlikely to occur right from the start. 
From the report of the SEDC, there is no market size value for demand response concerning wholesale markets in the Nord Pool Spot (SEDC, 2015).

\section{II.F.5. Improving the implementation of a complete smart-meter system}

As this case study is distinctive from the others, here we present some thoughts and ideas - some already being put in place - about developing a system with a complete smart-meter rollout. This can be useful to countries seeking smart meter installation, to help think through market designs and regulation. We conclude with the developments being made in Sweden, and why some measures are not yet being put in place.

A study undertaken in the Swedish city of Va"stera's provides a snapshot of the current state of play. The current practice in Sweden is to bill customers on a monthly basis. However, most DSOs do not offer any feedback services concerning consumers' consumption. The study also shows that only $13 \%$ of the customers with fixed electricity contracts are willing to change to variable-price contracts (Vassileva and Campillo, 2016).

There are already some displays and applications for tracking electricity consumption such as the E.ON 100Koll. It was introduced in February 2014 and it is an application for the smart phone that relies on an optical eye that is glued to the smart meter in order to access the instantaneous consumption (1 minute delay) (Tedenvall and Mundaca, 2016). It has a cost, and it comes with smart plugs. The consumers can access information on their consumption in monetary units. However, since no RTP is present, this becomes irrelevant when addressing the demand response problem. So, why are no dynamic price tariffs, such as RTP, present in Sweden?

\section{Feedback}

A directly related factor with this problem is feedback on consumption. Apart from the abovementioned E.ON application for smart-phones, almost all the other consumption is reported monthly. If the retailer and the grid operator aren't the same company, the consumer only has the possibility of having feedback on monthly consumption. Feedback and how feedback is communicated is highly important for the societal appropriation of dynamic tariffs. As Karjalainen shows us, the three most valued aspects of feedback by consumers are: cost of electricity through time, appliance consumption breakdown and historical comparison (Karjalainen, 2011). This is validated by a case study done on the E.ON 100Koll system. It is concluded that real time feedback used on isolation isn't effective (savings around 2\%) (Tedenvall and Mundaca, 2016).

Real time feedback must be complemented with cost of electricity through time, appliance consumption breakdown and some type of comparison of consumption in order to evaluate the development of behaviour. So first it is necessary to implement this well with ToU tariffs.

\section{District space and water heating}

A new policy on building construction to push ahead energy efficiency was first started in 1993, and in 2014 came out the third version of this policy, with each version stepping up the standards on this matter (Swedish Energy Agency, 2015b). 
In Sweden, the main use of energy is due to space and water heating (more than 60\%). And the majority of that energy comes from district heating. Also, the majority of the residence buildings possess a common laundry, and the load demanded by it is constant during the day (Swedish Energy Agency, 2015a). Given all these facts, the electricity load available for consumer flexibility shrinks to household and commercial appliances. There aren't many studies on how this affects viability of the demand side system, but it is obvious that it shrinks also the benefits.

\section{Present low incentives}

For the Swedish reality, the incentives that today exist to promote flexibility are quite small. Flexibility is not only reached by having smart meters installed, but also through programs of information and education, to raise awareness in different types of consumers. The study also shows that, in order for consumers to be willing to change their behaviour, incentives would have to be much higher than current ones (Broberg et al., 2015).

Also, the DSO's set the tariffs and prices, thus deciding if there should be a dynamic tariff or not. Given that the transition to ToU rates isn't being adopted massively, the lack of interest and knowledge of consumers might be a factor for DSO's not considering this chance yet.

\section{Markets with dynamic tariffs}

In Massachusetts, distribution companies are being forced to present to clients' products from the two options bellow: a rate of ToU combined with CPP or a flat tariff with peak time rebates. This happens because retail prices don't reflect the variation of prices in the wholesale markets, and therefore the innovation in the grid gets jeopardized. Also, as the prices used to be flat, the consumers who were willing to shift their consumption to off-peak hours would subsidize the ones who didn't change their consumption habits (FERC, 2012).

Reports from Texas show: no flat tariffs are present anymore. On incentive-based demand response, commercial consumers use more interruptible load control and residential consumers use more direct load control. On time based, commercial uses more real time pricing and residential more time-of-use, but time-of-use is by far the most present tariff. The report also shows that without time-based tariffs across the country, demand response deployment might be slowed (FERC, 2012).

A number of studies state that smart tariffs should be taken as default (Hogan, 2014). With widespread dynamic rates, the normal thing that happens is that ToU is the most commonly tariff used. However, Hogan also states that when RTP is present a lot is not done for the implementation to be up to its fullest potential. This means that RTP-like tariffs are of complex implementation and usage. 


\section{II.G. Global overview of Smart Energy Solutions}

Throughout the world, especially in the developed countries, smart energy solutions are being deployed at various rates. Here we explore the most developed and potentially biggest markets for smart energy technologies: USA and China. However, evolution concerning this matter is also present and spreading fast in other countries including Australia, Japan, and Canada.

\section{II.G.1. United States}

The grid in USA is divided in three general interconnecting grids, each operating separately: the western grid, the eastern grid and ERCOT (in the state of Texas). Smart grid technologies are being deployed throughout USA, across all the three major interconnections. Smart meters are being installed, with the present number reaching 58.5 million meters nationwide (40.6\%) (DoE, 2016).

The national report shows that the potential of peak load reduction for demand side programs is increasing - from $28,934 \mathrm{MW}(6.2 \%)$ in 2014 to $31,754 \mathrm{MW}(6.6 \%)$ in 2015 . For retail markets specifically, the three largest contributions are from industrial, commercial and residential customers. In 2014, industrial demand response reached 16,505MW (53\% of the total), commercial DR $6,215 \mathrm{MW}(20 \%)$ and residential $8,118 \mathrm{MW}(26 \%)$. The number of customers enrolled in incentive-based programs and time-based programs is significant. For incentive-based programs, the number of customers enrolled in 2014 was 9,265,629. For time-based programs, in the same year, the number was $6,894,826$. In terms of financial benefits, the DoD (Department of Defence) alone - the biggest national consumer of electricity of the federal agencies - undertook a DR program in 15 states covering $80 \%$ of their activity and reported a net benefit of $\$ 3.2$ million annually, resulting from 236.6MW of flexible load (DoE, 2016).

EV's in the U.S. have a $0.7 \%$ of the total market share. However, the U.S. is the second biggest worldwide market and in 2015 registered over 100,000 new registrations for EV's. Despite, 2015 was the first year of non-growth since the start of the EV era (IEA, 2016).

\section{II.G.2. China}

In China, smart energy solutions are being pushed forward by governmental policies. In 2002, the electric power system underwent significant reform and since then it has been a priority to deploy smart energy technologies. By the end of 2015, China had installed 340 million smart meters and is expected to invest $€ 450$ billion in smart meter technologies in the period from 2012 to 2020 (Azure International, 2015).

Concerning demand side management programs, pilot projects were undertaken in four cities: Suzhou, Beijing, Foshan, and Tangshan. These pilots focused more on commercial, industrial and municipal facilities and experimented with various pricing schemes, such as RTP, CPP and interruptible loads. Suzhou was the city among the pilot projects with the most ambitious targets: $1 \mathrm{GW}$ of load reduction and more than 400 participating enterprises. A pilot was also started in Shanghai in 2014 with around 64 voluntary customers ranging from commercial and industrial companies, aggregating a total amount of $100 \mathrm{MW}$ of potential flexible load. This pilot is meant to test the incentive scheme put in place and to demonstrate the performance of demand side 
management technologies. Some non-Chinese companies such as Siemens, Alstom, Honeywell, IBM, and Schneider Electric, are trying to compete with national companies and anticipate the market opening for new opportunities (Azure International, 2015).

China also represents the largest deployment of electric scooters and buses. With restrictions on 2wheelers in large cities due to pollution, the stock of these new electric scooters is estimated to be around 200 million (40\% of the total market share). Further, there are already 170,000 electric buses already in commission (IEA, 2016). China is today the biggest market for electric cars as well, surpassing the U.S. in 2015 with the highest number of new registrations - 200,00 (20\% of global market share). However, the share of EV's in China car stock is still only $1 \%$. 


\section{iII. Potential of Demand Response as a Smart Energy Solution in EUROPE}

In the previous sections, selected Member State case studies highlighted the state of play of smart energy solutions. The purpose of the section is to provide a wider perspective of these solutions in terms of the European system today. Based on the projected deployment of smart meters in Europe, we describe the technical, social and economic potential of these new technologies. We first propose a methodology to better understand and assess demand response in EU's member states. The methodology is a result of the analysis of the case studies and several other studies and reports present throughout the report.

\section{III.A. Methodology and indicators to determine Demand Response potential of the EU}

The methodology proposed in this section is a simple, stage-based analysis through the major and most important topics for successfully developing and implementing demand response programs. This methodology provides a standard procedure and guidance to perform a first assessment of the state of play in a member state basis, in what demand response is concerned. However, detailed information for specific cases must be gathered for a more accurate provision.

The table below is the developed methodology to assess the current deployment and future potential of SES by each member state. It is divided in four main stages. Each stage contains a set of considered minimum requirements for a successful deployment, as well as important barriers and challenges that should be addressed during the given phase. Another important issue are information campaigns and the way they should be addressed. In each stage, it is given recommendation on how this can be accomplished.

The first stage concerns smart energy solution penetration and it is directly related to the percentage of smart meters installed. Stage number two has to do with electricity tariffs and prices. It is an important stage, because it will be the driver of the technology and the main incentive for consumer behavioural change. The third stage relates to feedback information and the way this feedback is provided to the consumer. In order to inform better and exploit full potential from the change in behaviour, this stage is challenging but important. In the final stage, an evaluation is needed. Ultimately, it is needed to show if the deployment is being successful.

To evolve from stage to stage the Member States should comply with the majority of the points addressed in the methodology in the present stage. For example, it is senseless to discuss new tariffs and prices for electricity without any smart meter installed, as it won't have the desired impact. However, these stages can be dynamic and be looked out with a back and forth approach. To use the same example, a Member State can have its rollout incomplete when it discusses possible market structures and new business cases for electricity prices.

The key indicators were underlined. By key indicators it is understood all the necessities for a successful deployment or without which, the process will be seriously jeopardized. These key 
indicators were retrieved from the case studies presented above. The studies provide us information on member estates in different stages of SES implementation, and so, can be a tangible sample to validate these indicators. 


\section{METHODOLOGY TO ASSESS THE POTENTIAL OF SES ON A MEMBER STATE LEVEL}

Stage 1: SES penetration

- Smart meters roll-out

- Functionalities of the smart meter/technology enabling

- Studies and preliminary pilots

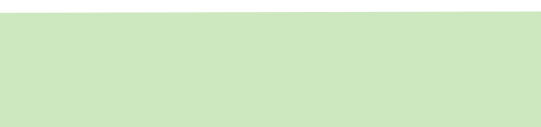

Information campaigns: during installation of smart meters.

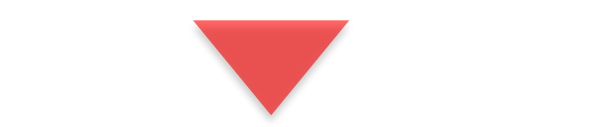

\section{BARRIERS AND CHALLENGES}

\section{Legal:}

-Smart meter data with easy access -Legislator framework

-Consumer privacy policy

\section{Stage 2: Prices and tariffs}

- ToU required

- CPP, RTP and other price schemes

- Regulated markets

- Easy and free of charge information on suppliers for consumers

Information campaigns: provided from services companies and municipality comparative website.

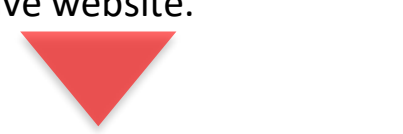

\section{BARRIERS AND CHALLENGES}

\section{Legal:}

-Market regulation

-Regulation framework in a EU wide range

Economical:

-Market entry

-Prices and tariffs' complexity

\section{Stage 3: Load/ Consumption}

- Feedback information on

consumption

- Electricity marginal/real costs

data

- Demand profile of utilities for

each sector

Information campaigns: through feedback

electricity

information on consumption.

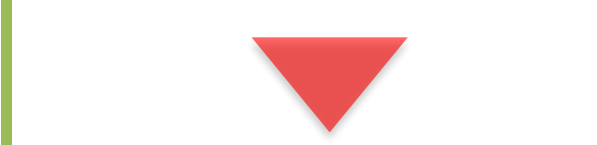

\section{BARRIERS AND CHALLENGES}

\section{Legal:}

- Penalty policies needed

-Transparent methodology

consumer baseline

Social:

-Increase consumer knowledge

for

\section{Stage 4: DSM Potential}

- Peak demand shifted

- Consumer engagement

- Social and economic welfare

- Own price/cross price elasticity

of demand

- Market size and competitiveness

Information campaigns: as a way

of education.

\section{BARRIERS AND CHALLENGES}

\section{Social:}

-Benefits split in equal forms

Economical:

-Lack of incentive shifting 


\section{III.B. Assessment of the theoretical demand response potential in Europe}

Based on the methodology and the case studies described above, we can determine the present level of demand response throughout Europe, necessary to consider future prospects.

The rollout of smart meters in EU Member States is not homogeneous. The Third Energy Package's target of $80 \%$ roll-out being complete in all Member States with a positive Cost-Benefit Analysis (CBA) by 2020 is forecasted to be achieved (see Figure III-I) and it will also happen in Malta and Spain (CBA's not available) (European Commission, 2014). Italy isn't part of this group as it was the second European county to have a complete rollout, but the access to the CBA is not available. However, countries like Germany, Belgium, Czech Republic or Portugal the rollout isn't likely to occur soon or on a countrywide base. Without the installation of smart meters, we cannot have access to a comprehensive and reliable base line data. In this regard, the EC issued ten minimum requirements for smart meters to deliver their full potential (European Commission, 2011).

The case studies are related to countries with positive CBA results, but it is also relevant to assess the potential of demand response (DR) in negative CBA countries. Further studies need to be performed on negative or inconclusive CBA countries, as the potential benefits of smart meter deployment - and the new market possibilities it can facilitate - may be underestimated. Moreover, there is a need to assess the potential social benefits and if there is still a governmental or regulatory role missing (e.g. unnecessary regulatory barriers). Gils (Gils, 2016) shows that in Germany, a country with a reportedly negative CBA, the potential of DR is mostly related with industry, as it is especially energy-intensive. DR in the industrial sector can thus help avoid costs on new medium- and peak-load power plants. However, DR in Germany's residential sector still needs to show more economical benefits to become viable. 


\begin{tabular}{|c|c|c|}
\hline \multicolumn{3}{|c|}{ Electricity Smart Meters Roll-Out Timelines in MS (at least $\mathbf{8 0} \%$ coverage) } \\
\hline Sweden & $2003 \Longrightarrow 2009$ & Completed \\
\hline Italy & $2001 \Longrightarrow 2011$ & Completed (ENEL: 2001-2006) \\
\hline Finland & \multicolumn{2}{|c|}{$2009 \Longrightarrow 2013$} \\
\hline Malta & \multicolumn{2}{|c|}{$2009 \Longrightarrow 2014$} \\
\hline Spain & \multicolumn{2}{|c|}{$2011 \Longrightarrow 2018$} \\
\hline Austria & \multicolumn{2}{|r|}{$2012 \Longrightarrow 2019$} \\
\hline Poland & \multicolumn{2}{|r|}{$2012 \Longrightarrow 2020$} \\
\hline UK & \multicolumn{2}{|r|}{$2012 \square 2020$} \\
\hline Estonia & \multicolumn{2}{|r|}{ 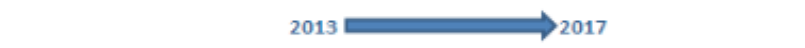 } \\
\hline Romania & \multicolumn{2}{|r|}{$2013 \Longrightarrow 2020$} \\
\hline Greece & \multicolumn{2}{|r|}{$2014 \Longrightarrow 2020$} \\
\hline France & \multicolumn{2}{|r|}{$2014 \Longrightarrow 2020$} \\
\hline Netherlands & Mandated (timetable TBC) & 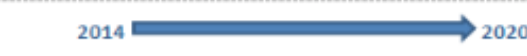 \\
\hline Denmark & Mandated (>1.5mn SM already installed) & $2014 \Longrightarrow 2020$ \\
\hline Luxembourg & Mandated & $2015 \Longrightarrow 2018$ \\
\hline Ireland & Mandated & $\Rightarrow 2019$ \\
\hline
\end{tabular}

Figure III-I - Evolution of Smart-Meter roll-out in Member States (Source: European Commission)

Several EU Member States have had variable electricity pricing in the industrial sector for years Torriti et al. (Torriti et al., 2010) describe examples in the UK, Spain and Italy, accounted in further detail in the next section. However, its implementation in the residential and tertiary sectors is essential to achieve energy efficiency goals. For instance, commercial ventilation and household appliances - representing $15 \%$ and $17 \%$ of the annual average reduced load, respectively - are predicted to have a big role to play in reducing peak-load demand in the future (Gils, 2014).

In this part of the report we try to focus on key indicators that can help measure the implementation and impact that the deployment of SES can have on Europe's future electricity system. These key indicators are taken from the full list of indicators present in section 0 and are suited to give us simple potential analysis. Full implemented SES can achieve high values in investment avoided in capacity generation, operating costs saved from new generation plants, costs (in $€$ and in GW) of new storage facilities, \% of peak demand reduction, electricity shifted and shed, and cost of new storage facilities. The studies assessing theoretical potential of these numbers present in the literature can enlighten us.

Gils assesses that the potential of DR in Europe can go as high as $26 \%$ of load reduction to annual peak load and $172 \mathrm{GW}$ of power decrease due to deferring or shedding loads (with an average of 93GW) (Gils, 2014). These numbers are comparable with the $73 \mathrm{GW}$ predicted by Capgemini in their moderate scenario model (Capgemini, 2008). Still from Gils study, the figures for each sector are as follows: $25 \mathrm{GW}$ in industry, $31 \mathrm{GW}$ in tertiary sector and $37 \mathrm{GW}$ in the residential sector. It is 
important to note that that in PV-dominated regions, DR partially substitutes short-term energy storage when the PV generation is at its peak. This allows for even more RE penetration that is not wind-related.

In Ireland a study was carried for its residential sector. It was estimated that the DR potential for interruptible loads is $147 \mathrm{MW}$ on average for 2020 (O'Dwyer et al., 2012). In France, where Energy Pool is an aggregator, demand response represents $1,000 \mathrm{MW}$ of flexible capacity in the form of load reduction, and in Sweden - a country with 100\% smart meter roll-out - the town of Sala implemented ToU prices for the electricity distribution service and showed an average reduction of $8.4 \%$ to $15.6 \%$ during the peaks in the distribution system (Eid et al., 2016).

Although prospects are good, accurate assessments for all EU Member States is still missing. Gils suggests that "a consumer and country-specific analysis of the flexible loads on the European continent is missing so far" (Gils, 2014). This is important to accurately assess the techno-economic potential of SES in the EU, given the diversity of energy systems within its Member States.

\section{III.C. Prices, tariffs and elasticity}

This topic, already assessed previously, can also provide us with some important indicators. The way that these services are going to charge electricity prices and tariffs is a member state level issue that is still in the development phase, but in the future it can have a different scenario as the markets evolve. There are a lot of studies in this area that comprise voluntary and non-voluntary pilots done in the US and in Europe. In Figure III-II, Eid et al. explain in a simple way how the various tariffs work (Eid et al., 2016). It is unanimous that flexible hourly prices are key for demand side response, but there is room for discussion in what terms it should be applied. The frequency of the price flexibility and in time given to consumers after the price change notification is as important. Whether the studies are done in a voluntary base or not can have relevance for the policy makers.

A study by Torriti et al. for Northern Italy found that mandatory ToU tariffs increased consumption by $13.69 \%$ and electricity bills reduced by $2.21 \%$ (Torriti, 2012). This supports the idea of Steen et al. that tariffs need to be combined (Steen et al., 2012). Using the study of the city of Gothenburg in Sweden, the authors suggest, "RTP (real time pricing) seems to be the most suitable choice to increase the possible amount of renewable energy generation". However, in order to avoid peak demand locally, RTP needs to be combined with other tariffs, such as Location Marginal Price - that reflects the real marginal price of electricity in a given region or location of a country. They further suggest that Critical Peak Price (CPP) can be advantageous for the consumer, but is limited to few hours per year.

In California, a state wide pricing pilot concluded that when TOU rates were used, consumerresponsiveness resulted in a $5 \%$ decrease in peak demand load. But, when consumers were signalled with CPP the results showed a decrease in peak load demand 8-15\% with no enabling technology, and 25-30\% with an enabling technology (Faruqui and George, 2005).

Examples of innovation in smart meter-enabled technologies include a 'power of attorney' service that uses a website (moneysavingexpert.com) price engine to help its subscribers change 
automatically to a cheaper provider and thus saving a minimum average of $75 £$ (Cheap Energy Club). Services that, instead of changing the contracts with the providers, can elaborate a comprehensive plan of investment in energy savings given your location, age of the building, consumer habits and utilities used (DoE \& CC, 2015).

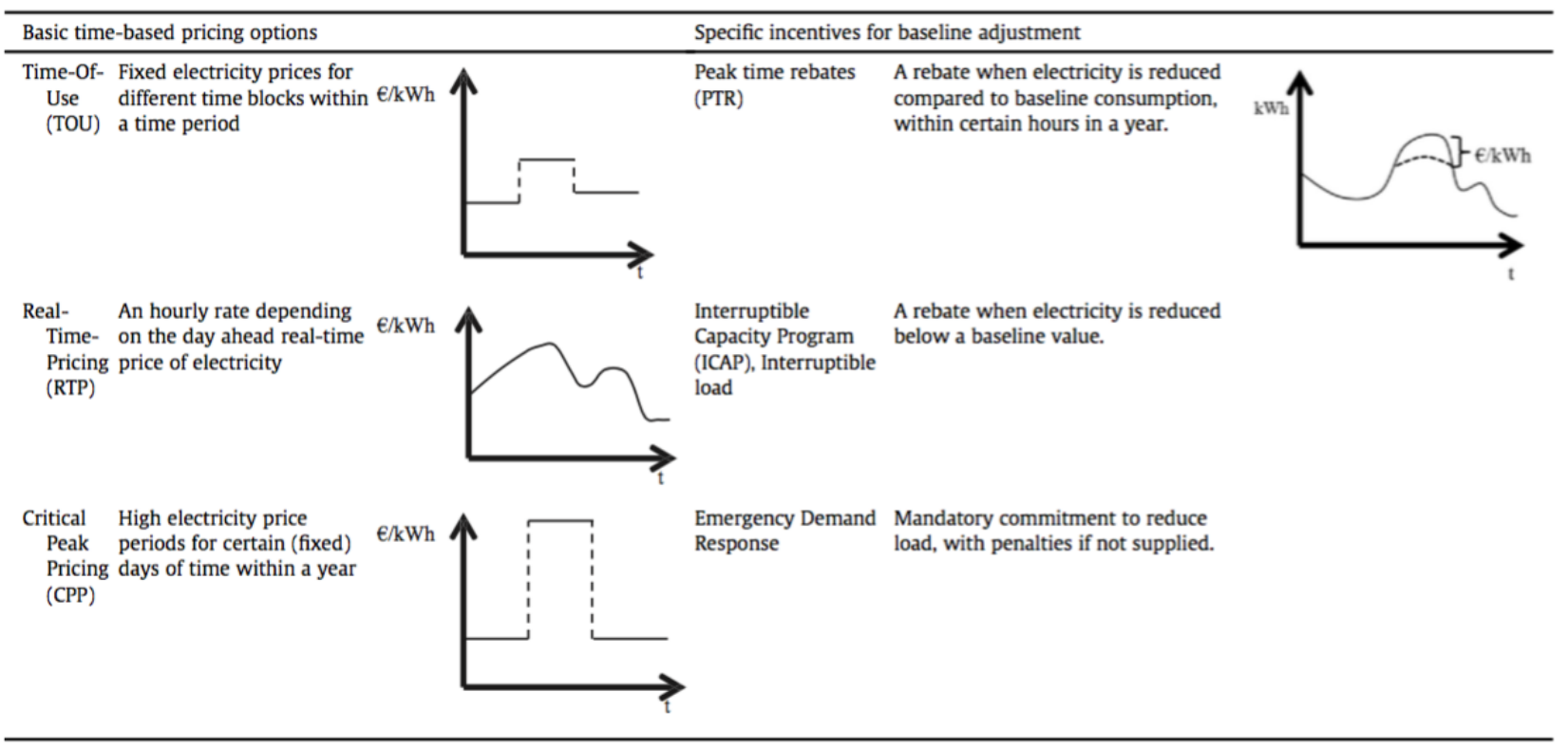

Figure III-II - Explanation of pricing schemes

Katz et al. give us another point of view (Katz et al., 2016). From the results of their model, RTP is the most economically efficient type of dynamic pricing, but maybe not from the starting point. If consumers are targeted with highly complex dynamic pricing schemes from the start, they are more likely to be overwhelmed and therefore not willing to give up their comfort in order to have some economic benefit. Rather, mixed and more complex price tariffs can be implemented in a second stage. By this point, consumers are already familiar with dynamic pricing and TOU alone is able to provide the economic efficiency that other tariffs can. Figure III-III explains what this means in a simple way, confronting the complexity of the rates with its economic potential.

The level of transparency to which these strategies are going to be handled is uncertain, but it is a priority for the European Commission that the consumer receives fair treatment. The goal here is for the market to deliver public data of real-time accurate prices of electricity according to the fluctuation of its marginal costs. 
Data on the elasticity of demand is also valuable to evaluate impacts on consumers' consumption and behaviour. We can assess the own price elasticity, the cross price elasticity and the elasticity of substitution. The own price elasticity of demand is important to see how the demand fluctuates in $\%$ when the electricity prices increase by $1 \%$. The cross price elasticity of demand shows the change in $\%$ of demand in one period when taking into account a $1 \%$ increase of the electricity price in another period (e. g. off-peak and on-peak). The elasticity of substitution tell us how much load shifted from on-peak to off-peak due to a $1 \%$ increase in the relative price of electricity from offpeak to on-peak (Conchado and Linares, 2012). From the values we can conclude whether or not the consumers are responsive to price changes, thus we can predict up to some extent how successful demand response can be. As Albadi \& El-Saadany conclude: "The performance of DR programs is measured by peak load reduction and demand elasticity" (Albadi and El-Saadany, 2008).

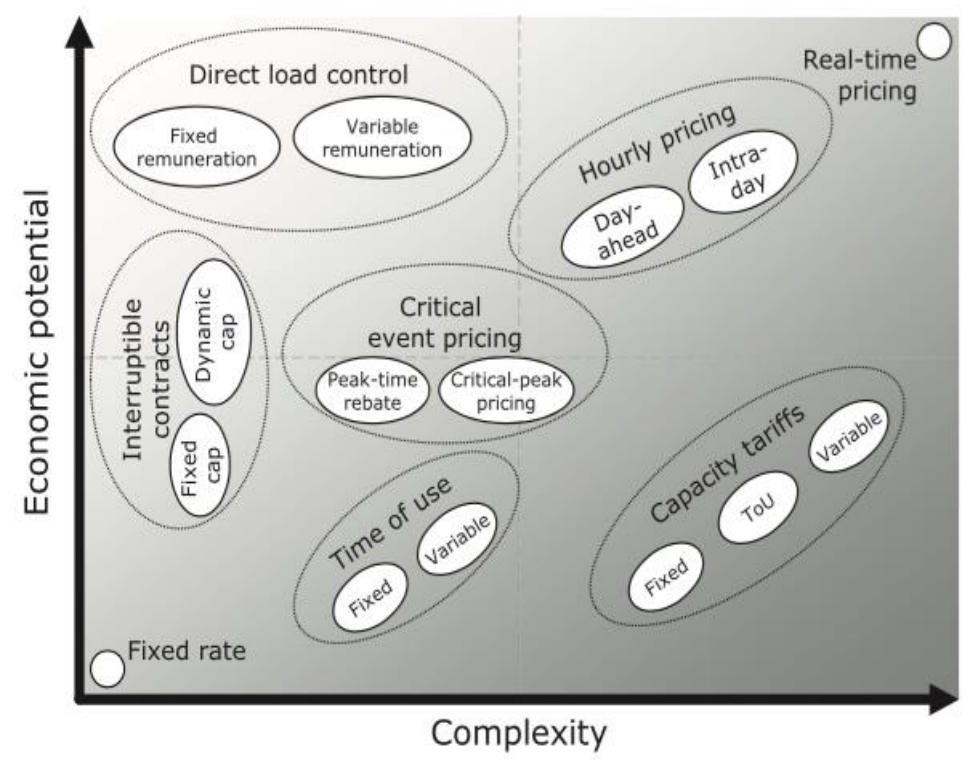

Figure III-III - Economic potential and complexity of dynamic tariffs Source: Katz et al. (Katz et al., 2016)

In France, a combination of CPP and TOU is used for costumers that apply for the 'Tempo Tariff' and it resulted on average in a reduction of consumption of $15 \%$ on normal days and $45 \%$ on peak days. Further, it led to consumers to save, on average, $10 \%$ of their electricity bill. (Eid et al.) This program also calculated the own-price elasticity of demand to be 0.18 in off-peak usage to 0.79 during peak (Albadi and El-Saadany, 2008).

\section{III.D. Load profiles}

Demand side management relies a lot on smart-meters and the information they provide. The principle behind dynamic pricing tariffs is that electricity prices fluctuate in the same proportion as demand fluctuates away from its baseline. Because generation capacity is managed in order to meet demand, the marginal cost of electricity increases as the demand increases. This happens due to the fact that generation technologies (e.g. natural gas fuelled power plants) to meet peak demand are in most cases more expensive - considering operating costs related to ramp up and 
rapid dispatch - than low and medium demand generation technologies, like renewables. This approach leads to one key issue related to electricity markets: how is the consumer baseline defined in order to determine the fluctuation of the demand? For the aggregator perspective, it can be useful to under-predict the available capacity in order to increase the demand fluctuation, meaning higher prices (Gast et al., 2014). From the consumer perspective, if the high prices happen when a big fluctuation happens, it can be useful to simply inflate the baseline so that the fluctuations are smaller (Chao and DePillis, 2013; EnerNOC, 2009). This can also be addressed as asymmetry of information, which contributes to oscillatory behaviour on the demand side. As N. O'Connell et al. state, "it occurs when there is a delay between price setting and consumption, so a prediction of the response is required, that is, the operator must predict information which the end-user already knows" (O'Connell et al., 2014).
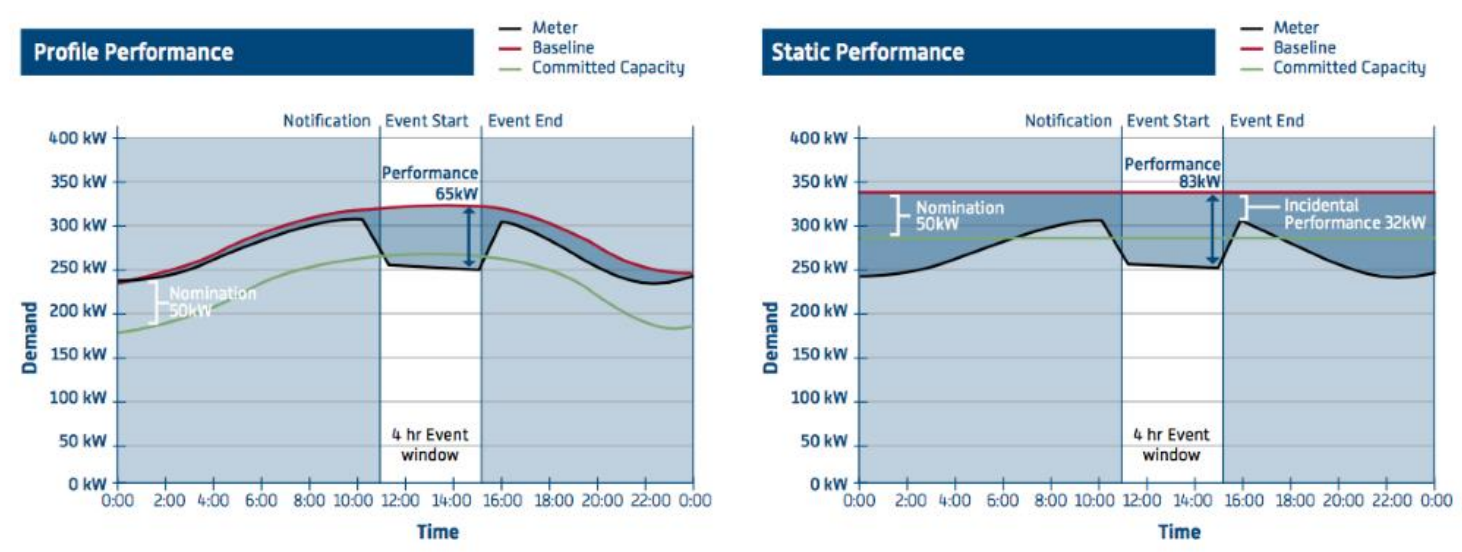

Figure III-IV - Consumption baseline. Source: EnerNOC

Several member states have no regulation concerning baseline measurement yet, and this is especially important when evaluating TSO and DSO's products in the consumer perspective. Countries like Denmark, Sweden and Ireland have no public or standardized methodology. In the Netherlands and in Germany and this is agreed by contractor and consumer (SEDC, 2015).

For example, EnerNOC, a US company that recently acquired German and Irish market leader companies ("Profitable interruptions," 2014), uses two approaches to calculate the baseline (EnerNOC, 2009). In
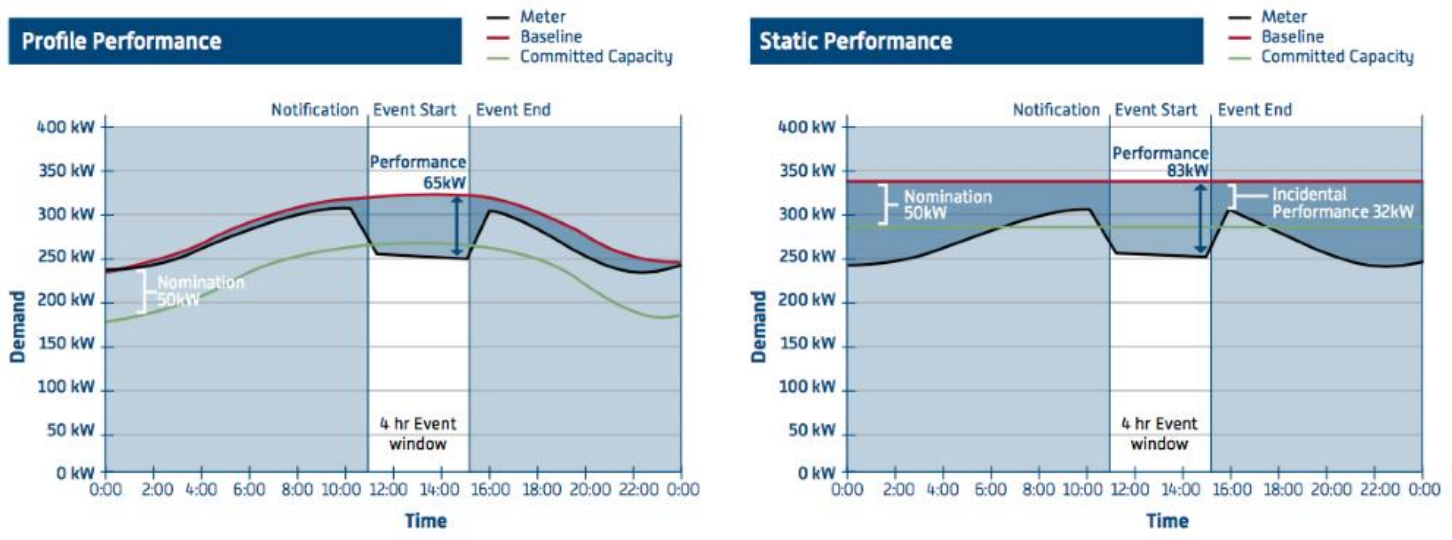
Figure III-IV, we have the graphical representation of the two. Profile performance uses granular time interval measures to mimic the dynamic demand of the end-consumer, and Static performance averages the peak monthly demand over the previous delivery period. The second approach results in a better performance in exchange of a higher average demand. Whether one or another is more adequate is not for us to discuss because both options are available for the costumer to decide.

As markets evolve and competition gets tighter, these methodologies will eventually become more transparent and beneficial for the end-consumer, but regulation could help speed up this evolution and facilitate market entry for new costumers.

\section{III.E. Economic benefits}

The economic aspect is key for a good working market. For the European energy market to function in a competitive and fair way it needs to be economically interesting and efficient, so that every party along the supply chain and ultimately the end-user can take advantage of its added value. Here, the potential economic benefits that come from established and new markets are addressed.

In previous sections we have discussed the potential of this way of balancing energy demand in terms of power shifted, energy stored and saved, but now we focus on what those numbers reflect in terms of economic benefits. Some of those benefits have been discussed previously with some \% of the savings in electricity bills in the end-consumers' perspective.

From the Capgemini report (Capgemini, 2008), we can see an estimated $€ 20$ billion of avoided investment and $€ 25$ billion savings in electricity bills for costumers (moderate scenario). In the US, over $€ 3.5$ billion are annually earned by the local economy through DR (Stromback, 2015).

Faruqui et al. estimate that the total cost of smart meter implementation in the EU to be $€ 51$ billion (Faruqui et al., 2010). And apart from the operational savings - that are worth something like $€ 26$ to $€ 41$ billion - the benefits that come from dynamic pricing alone would cover the implementation costs. In the paper it says that "overcoming barriers to the adoption of dynamic tariffs could be worth as much as $€ 53$ billion".

In a member estate perspective, we have already seen the prospects for the UK in section II.D. We can have a further look at other examples. Conchado et al. (Conchado et al., 2016) provide results on the economic benefit DR could have in Spain: assuming a $0.5 \%$ in annual demand growth for 10 year period, total savings could add up to $€ 270$ million ( $0.4 \%$ of system costs) for a $25 \%$ DR system or to $€ 1080$ million ( $1.7 \%$ of system costs) for a $100 \%$ DR system. The surprising fact is that none of these savings are realised in avoided investments, because Spanish generation capacity can cope with the rate growth for the study period. What this means in reality is that, on average, we would see a reduction of $10 €$ to $20 € /$ year per residential costumer with a $400 €$ /year electricity bill, which the authors classify as "quite low". In line with the authors point of view, Prüggler (Prüggler, 2013) suggests that household savings would have to be around $65 €-120 € /$ year for consumers to engage in DR programs. However, the high penetration of renewables can be a very important issue to the topic. Gils studied the economic potential of demand response in Germany with an assumption of $70 \%$ share of VER in the energy power system and concluded that "the reductions in annual power supply costs achieved add up to several hundreds of millions of Euros" (Gils, 2016). 


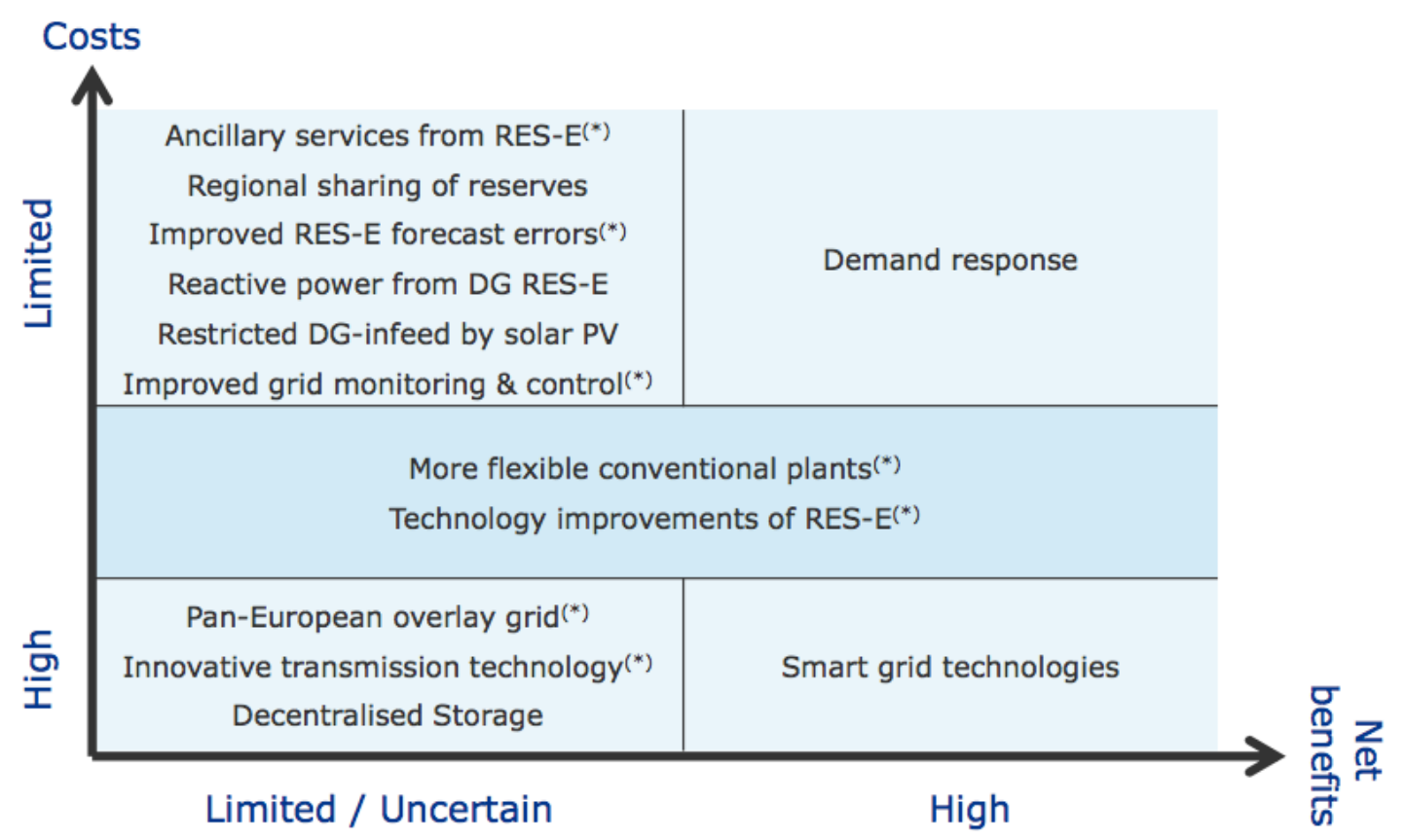

Figure III-V - Economic benefits and costs of different available technologies (Source: (DNV GL et al., 2014))

From the report of GNV GL to the EC, focusing on renewable energy systems expansion between 2020 and 2030, it results the following: "a cost-efficient integration of a high share of RES-E, demand response stands out as particularly promising. The analysis in this study suggests that an effective use of DR may yield annual savings in the order of $€ 60$ to 100 billion" (DNV GL et al., 2014). However, these savings don't account for the deployment costs - from which the biggest part is from smart meter costs -, but these are already being spent in the rollout programs of several member states. We can see in Figure III-V that demand response provides the highest net benefits with the least cost, in a high share RES perspective. It is important to explain that smart grid technologies include smart-meters and other devices. It is with the use of these devices that demand response is possible. In other words, demand response is an application of the smart grid technologies. However, smart grid technologies go beyond the smart-meters and expand to the wider range of the electrical grid.

\section{III.F. Barriers}

Until the EU implements a common, internal energy market, it may be premature to talk of harmonized DR programmes at the EU level (Torriti et al., 2010). It is possible that this may still be true when such an EU wide energy market exists. Due to the heterogeneity of EU countries, different DR programs may target different sectors (or even demographic groups) in each Member in order to exploit maximum economic benefit. Standardized regulation, especially for countries with more than one TSO (e.g. Germany) is needed (SEDC, 2015). Further, the initial investment cost - around $250 €$ /smart meter (European Commission, 2014)- should be divided in the same way that benefits are (between provider, distributor, aggregator, retailer and consumer). But apart from investment and benefits, there has to be a clear regulatory framework in order to prevent imbalanced market power on any side. As Eid et al. reports, "The value of DR should be distributed along the supply 
chain, together with incentives for participation for each agent under clearly elaborated business models" (Eid et al., 2016).

As we can see from SEDC report, other barriers can cause a scarce entry in the market, such as surpassed communications systems (telephone bidding) and inappropriate minimum bid sizes (50MW). In Germany, for example, the pre-qualification process can take up to one year (SEDC, 2015).

Aggregation services need to be considered as a resource so that market entry happens on an equal footing as capacity, balancing and storage resources do. However, improvements have been made in a few countries leading the DR revolution. Great Britain already enables independent aggregators and both France and Switzerland already have restructured roles and responsibilities of market participants, especially in order to enable independent aggregators (SEDC, 2015).

Further, fragmentation of DR markets due to the early development phase and also to widely regulations and participation rules at the Member State-level. For example, there can be different markets (intra-day, day-ahead, feeding, etc.) with different participation rules for each. As long as the rules do not have a technical basis to be different, these should all be standardized at the Member State level, or ideally at the EU level.

The real technical and economic potential of smart energy solutions in Europe is as yet unknown. Many of the studies available do not address some important aspects. Suggestions for the parameters that should be addressed in further studies include the high penetration of smart meters at the EU level (ideally $80 \%-90 \%$ ), combined with the penetration of storage capacity in households/SME, and the adoption of Battery Electric vehicles (BEV) across Europe. With so many unknown variables, the studies are more theoretical and can be translated into reliable estimations only when smart meter data, variable price data, and appliance load profiles are gathered.

\section{III.G. Consumer awareness / Information campaigns}

Another important factor to realise DR potential are information campaigns and educational programs. This is of crucial importance to encourage consumer participation. As Torriti et al. state (Torriti et al., 2010), "The main obstacles in DR are recognized to be the inelasticity of demand and low level of participation due to asymmetries in information." Therefore, the full implementation of these smart energy solutions can only prove its full potential when effective information campaigns and education programs are put in place. These should align with proper market design and the minimisation of regulatory barriers to allow for effective consumer engagement. This not only intersects the objectives of the Commission of putting the consumer at the centre of the energy system (SET Plan Steering Group, 2014), but also reduces the consumers' learning curve. This, in turn, can translate to increased volumes of energy shifted and decreased peak energy demand (Taylor et al., 2005).

To show how much importance the information and consumer awareness can have in the endconsumer engagement in balancing the energy demand, we can a look a report from McKinsey for the US DOE (McKinsey, 2010). We can see that in McKinsey's perspective, for a successful DSM six levers of action are needed: Rates, Incentives, Access to information, Utilities control, Education \& 
Marketing and Costumer insight \& verification. Two of the levers are directly related to ways of communication with the user, which can mean that $1 / 3$ of the full potential of demand response lies within the message is received and acknowledged by the end-user.

In the graph presented below, it shows the perspective for the different stages of societal appropriation (Jullien and Serkine, 2016).

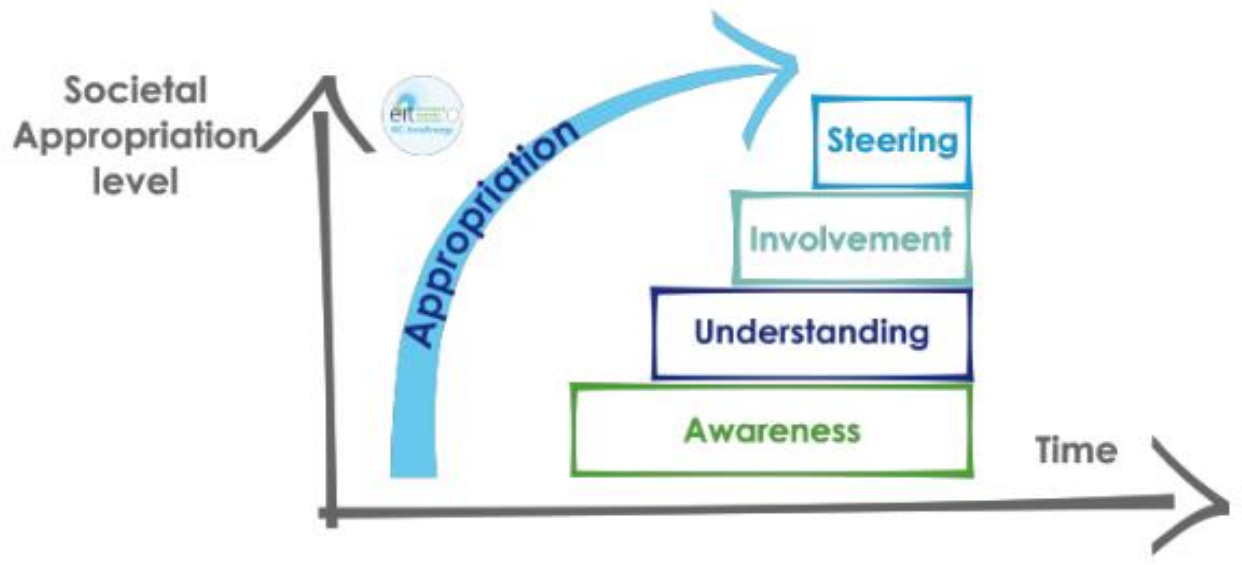

Figure III-VI - Societal appropriation of DSM (Source: INSIGHT_E (Jullien and Serkine, 2016))

For the purpose of this policy report it is important to understand how these social behaviour issues can affect the potential outcome of the future energy system, but exactly how this can be achieved is out of our scope. In order to find a more deep perspective on this topic please look into the INSIGHT_E Hot Energy Topic on Societal Appropriation concerning end-users (Jullien and Serkine, 2016). 


\section{iV. Conclusions AND policy ReCOMmendations}

Having a smart and integrated energy system with active end-consumers is a big priority for the European Union. This means to keep pushing forward the policies and frameworks for market opening, to remove legal barriers to better develop successful business models, and to ensure fair treatment for the consumers, including securing privacy in relation to data. These are some of the actions that need to be taken for that priority to become a reality.

In this section, based on the Member State case studies (section II) and the opportunities for the EU (section 0), we highlight the main findings from the review, and make a number of recommendations for indicators necessary for the monitoring of SES progress, and role in the future sustainable energy system.

\section{IV.A. Results from the case studies}

Analysing the case studies from Switzerland, France, Ireland, UK and Sweden presented in section II, the main conclusions are presented below.

Apart from Sweden, that has a complete smart-meter rollout, all the other countries are still ongoing or starting this stage. Switzerland hasn't a planned rollout so far. Ireland will start in 2018. Both France and the UK are on-going roll out, with shares of $9 \%$ and $4 \%$, respectively.

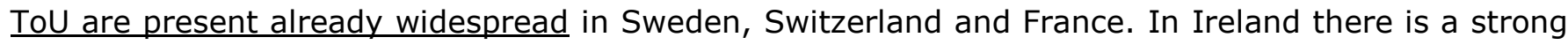
push in favour of it, but not in the UK. Ireland is also trying to remove flat tariffs but a data for it to be extent was not set.

No smart tariffs are present in any of the case study countries. Apart from ToU, that in some cases are wide and free of choice to consumers, no price or tariffs is prepared or has the structure needed to reflect real electricity marginal costs that float with generation. ToU are contracts that have different prices for different hours of the day, separating the day in blocks of on and off-peak hours, for example. However, it doesn't reflect the variation in the real cost of electricity or in the increase of demand.

In all the case studies it was clear that, apart from Sweden, no real-time access to data on consumption was available as a type of feedback to consumption. Easy access to real time consumption and prices is key for the development of the smart grid. However, the Swedish example of the application for smartphones from the energy company E.ON goes against the tide. Also in Sweden, there is a think tank in place to understand the best way to develop an information hub of consumption data that can be accessed by all in the easiest way possible. In France there is a platform that is being set up so the consumers can be have access to it through the DSO's website, but an important communication barrier between the suppliers and consumers is then created. In Sweden

Sweden, having a complete rollout of smart-meters still doesn't have dynamic tariffs. This can be explained by the complexity of the implementation and usage of these tariffs, the potential low impact of these in the Swedish reality due to district heating - providing more than $60 \%$ of the 
energetic needs to commercial and residential consumers- and given that flat tariffs are still present and when combined with lack of consumer interest and knowledge, still become very popular.

In the majority of the countries assessed there is free choice for the supplier of electricity to endconsumers. When ToU were introduced, it resulted in a relevant amount of consumers changing supplier of electricity. In Sweden, there is a state web site that provides free-of-charge comparison services for consumers to choose the option that fits better their needs.

In Switzerland, it is expected that by 2050 the share of EVs to reach $95 \%$ of the total vehicle fleet. In France there is a slower transition, and the number show a decrease in the number of EV licenses from 2015 to 2016. In Ireland and UK, there is a small uptake to date and a very strong commitment to push EVs forward. Sweden has one of the highest share rates of EV in the world, while offering incentives from tax and rebates. However, for the national goal of decarbonising the transport sector in 2030, this share is increasing at a slow pace.

Table IV-I - Summary of case studies

\begin{tabular}{|c|c|c|c|c|}
\hline Summary & $\%$ Roll Out & $\begin{array}{c}\text { Presence of } \\
\text { ToU }\end{array}$ & $\begin{array}{l}\text { Feedback on } \\
\text { Consumption }\end{array}$ & $\begin{array}{c}\text { Share of EV's } \\
(\%)\end{array}$ \\
\hline Switzerland & $\begin{array}{c}\text { Not } \\
\text { planned** }\end{array}$ & Yes & No feedback & 0,2 \\
\hline France & $9 \%$ & Yes & No feedback & 1,2 \\
\hline UK & $4 \%$ & First trials & No feedback & 1 \\
\hline Ireland & Start in 2018 & Yes & No feedback & $*$ \\
\hline Sweden & Complete & Yes & Possibility of Real time & 2,4 \\
\hline
\end{tabular}

* Not available

** Country outside the EU 


\section{IV.B. Future potential}

The potential of smart energy solutions - especially in demand side strategies focusing in demand response - was analysed relying in several studies on the matter. The conclusions presented relate to the potential of these strategies in economical and energetic indicators.

The studies addressed in section 0 show a big untapped potential of demand response. The results reached in these studies show that possible load reduction is around 93GW (18\%) and 75GW (15\%) throughout Europe, for a system with full implementation of smart energy solutions to enable load shedding and shifting. This reduction has potential for large impacts not only on generation planning and the need for generation reserves, but also in markets, due to the fact that marginal cost of generating electricity increases when reserves are needed to meet peak demand.

Related to the last paragraph, the reduction in load is estimated to lead to a value of capital saved due to avoided generation installed of estimated 20BE - see section III.E -, and close to an equal amount through electricity bill savings for end-user consumers. Since that it is expected an active intervention in the market from end-users, their economic benefits come from savings and from rebating schemes, rewarding them for flexibility of demand.

However, as it was found in some studies, DR programs can sometimes have the effect of peak shifting and increasing consumption. This can be a direct consequence of real time prices and big end-user engagement.

In terms of pricing schemes, the analysed studies provide a very wide result base and therefore it is not easy to conclude on this matter. It is accurate to say that for tariffs and prices there isn't a 'one size fits all', and it should be up to end-consumers to serve as market drivers to decide which pricing scheme fits better one region or a certain country. 


\section{IV.C. Key indicators}

The purpose of this report was to assess indicators to understand the current and future state of smart energy solutions. The key indicators are concluded to be the ones that can give an accurate state of play and predict in a feasible manner short-term evolutions.

The key indicators presented below were condensed and summarized from the case studies, from the literature and also the indicators developed by the methodology proposed in section $\mathrm{V}$ :

- \% of smart meter roll-out complete: the installation of smart meters is the starting point of an integrated smart grid. It is therefore important to understand up to which extend is this starting point being achieved;

- Presence of dynamic pricing schemes: Once the installation process is complete and smart meters are operational, it is necessary that there are tools to exploit their full potential. Using adequate frequency monitoring, prices have to be dynamic to reflect real variations in generation costs;

- Feedback information: having explanatory electricity bills and real time feedback on consumption and prices is important to explain to end-costumers the impact their behaviour and changes of it can have in their electricity bill. Not only that, gathering the impact of all the consumers, it will mean a big impact in the overall system;

- Quantification of consumer engagement: with the installation and with possible real time prices programs, it must be understood if the strategies being used are appealing enough for end-users to engage and change their habits;

- Economic and environmental benefits: once every variable mentioned above is up and running, the benefits and real impact of these smart solutions can be attained;

- $\%$ of government budget: hand-in-hand with the benefits, it is relevant for governments and policy institutions to conclude what measures can be taken to improve and maintain the smart-grid and how much of the countries budget should it be addressed for such cause.

Ranging from short- to long-term indicators, keeping in mind that the implementation and deployment of these smart solutions cannot be the end in itself, a broad and informative picture can be drawn from, while also giving important tools to point out what can be changed to overcome possible shortcomings. 


\section{IV.D. Policy recommendations}

Policy recommendations are a set of the barriers encountered over the course of this report and the conclusions drawn from the report. It is also mentioned some of the best practices that are being undertaken in some member states that are advisable to be widened to all the EU. Future measures that need to be taken for every EU that haven't been put in place by any member state are also present in these recommendations.

The role of the EU commission really is to push the markets and the system towards a thing that its profitable so that the investors want to be part of and also to assure that consumers take a relevant role in it as well, by having some economic benefits of their own. Not only this leads to an increase of energy efficiency but also to an increase of social welfare. The framework from the Commission that is addressed in the recent released winter energy package - is key for a successful transition to consumer engagement. It needs to be understood if these measures are enough to allow the market to flow and evolve by itself, or if some kind of subsidies policies is also needed to drive the energy transition.

For the smart consumers' perspective, and for a deeper engagement it is important that information flows exist in relevant amounts to end-consumers. The clear electricity-pricing bill put in place by the winter package is a step ahead, but the real challenge is to make consumers engage and increase the levels of change in terms of behavioural consumption. This can't be achieved only by variant prices, and a strong information campaign outlining not only economic benefits but as well as environmental ones is needed.

It is clear from the report that there is space for tackling barriers on information. Flows of information on consumption and prices need to be clear and standard for the market players. The concept of information hubs, countrywide or EU wide is very appealing to this problem. ICT can have the answer, providing cost-effective and innovative solutions.

As mentioned above, one of the most pressing and evident challenges once dynamic tariffs are put in place will be the marketing and information campaigning for consumer engagement to be exploited to its full potential. The role companies and organizations will play can be maximised through incentives for the initial deployment phase. It is important that campaigns and clarifying sessions provide the information for end-consumers to associate their knowledge to changes in prices.

New market design, fair distributed costs (e.g. smart meters and O\&M of the grid) and benefits for players throughout the supply chain that provide an added value to the system.

Market entry should be facilitated as much as it can so that the markets are vibrant and profitable for those who populate them - so that there can be progress. Key features for this require first facilitating regulatory bureaucracy needed. Also, it is required the minimum bids downsize to allow small producers to participate.

It is relevant to continue to fund future studies that focus on the impact of voluntary change to programs that attain a real-time pricing of electricity, as well as some events of critical peak prices. On some occasions, the years that can be predicted to have a large load demand for a certain period 
of time, and that these events are treated differently than the normal status of things so that the consumers are aware of it, not only by high prices.

In terms of policies, it is important to understand which barriers exist, and from these, which are delaying the evolution of technology and growth. These comprise legal, economic and social barriers. From what it was gathered there is space for intervention in order for a better integration of the end-users into the energy system, acting actively as players. The main barriers that are advisable to be addressed in the near future are the following:

- Over-bureaucratic market entry for new players

- Lack of regulatory frameworks to implement demand side management strategies

- Lack of incentives or policies to deploy dynamic tariffs for countries with liberalised markets

- Lack of public interest and knowledge that leads to low levels of participation 


\section{IV.E. Concluding remarks}

It is important to state that demand side management needs to be looked at as a real asset to balancing the supply and demand of energy, and it needs to be looked at as a relevant resource just as another power plant for energy generation. With different characteristics and different costs associated, but very helpful to Europe in achieving its goals in terms of energy efficiency goals, emission reduction goals and more importantly and directly related, it will help increase the share of energy generation that comes from renewable sources.

As mentioned earlier, future indicators will need to consider how the smart meter is being used, to better understand the additional potential. A number of indicators could be foreseen that provided information on the level of automation of the household system (uptake of smart appliance systems), through types of agreements with suppliers on handing over some control for automation, the uptake of time-of-use tariffs, and other key elements of smart energy solutions that might further the role of the smart meter e.g. home power storage systems, electric vehicle ownership etc.

There is a need for further studies concerning types of smart energy solutions that are only mentioned in surface in this report. These comprise mainly batteries and penetration of EV's and their influence in the future smart grid, taking into account systems that enable V2G technologies and their impact in balancing the electricity load. 


\section{REFERENCES}

Albadi, M.H., El-Saadany, E.F., 2008. A summary of demand response in electricity markets. Electr. Power Syst. Res. 78, 1989-1996. doi:10.1016/j.epsr.2008.04.002

Auto, 2016. Chiffres des ventes \& immatriculations de voitures électriques en France. Automob. Propre.

Azure International, 2015. Demand Response in China.

BEIS, 2016a. Smart Meters: Quarterly Report to end June 2016 Great Britain.

BEIS, 2016b. Smart Meters Methodology Note.

BFE, 2014a. Bases pour l'introduction de systèmes de mesure intelligents auprès du consommateur final en Suisse - Exigences techniques minimales et modalités d'introduction.

BFE, 2014b. ewz-Amphiro Study On the Effectiveness of Real-Time Feedback: The Influence of Demographics, Attitudes, and Personality Traits.

BFE, 2014c. FlexLast - Erzeugung von Sekundär- Regelenergie durch ein dynamisches Lastmanagement bei Grossverbrauchern.

BFE, 2012. Folgeabschätzung einer Einführung von «Smart Metering» im Zusammenhang mit «Smart Grids» in der Schweiz.

BIS, 2013. The Smart City Market Opportunities for the UK (No. BIS Research Paper No. 136).

BKW, 2016. BKW Home Energy élargit son offer / Le plein de soleil: BKW lance la fonction E-mobility [WWW Document]. $\quad$ presseportal.ch. URL http://www.presseportal.ch/fr/pm/100001009/100791906 (accessed 12.16.16).

Broberg, T., Brannlund, R., Kazukauskas, A., Persson, L., Vesterberg, M., 2015. An electricity market in transition.

Capgemini, 2008. Demand Response: a decisive breakthrough for Europe.

CEN-CENELEC-ETSI, 2012. Smart Grid Coordination Group: First Set of Standards.

CER, 2015a. National Smart Metering Programme - "Phase 3" Overview.

CER, 2015b. National Smart Metering Programme Rolling out New Services: Time-of-Use Tariffs.

CER, 2014. CER National Smart Metering Programme - Smart Metering High Level Design.

CER, 2011. Smart Metering Information Paper 4: Results of Electricity Cost-Benefit Analysis, Customer Behaviour Trials and Technology Trials.

Chao, H., DePillis, M., 2013. Incentive effects of paying demand response in wholesale electricity markets. J. Regul. Econ. 43, 265-283. doi:10.1007/s11149-012-9208-1

Citizen's Advice Bureau, 2014. Take a walk on the demand-side: Making electricity demand side response work for domestic and small business consumers.

CNIL, 2012. Rapport d'activité 2012.

Committee on Climate Change, 2015. Meeting Carbon Budgets - Progress in reducing the UK's emissions 2015 Report to Parliament.

Conchado, A., Linares, P., 2012. The Economic Impact of Demand-Response Programs on Power Systems. A Survey of the State of the Art, in: Sorokin, A., Rebennack, S., Pardalos, P.M., Iliadis, N.A., Pereira, M.V.F. (Eds.), Handbook of Networks in Power Systems I, Energy Systems. Springer Berlin Heidelberg, pp. 281-301. doi:10.1007/978-3-642-23193-3_11

Conchado, A., Linares, P., Lago, O., Santamaría, A., 2016. An estimation of the economic and environmental benefits of a demand-response electricity program for Spain. Sustain. Prod. Consum. doi: 10.1016/j.spc.2016.09.004

CRE, 2016. Les compteurs évolués / La généralisation du système de comptage évolué Linky [WWW Document]. URL http://www.smartgrids-cre.fr/index.php?p=compteurs-generalisation-linky (accessed 12.16.16).

DECC, 2015. Towards a Smart Energy System. Department of Energy and Climate Change. 
DECC, 2014. Smart Metering Implementation Programme: Smart Metering Equipment Technical Specifications (SMETS).

DECC/Ofgem, 2014. Smart Grid Vision and Routemap.

DNV GL, Imperial College, NERA, 2014. Integration of Renewable Energy in Europe - Final Repor (No. 9011-700).

DoE, 2016. Assessment of Demand Response and Advanced Metering.

DoE \& CC, 2015. Metering-enabled Innovation in energy management in the non-domestic sector (No. URN 15D/002). UK GOV.

$\mathrm{Ei}, 2015$. An information management model for the future Swedish electricity market (No. Ei R2015:15). Energimarknadsinpektionen.

Eid, C., Koliou, E., Valles, M., Reneses, J., Hakvoort, R., 2016. Time-based pricing and electricity demand response: Existing barriers and next steps. Util. Policy 40, 15-25. doi:10.1016/j.jup.2016.04.001

Element Energy, De Montfort University, 2012. Demand side response in the non-domestic sector.

Enercoop, 2016. Offre particuliers [WWW Document]. Enercoop. URL http://www.enercoop.fr/nosoffres/particuliers (accessed 12.16.16).

EnerNOC, 2009. The Demand Response Baseline.

European Commission, 2014a. Benchmarking smart metering deployment in the EU-27 with a focus on electricity.

European Commission, 2014b. Cost-benefit analyses \& state of play of smart metering deployment in the EU-27.

European Commission, 2011. Set of common functional requirements of the SMART METER.

Faruqui, A., George, S., 2005. Quantifying Customer Response to Dynamic Pricing. Electr. J. 18, 5363. doi:10.1016/j.tej.2005.04.005

Faruqui, A., Harris, D., Hledik, R., 2010. Unlocking the $€ 53$ billion savings from smart meters in the EU: How increasing the adoption of dynamic tariffs could make or break the EU's smart grid investment. Energy Policy, The socio-economic transition towards a hydrogen economy findings from European research, with regular papers 38, 6222-6231. doi: $10.1016 /$ j.enpol.2010.06.010

Fell, M.J., 2016. Taking Charge: Perceived control and acceptability of domestic demand-side response. UCL (University College London).

FERC, 2012. Demand Response \& Advanced Metering.

Foucaud, I. de, Figaro, S. infographie du, 2015. Électricité : comment le compteur «intelligent» Linky est installé chez vous. Le Figaro.

Fournisseur, 2016a. Liste des fournisseurs d'électricité en France [WWW Document]. URL https://www.fournisseurs-electricite.com/liste-des-fournisseurs-delectricite (accessed 12.16.16).

Fournisseur, 2016b. Enedis (anciennement ERDF) [WWW Document]. URL https://www.fournisseurs-electricite.com/guides/acteurs/enedis (accessed 12.16.16).

Frontier Economics, 2015. Future potential for DSR in GB.

Gast, N., Le Boudec, J.-Y., Tomozei, D.-C., 2014. Impact of Demand-response on the Efficiency and Prices in Real-time Electricity Markets, in: Proceedings of the 5th International Conference on Future Energy Systems, E-Energy '14. ACM, New York, NY, USA, pp. 171-182. doi: $10.1145 / 2602044.2602052$

Gils, H.C., 2016. Economic potential for future demand response in Germany - Modeling approach and case study. Appl. Energy 162, 401-415. doi:10.1016/j.apenergy.2015.10.083

Gils, H.C., 2014. Assessment of the theoretical demand response potential in Europe. Energy 67, 118. doi:10.1016/j.energy.2014.02.019

GWF, 2016. NXT4 R: Compteur électronique d'électricité domestique.

GWF, 2015. Fiche d'information de GWF: Mise en place de systèmes intelligents de mesure. 
Hierzinger, R., Albu, M., van Elburg, H., Scott, A., Łazicki, A., Penttinen, L., Puente, F., Sæle, H., 2012. European Smart Metering Landscape Report 2012 - update May 2013. Vienna, Austria.

Hilty, L.M., 2013. Smart Solutions, Energy Efficiency, and Sustainability - Updating the Research Agenda for Environmental Informatics, in: Proceedings of the 27th EnviroInfo 2013 Conference. Hamburg, pp. 465-469.

Hilty, L.M., Aebischer, B., Rizzoli, A.E., 2014. Modeling and evaluating the sustainability of smart solutions. Environ. Model. Softw. 56, 1-5. doi:10.1016/j.envsoft.2014.04.001

Hogan, W.W., 2014. Time-of-use Rates and Real-Time Prices.

Höjer, M., Wangel, J., 2015. Smart Sustainable Cities: Definition and Challenges, in: Hilty, L.M., Aebischer, B. (Eds.), ICT Innovations for Sustainability. Springer International Publishing, Cham, pp. 333-349.

IEA, 2016. Global EV Outlook 2016.

International Energy Agency, 2014. More Data, Less Energy: Making Network Standby More Efficient in Billions of Connected Devices. International Energy Agency.

Jullien, C., Serkine, P., 2016. End-users: The trigger to shape the European Energy System.

Kannan, R., Hirschberg, S., 2016. Interplay between electricity and transport sectors - Integrating the Swiss car fleet and electricity system. Transp. Res. Part Policy Pract. 94, 514-531. doi:10.1016/j.tra.2016.10.007

Karjalainen, S., 2011. Consumer preferences for feedback on household electricity consumption. Energy Build. 43, 458-467. doi:10.1016/j.enbuild.2010.10.010

Katz, J., Andersen, F.M., Morthorst, P.E., 2016. Load-shift incentives for household demand response: Evaluation of hourly dynamic pricing and rebate schemes in a wind-based electricity system. Energy. doi:10.1016/j.energy.2016.07.084

Koomey, J.G., Scott Matthews, H., Williams, E., 2013. Smart Everything: Will Intelligent Systems Reduce Resource Use? Annu. Rev. Environ. Resour. 38, 311-343. doi:10.1146/annurevenviron-021512-110549

McKinsey, 2010. The smart grid and the promise of demand-side management.

Mock, P., Yang, Z., 2014. Driving Electrification: a global comparison of fiscal incentive policy for electric vehicles. ICCT.

National Infrastructure Commission, 2016. Smart power.

Nord Pool Spot, 2015. Transmission system operators [WWW Document]. URL http://www.nordpoolspot.com/How-does-it-work/Transmission-system-operators-TSOs/ (accessed 10.26.16).

Nord Pool Spot, 2012. The Nordic Electricity Exchange and The Nordic Model for a Liberalized Electricity Market.

NordREG, 2014. Recomendations on Common Nordic Metering Methods (No. Report 2/2014).

O'Connell, N., Pinson, P., Madsen, H., O'Malley, M., 2014. Benefits and challenges of electrical demand response: A critical review. Renew. Sustain. Energy Rev. 39, 686-699. doi:10.1016/j.rser.2014.07.098

O'Dwyer, C., Duignan, R., O'Malley, M., 2012. Modeling demand response in the residential sector for the provision of reserves, in: 2012 IEEE Power and Energy Society General Meeting. Presented at the 2012 IEEE Power and Energy Society General Meeting, pp. 1-8. doi:10.1109/PESGM.2012.6344757

Ofgem, 2016. Elective half-hourly settlement: conclusions paper.

Ofgem, 2014. Monitoring suppliers' smart meter roll-out activities. Letter to Suppliers, consumer groups and other interested parties.

Parliamentary Office of Science and Technology, 2014. Electricity Demand-Side Response.

Profitable interruptions, 2014. . The Economist.

Prüggler, N., 2013. Economic potential of demand response at household level-Are CentralEuropean market conditions sufficient? Energy Policy 60, 487-498. doi:10.1016/j.enpol.2013.04.044 
Redpoint/Baringa, 2012. Electricity System Analysis - future system benefits from selected DSR scenarios.

SEAI, 2011a. Electric Vehicle Roadmap.

SEAI, 2011b. Smart Grid Roadmap.

SEDC, 2015. Mapping Demand Response in Europe Today.

SET Plan Steering Group, 2014. Strategic Energy Technology (SET) Plan.

Siemens AG, 2016. eHighway: solution for electrified road freight transport.

"Skip" Laitner, J.A., 2010. Semiconductors and Information Technologies: The Power of Productivity. J. Ind. Ecol. 14, 692-695. doi:10.1111/j.1530-9290.2010.00284.x

Soares M.C. Borba, B., Szklo, A., Schaeffer, R., 2012. Plug-in hybrid electric vehicles as a way to maximize the integration of variable renewable energy in power systems: The case of wind generation in northeastern Brazil. Energy, 7th Biennial International Workshop "Advances in Energy Studies" 37, 469-481. doi:10.1016/j.energy.2011.11.008

Söderbom, J., Vattenfall AB, 2013. Overview of the Swedish Smart Grid Community.

Söderbom, J., Vattenfall $A B, 2012$. Smart Meter Roll out experiences from Vattenfall.

Steen, D., Le, T., Bertling, L., 2012. Price-Based Demand-Side Management For Reducing Peak Demand In Electrical Distribution Systems - With Examples From Gothenburg, in: Chalmers Publication Library (CPL). Presented at the NORDAC 2012.

Strbac, G., Konstantelos, I., Aunedi, M., Pollitt, M., Green, R., 2016. Delivering future-proof energy infrastructure: Report for National Infrastructure Commission.

Stromback, J., 2015. Stauts of Demand Response in Europe.

Swedish Energy Agency, 2015a. Energy in Sweden 2015 (No. ET015:19). Swedish Energy Agency.

Swedish Energy Agency, 2015b. Energy Efficiency trends and policies in Sweden.

Taylor, T.N., Schwarz, P.M., Cochell, J.E., 2005. 24/7 Hourly Response to Electricity Real-Time Pricing with up to Eight Summers of Experience. J. Regul. Econ. 27, 235-262. doi: $10.1007 / \mathrm{s} 11149-005-6623-6$

Tedenvall, M., Mundaca, L., 2016. Behaviour, context and electricity use: Exploring the effects of real-time feedback in the Swedish residential sector.

Torriti, J., 2012. Price-based demand side management: Assessing the impacts of time-of-use tariffs on residential electricity demand and peak shifting in Northern Italy. Energy, Integration and Energy System Engineering, European Symposium on Computer-Aided Process Engineering 2011 44, 576-583. doi:10.1016/j.energy.2012.05.043

Torriti, J., Hassan, M.G., Leach, M., 2010. Demand response experience in Europe: Policies, programmes and implementation. Energy, Demand Response Resources: the US and International ExperienceDemand Response Resources: the US and International Experience 35, 1575-1583. doi:10.1016/j.energy.2009.05.021

UK Department for Transport, 2016. Vehicle Licensing Statistics: Quarter 2 (Apr - Jun) 2016.

US Department of Energy, 2006. Benefits of demand response in electricity markets and recommendations for achieving them.

Vassileva, I., Campillo, J., 2016. Consumers' Perspective on Full-Scale Adoption of Smart Meters: A Case Study in Västerås, Sweden.

VSE, 2016a. Flexibilisation de la demande: piloter la consommation d'électricité.

VSE, 2016b. Electromobilité.

VSGS, 2015. Livre blanc Smart Grid Vol. 2. 